\title{
Lateral Attenuation of Aircraft Sound Levels Over an Acoustically Hard Water Surface: Logan Airport Study
}

May 2000
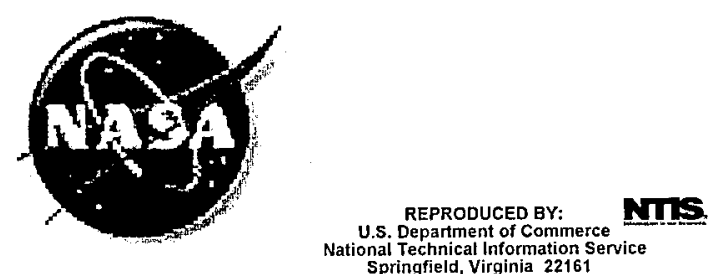

National Aeronautics and Space Administration Langley Research Center 
NOTICE

This document is disseminated under the sponsorship of the Department of Transportation in the interest of information exchange. The United States Government assumes no liability for its contents or use thereof. This report does not constitute a standard, specification, or regulation.

The United States Government does not endorse products or manufacturers. Trade or manufacturers' names appear herein solely because they are considered essential to the object of this document. 
Public reporting burden for this collection of information is estimated to average one hour per response, including the time for reviewing instructions, searching existing data sources, gathering and maintaining the data needed, and completing and reviewing the collection of information. Send comments regarding this burden estimate or any other aspect of this collection of information, including suggestions for reducing this burden, to Washington Headquarters Services, Directorate for Information Operations and Reports, 1215 Jefferson Davis Highway, Suite 1204, Arlington, VA 22202-4302, and to the Office of Management and Budget, Paperwork Reduction Project (0704-0188), Washington, DC 20503.

\begin{tabular}{|l|l}
\hline 1. AGENCY USE ONLY (Leave blank) & $\begin{array}{l}\text { 2. REPORT DATE } \\
\text { MaY 2000 }\end{array}$ \\
\hline
\end{tabular}

4. TITLE AND GUBTITLE

Lateral Attenuation of Aircraft Sound Levels Over an Acoustically Hard Water Surface: Logan Airport Study

3. REPORT TYPE AND DATES COVERED Final Report August 1998 - May 2000

6. AUTEOR (S)

David A. Senzig (1), Gregg G. Fleming(1), John-Paul B. Clarke(2)

7. PERFORMING ORGANIZATION NAME(S) : AND ADDRESS (ES)

(1) U.S. Department of Transportation Research and Special Programs Administration John A. Volpe National Transportation Systems Center Acoustics Facility, DTS-34 Cambridge, MA 02142 1093
(2) Massachusetts Institute of rechnology Department of Aexonatics and Astronauties Massachusetts Avenue Cambridge, MA 02139
5. FUNDING NUMBERS

VX005/N0306
9. SPONSORING/MONITORING AGENCY NAME(S) AND ADDRESS (ES)

National Aeronautics and Space Administration Langley kesearch Center

Two North Dryden Stree

Hampton, VA 23681
8. PERFORMING ORGANIZATION REPORT NUMBER

DOT-VNTSC-NASA-00-01

11. SUPPLEMENTARY NOTES: NASA Technical MoniLor: Kevin P. Shepherd

12a. DISTRIBUTION/AVALLABILITY STATEMENI PUblicly AVallable

12b. DISTRIDUTION CODE

13. ABSTRACT (Maximum 200 words)

The National Aeronautics and Space Administration (NASA), Langley Research Center (LaRC), sponsored the Acoustics Facility at the United states Department of Transportation's John A. Volpe National Transportation systems Center (Volpe Center) and the Massachusetts Institute of Technology (MIT) to conduct a noise measurement study at Logan International Airport in Boston, Massachusetts, during the summer of 1999 to examine the applicability of currently available mathematical models of lateral attenuation. Analysis of the data collected revealed that lateral attenuation is a function of aircraft geometry. Lateral attenuation for aircraft with tailmounted engines was found to agree with the published literature, as well as that included in existing aircraft noise models. Lateral attenuation for aircraft with wing-mounted engines was found to be less than documented in the literature. This lower lateral attenuation for aircraft with wing-mounted engines results in a general under-prediction of side-line noise in the existing noise models.

14. SUBJECT TERMS

noise, aircraft noise, airport noise, lateral attenuation, INM, Integrated Noise Model, noise prediction, computer noise model, noise contours, ground effect, over-water propagation

\begin{tabular}{|c|c|}
\hline $\begin{array}{l}\text { 17. SECURITY CLASSIFICATION } \\
\text { OF REPORT }\end{array}$ & $\begin{array}{l}\text { 13. SECURITY CLASSIFICATION } \\
\text { OF THIS PAGE }\end{array}$ \\
\hline Unclassified & Unclassified \\
\hline
\end{tabular}

NSN $7540-01-280-5500$
15. NUMBER OF PAGES

99

26. PRICE CODE
19. SECURITY CLASSIFICATION OF ABSTRACT

Unclassified
20. LIMITATION OF ABSTRACT

Standard Form 298 (Rev. 2-89) Prescribed by ANSI std. 239-18 



\section{Table of Contents}

Section

$\underline{\text { Page }}$

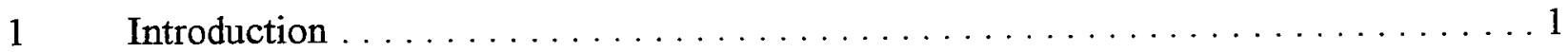

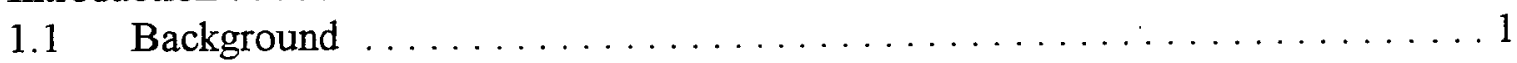

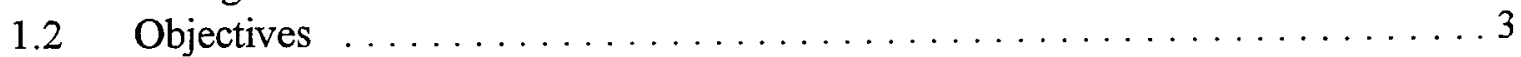

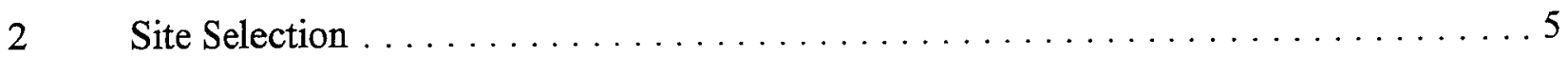

2.1 Exploratory Meeting with Logan Personnel $\ldots \ldots \ldots \ldots \ldots \ldots \ldots \ldots$

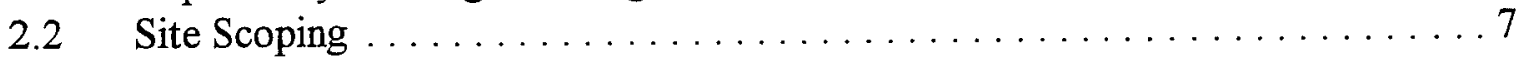

3 Instrumentation $\ldots \ldots \ldots \ldots \ldots \ldots \ldots \ldots \ldots \ldots \ldots \ldots \ldots \ldots$

3.1 Microphone, Preamplifier, and Windscreen $\ldots \ldots \ldots \ldots \ldots \ldots \ldots \ldots \ldots$

3.2 Spectrum Analyzer . . . . . . . . . . . . . . . . . . . . . . . 11

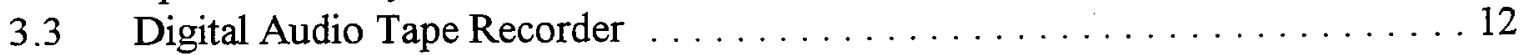

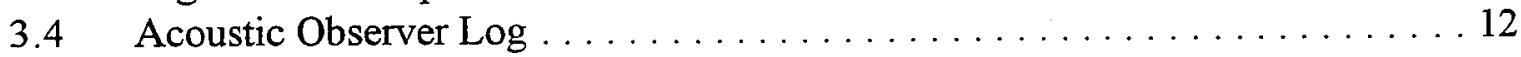

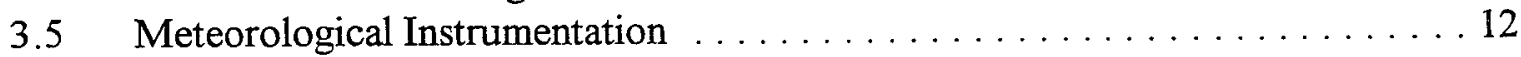

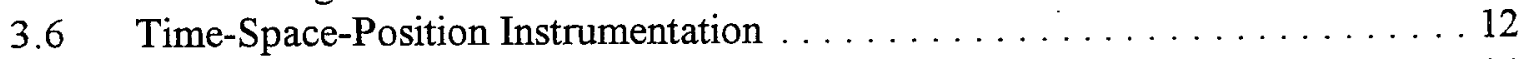

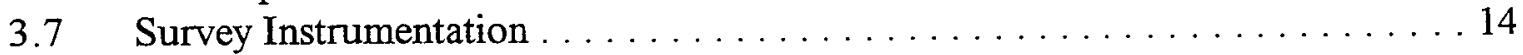

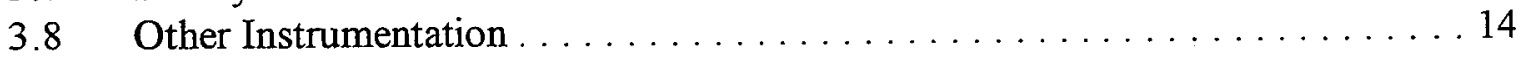

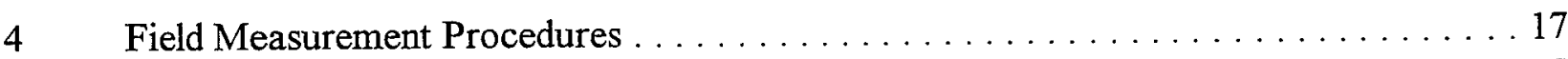

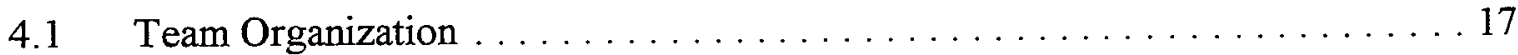

4.2 Measurement System Setup . . . . . . . . . . . . . . . . . . . . 17

4.3 Measurements . . . . . . . . . . . . . . . . . . . . . . 20

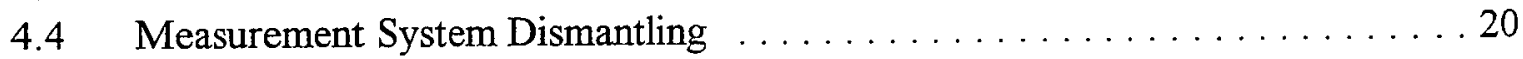

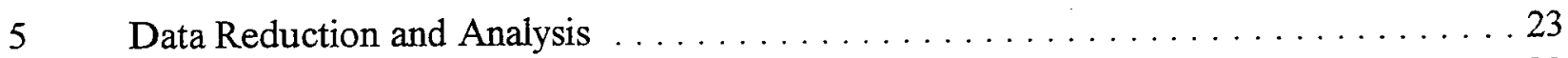

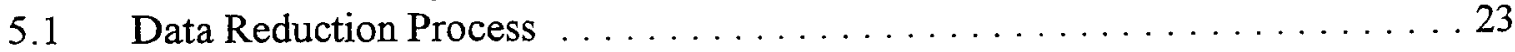

5.1.1 Acoustic Data Reduction - LD binary-to-ASCII Program . . . . . . . . . 23

5.1 .2 Video Data Reduction . . . . . . . . . . . . . . . . . 23

5.1.3 Data Extraction and Coordination Program . . . . . . . . . . . . . 25

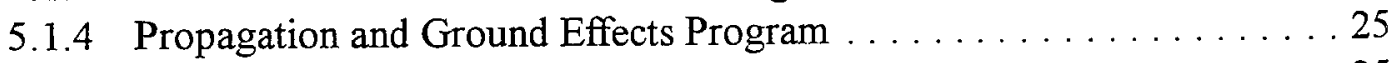

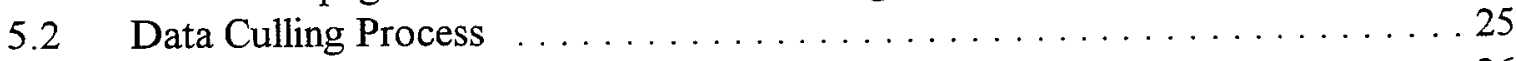

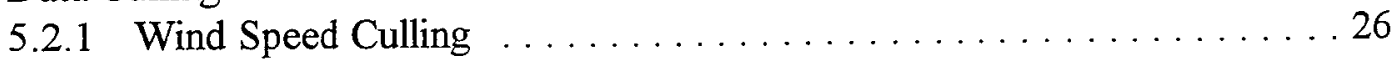

5.2 .2 Climb Gradient Culling . . . . . . . . . . . . . . . . . . 29

5.2 .3 Aircraft Types . . . . . . . . . . . . . . . . . . . . . . 29

5.3 Analysis of Retained Data . . . . . . . . . . . . . . . 34 


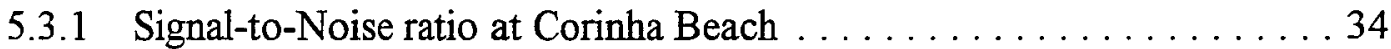

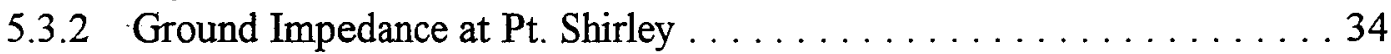

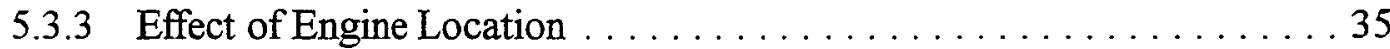

5.3 .4 Statistical Analysis . . . . . . . . . . . . . . . . . . . . . 39

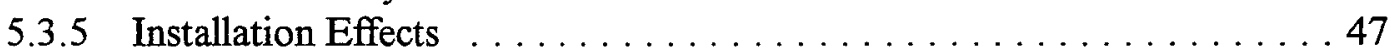

5.4 Additional Observations . . . . . . . . . . . . . . . . . . . . 48

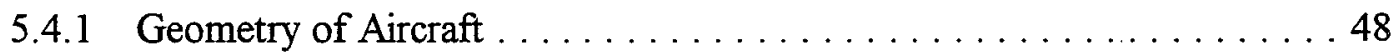

5.4.1.1 Aircraft with Tail-Mounted Engines . . . . . . . . . . . . 48

5.4.1.2 Aircraft with Wing-Mounted Engines . . . . . . . . . . . . 49

5.4.2 Relationship of $\mathrm{L}_{\mathrm{CPA}}$ and Integrated Metrics $\ldots \ldots \ldots \ldots \ldots \ldots$

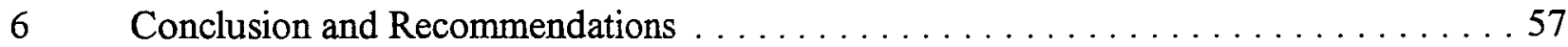

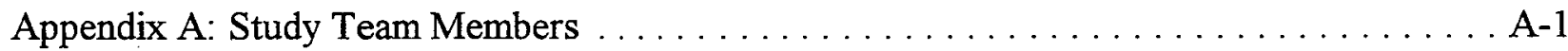

Appendix B: Statistical Analysis of Airport Noise Monitoring and Radar Tracking Data . . . B-1

Appendix C: Acoustic Instrumentation Systems Reference $\ldots \ldots \ldots \ldots \ldots \ldots \ldots \ldots$ C-1

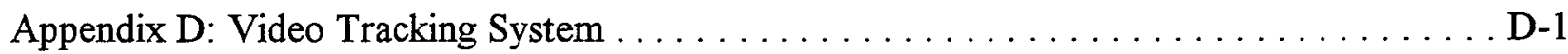

Appendix E: Ground Effects Model $\ldots \ldots \ldots \ldots \ldots \ldots \ldots \ldots \ldots \ldots \ldots \ldots \ldots \ldots \ldots \ldots \ldots \ldots$

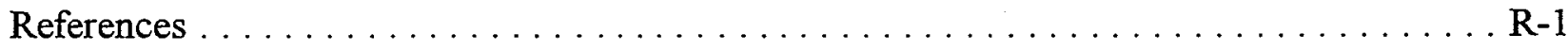

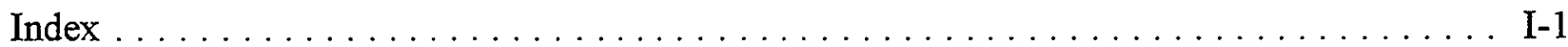

PROTECTED UNDER INTERNATIONAL COPYRIGHT

ALL RIGHTS RESERVED

NATIONAL TECHNICAL INFORMATION SERVICE

U.S. DEPARTMENT OF COMMERCE 


\section{List of Figures}

Figure

$\underline{\text { Page }}$

Figure 1

Figure 2

Figure 3

Figure 4

Figure 5

Figure 6

Figure 7

Figure 8

Figure 9

Figure 10

Figure 11

Figure 12

Figure 13

Figure 14

Figure 15

Figure 16

Figure 17

Figure 18

Figure 19

Figure 20

Figure 21

Figure 22

Figure 23

Figure 24

Figure 25

Figure 26

Figure 27

Figure B-1

Figure B-2

Figure B-3
Map of Measurement Area $\ldots \ldots \ldots \ldots \ldots \ldots \ldots \ldots \ldots$

Measurement Site Locations and Site Coordinate System . . . . . . . . . . . . 9

Acoustic Observer $\log \ldots \ldots \ldots \ldots \ldots \ldots \ldots \ldots$

Typical Microphone Arrangement . . . . . . . . . . . . . . . . . . . . 19

Flow Diagram of Data Reduction Process . . . . . . . . . . . . . 24

All Departure Data . . . . . . . . . . . . . . . . . . . . . 27

Wind Data, All Departure Events . . . . . . . . . . . . . . . 28

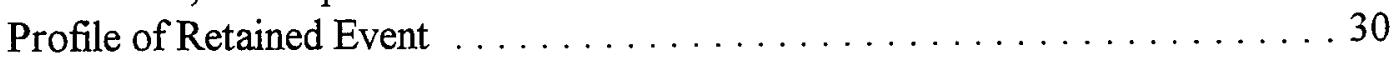

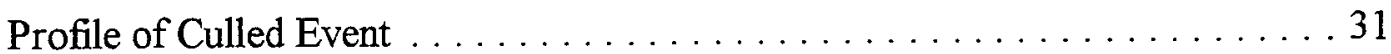

Retained Departure Data . . . . . . . . . . . . . . . . . 33

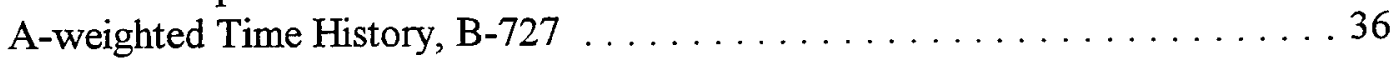

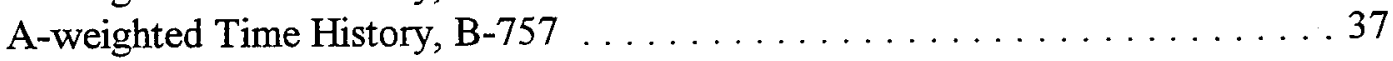

Comparison of Corrected Spectra at Pt. Shirley Using 150 and 300

c.g.s. Rayls Flow Resistivity . . . . . . . . . . . . . . . . . . 38

Regression through Logan Data, Tail-Mounted Engines . . . . . . . . . . . . 39

Comparison of Regressions, Tail-Mounted Engines . . . . . . . . . . . 40

Comparison of NATS Regressions with Original and New Coefficients,

Tail-Mounted Engines

Difference Between Logan Data and Original NATS Regressions,

Tail-Mounted Engines

Difference Between Logan Data and SAE AIR1751 Regressions,

Tail-Mounted Engines

Difference Between Logan B-727 Data and SAE AIR1751 Regressions . . . . . 44

Trend Line Through Logan Data, Wing-Mounted Engines . . . . . . . . . . . 45

Comparison of Trends/Regressions, Wing-Mounted Engines . . . . . . . . . 46

Residual as a Function of Frequency, Elevation Angles from 8 to 20 Degrees . . 47

Ground Effect, 1000 meters; Based on EPD model . . . . . . . . . . . . . . 51

A-weighted Time History of B-727 Departure, Corinha Beach and Pt. Shirley . 52 A-weighted Time History of B-757 Departure, Corinha Beach and Pt. Shirley . 53

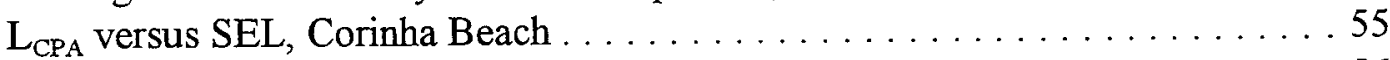

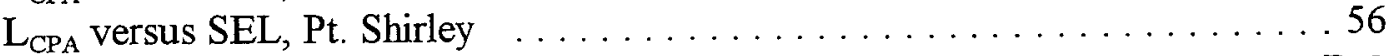

SEL versus Temperature, July $1998 \ldots \ldots \ldots \ldots \ldots \ldots \ldots \ldots \ldots$. . . . . . . . . . . . . . . . . . . . . .

SEL versus Wind Speed, July $1998 \ldots \ldots \ldots \ldots \ldots \ldots \ldots \ldots \ldots$. . . . . . . . . . . . . . . . . . . . . . .

SEL versus Time of Day, July $1998 \ldots \ldots \ldots \ldots \ldots \ldots \ldots \ldots$ B-4 
Figure E-1 Generic Geometry for EPD Model $\ldots \ldots \ldots \ldots \ldots \ldots \ldots \ldots \ldots \ldots$

Figure E-2 Example Computation for EPD Model $\ldots \ldots \ldots \ldots \ldots \ldots \ldots \ldots \ldots \ldots$ 


\section{List of Tables}

\section{$\underline{\text { Table }}$}

Page

Table 1

Summary of Retained Departure Data . 32

Table 2

System Performance Limits C-4 


\section{Executive Summary}

Lateral attenuation in the Federal Aviation Administration's (FAA) Integrated Noise Model (INM) has been based on the methods described in the Society of Automotive Engineers' (SAE) Aerospace Information Report (AIR) 1751. Released in 1981, SAE AIR 1751 is founded on data measured in the 1960s and 1970s. These measurements were dominated by the Boeing B-727 aircraft and were conducted over acoustically soft ground. Long-term measurements conducted with airport noise monitoring equipment have shown that the lateral attenuation algorithms in SAE AIR 1751 tend to under-predict the noise generated by modern aircraft.

The National Aeronautics and Space Administration (NASA), Langley Research Center (LaRC), sponsored the Acoustics Facility at the United States Department of Transportation's John A. Volpe National Transportation Systems Center (Volpe) and the Massachusetts Institute of Technology (MIT) to conduct a noise measurement study at Logan International Airport in Boston, Massachusetts, during the summer of 1999 to examine the applicability of currently available mathematical models of lateral attenuation. Logan Airport was chosen for this study because of the availability of measurement locations for which the sound propagation path from the aircraft was primarily over water (an acoustically hard surface). The study focused on departures from a single runway. Measurements were conducted at three locations: under the flight path along the projected runway centerline, approximately 1,000 feet from the projected runway centerline, and approximately 3,000 feet from the projected runway centerline.

The measurements were conducted using equipment capable of continuously recording aircraft noise spectra and position throughout the flight segment of interest. Equipment to perform this task consisted of spectrum analyzers, digital audio tape recorders, meteorological instruments, video tracking equipment, survey equipment, and other supporting equipment.

The data collected when aircraft were at the closest point of approach to each of the microphones were subjected to further analysis. These collected data were corrected for spherical spreading, atmospheric absorption, and ground reflection. The corrected data were then compared to data collected at a reference microphone. The difference between the corrected data and the reference data was termed "residual", sometimes referred to as "engine installation effect".

The conclusions of the study can be summarized as follows:

- The ground effects algorithms based on the work of Embleton, Piercy and Daigle appear reasonable for A-weighted metrics. 
- Aircraft engine location directly impacts lateral attenuation / installation effects. For the six types of aircraft used in the final analysis, these aircraft have distinctly different engine installation effects at the closest point of approach.

- Lateral attenuation/installation effects for the aircraft with tail-mounted engines substantially agree with SAE AIR1751 and data recently collected by the U.K. National Air Traffic Services Ltd.(NATS). As expected, the primary aircraft included in the development of SAE AIR 1751 have measured lateral attenuation/installation effects consistent with the SAE AIR 1751 algorithms.

- Significant differences exist between aircraft with wing-mounted engines and SAE AIR 1751. For the flight track-measurement geometries in this study, aircraft with wing-mounted engines had a lateral augmentation, not an attenuation. The data collected in the current study for aircraft with wing-mounted engines also differs from data recently collected in the U.K., especially at elevation angles below about 20 degrees.

- Because aircraft with wing-mounted engines have become much more predominant in the fleet since SAE AIR 1751 was developed, inclusion of updated lateral attenuation algorithms for these aircraft in the next generation of noise models will result in a substantial improvement in model accuracy, as well as an increase in the areas of the predicted noise contours.

Before AIR-1751 can be modified, more data are required to help understand the differences observed in the current study and the recent U.K. studies. These data should be collected in an environment where all aircraft parameters can be controlled. The metrics used in such a data collection effort should be the same as those used in the standard noise models that would make use of such data. Further, since relatively good agreement has been obtained for aircraft with tailmounted engines, this additional work should focus on aircraft with wing-mounted engines. 


\section{Introduction}

Lateral attenuation of sound is an essential component in the accurate prediction of aircraft noise. "Lateral attenuation" contains many aspects of sound generation and propagation, including ground effects (sometimes referred to as excess ground attenuation), shielding and reflections from aircraft structures, aerodynamic refraction of sound, jet shielding due to closely-spaced jet engine exhausts, as well as other factors. Although much work has been done to quantify lateral attenuation as it relates to aircraft ${ }^{1-5}$, there continue to be wide discrepancies between predicted and measured noise levels, especially for situations involving sideline receptors and aircraft at low altitudes, where lateral attenuation effects can be substantial. These discrepancies, which tend to be larger for many of the more modern jet aircraft, are even more of an issue at airports surrounded by acoustically varying land cover, e.g., coastal airports surrounded by a mix of both water and grass. These discrepancies exist because most modern aircraft noise prediction models rely on algorithms that assume propagation over acoustically soft ground, and are based on data from older jet aircraft.

The National Aeronautics and Space Administration (NASA), Langley Research Center (LaRC), sponsored the Acoustics Facility at the United States Department of Transportation's John A. Volpe National Transportation Systems Center (Volpe Center) and the Massachusetts Institute of Technology (MIT) to conduct a noise measurement study at Logan International Airport in Boston, Massachusetts, during the summer of 1999 to examine the applicability of currently available mathematical models of lateral attenuation. The results of that measurement study are presented herein.

This report presents the background and objectives of the study (Section 1), the site selection process, and related logistic issues (Section 2), the measurement instrumentation used (Section 3), the field measurement procedures employed (Section 4), data reduction and analysis, as well as additional observations (Section 5), and the conclusions and recommendations of the study (Section 6). Also presented in Appendices A, B, C, D and E, respectively, are a list of the study team members and their responsibilities; the results of a statistical analysis of Logan Airport's noise monitoring and complementary radar tracking data; the specifications of the acoustic measurement system used; a description of the video tracking system; and a description of the ground effects model used in the data reduction and analysis.

\section{$1.1 \quad$ Background}

Lateral attenuation in the Federal Aviation Administration's (FAA) Integrated Noise Model (INM) has been based on the methods described in the Society of Automotive Engineers' (SAE) Aerospace Information Report (AIR) $1751^{1}$. It contains two algorithms, one used to compute attenuation due 
to air-to-ground propagation (for airborne aircraft), and one for computing attenuation due to groundto-ground propagation (for aircraft taxiing, landing or in takeoff-ground roll). Within the INM, up to and including Version $6.0^{6,7}$, these two field-measurement-based (empirical) equations have been used for computing ground effects for all commercial aircraft within the model. Similar empirical equations have been used for military aircraft in INM.

Released in 1981, SAE AIR 1751 is based on data measured in the 1960s and 1970s. The majority of the aircraft represented in the AIR were equipped with low-bypass ratio jet engines. In particular, the data set is dominated by a single type of jet aircraft, the Boeing Model 727-100, which first flew in 1963. The inclusion of the SAE AIR 1751 lateral attenuation algorithms in the INM leads to two generalizations that lower the accuracy of the model: (1) lateral attenuation data dominated by one type of aircraft is applied to the entire aviation fleet equally; and (2) propagation effects over acoustically hard terrain are not considered, a major weakness at airports in coastal areas. Consequently, in 1997 the INM development team initiated the task of revising the lateral attenuation algorithms within the model.

At the most fundamental level, lateral attenuation of aircraft noise comprises two basic physical phenomena, engine installation effects and ground attenuation effects. Engine installation effects, which are implicit in the SAE AIR 1751 algorithms, include shielding and reflections from aircraft structures, aerodynamic refraction of sound, and jet shielding due to closely-spaced jet engine exhausts. These engine installation effects are not well understood. In the latest version of the United States Air Force's NOISEMAP computer program for assessing noise impact in the vicinity of military installations, engine installation effects are neglected and modeling of lateral attenuation is based solely on ground attenuation effects. ${ }^{3}$. However, the data that were used in the development of SAE AIR 1751 seem to indicate that for some commercial aircraft, e.g., the Boeing Model 727, engine installation effects may be important, depending upon source-to-receiver geometry. Conversely, ground attenuation effects account for the introduction of an impedance boundary, in this case the ground surface, into a given aircraft-to-receiver geometry. This study examines both of these components of lateral attenuation, with a primary focus on the less understood engine installation effects.

Various institutions have sought to update the existing lateral attenuation algorithms in the standard noise models. The Department of Operational Research and Analysis of the National Air Traffic Services Ltd. (NATS) in London has collected a large database of aircraft departure data at London's Gatwick Airport ${ }^{8}$. These data were collected between 1996 and 1999. The data show that lateral attenuation appears to be a function of aircraft geometry, i.e., the specific placement of engines and structural components of an aircraft influences lateral attenuation. 


\subsection{Objectives}

The objectives of this study were to:

- assess the accuracy of the new ground effects regressions developed for future inclusion in the FAA's INM,

- $\quad$ examine and, if possible, quantify the engine installation component of the lateral attenuation, and

- $\quad$ quantify the error in utilizing SAE AIR 1751 for computing fleet-wide lateral attenuation and provide a database to assist in the process of updating SAE AIR 1751.

A secondary objective was to compare data collected in this study with the data collected in the previously mentioned NATS study.

Since Logan is a coastal airport, the study concentrated on the assessment of the ground effects regressions developed for propagation over an acoustically hard surface. Also, because ground effects for propagation over an acoustically hard surface are more predicable than for propagation over an acoustically soft surface, engine installation effects could be more easily quantified in this study, compared to a study conducted with propagation over acoustically soft ground. 


\section{Site Selection}

In 1998, the study team (Appendix A lists the members of the study team along with their responsibilities) initiated the process of identifying the most suitable locations around Logan Airport at which to conduct measurements. This process required support from the authorities at Logan. On January 9, 1998, several members of the study team conducted an exploratory meeting with personnel from Logan's Noise Office to apprize them of the need for the current study. The study team conducted a site scoping visit on September 21, 1998. This section discusses the results of both the exploratory meeting (Section 2.1) as well as the scoping visit and final site selection process (Section 2.2).

\subsection{Exploratory Meeting with Logan Personnel}

The meeting began with a discussion of the objectives of the study, and the study's relationship to FAA's INM, which is an issue of importance to Logan personnel. As part of the meeting, team members reviewed the technical issues associated with site selection, as follows:

Over-water Propagation: The ideal measurement site(s) would be one in which the majority of the propagation path from aircraft to measurement microphone occurs over water. As discussed in Section 1.2, this arrangement more easily facilitates quantification of possible engine installation effects, as compared with measurements taken over acoustically soft terrain.

Ambient Sound Levels: Measurement sites had to be selected such that ambient sound levels are at a minimum. This is of major concern due to Logan's proximity to many busy thoroughfares, as well as the substantial on-airport activity.

Aircraft Activity: Measurement sites should be selected to be representative of a wide range of aircraft types, aircraft operations (i.e., both approaches and departures), and aircraft-to-receiver geometries.

Logistics/Access: The measurements sites had to be accessible. Because of the substantial quantity of equipment required at each site, public road access was most desirable.

Given the above criteria as well as some of the other concerns voiced by the study team, the following topics were discussed at the meeting: (1) site selection and access, including logistics; (2) procedures for obtaining approval for performing measurements in the vicinity of Logan; (3) temporal variations in aircraft activity; and (4) temporal variations in weather (primarily wind).

In terms of the first discussion topic, the Winthrop area to the northeast of the airport was determined 


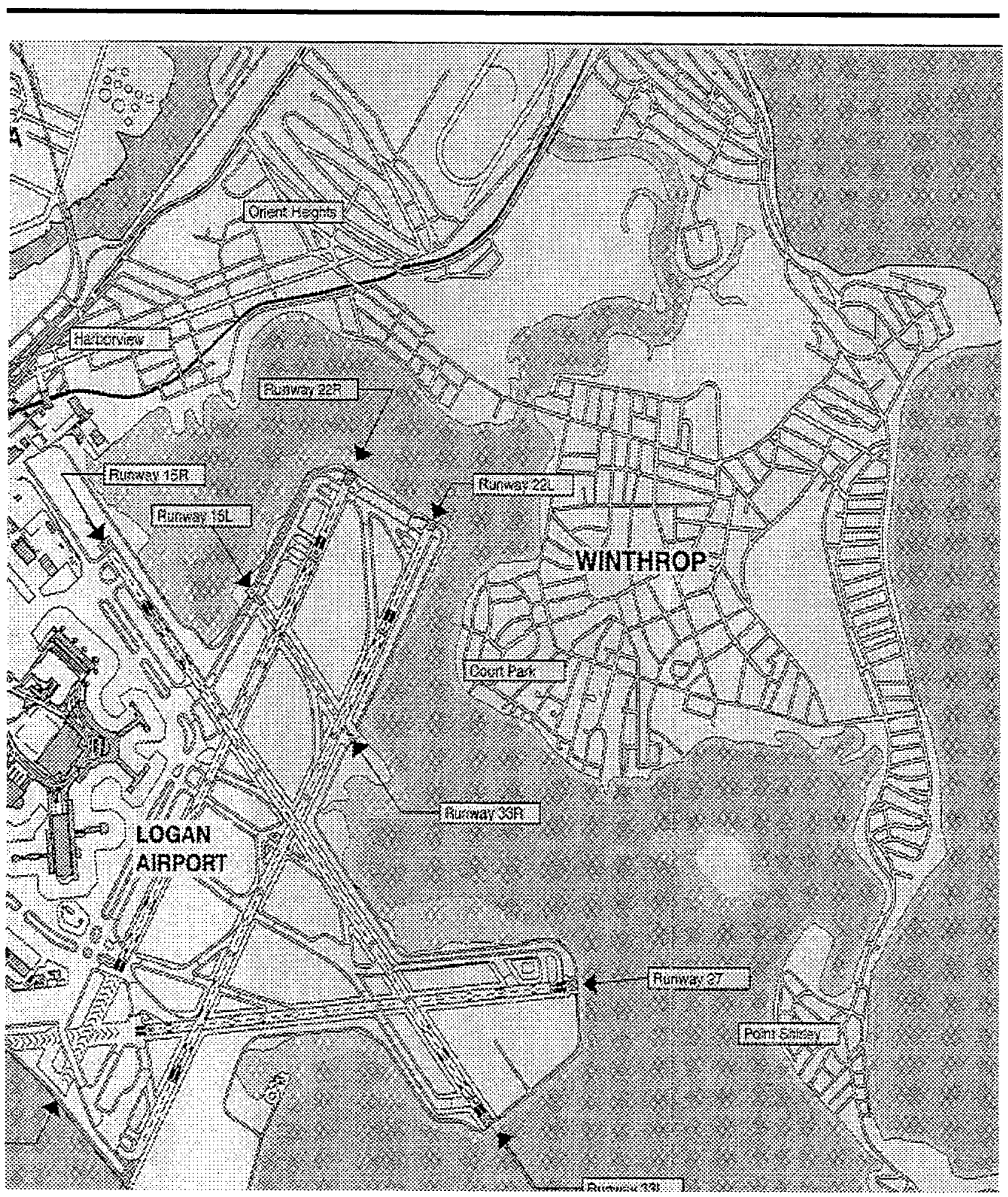

Figure 1. Map of Measurement Area 
to be the most desirable area (see Figure 1). Access to potential measurements sites in the Winthrop area were easily facilitated through public-access roadways, and the suggested area neighborhoods have been relatively receptive to past noise-related research.

Acknowledgment of the test plan and approval to operate equipment on public land was given by the Town of Winthrop Board of Selectmen on May 4, 1999.

Selection of the Winthrop area resulted in focusing on operations occurring on Runway 9/27. Winthrop also offered the lowest-level (although not necessarily ideal) ambient environment as compared with other surrounding communities. In addition, there are several areas in Winthrop, just to the north of the projected centerline of Runway $9 / 27$, where aircraft-to-receptor propagation occurs entirely over water.

In response to weather concerns, Logan personnel recommended measurements early in the morning, before coastal winds increase.

The study team was provided with ancillary material to further facilitate planning of the measurement study. Such material included Logan's 1996 Annual Update ${ }^{9}$ (which includes detailed area maps and information on aircraft activity), and Logan Airport's Noise Information Report (which documents all aspects of the noise measurement and modeling activity occurring at Logan). Logan personnel also provided airport noise monitoring data and complementary radar tracking data. Appendix B presents the results of a limited statistical analysis of these data.

\section{$2.2 \quad$ Site Scoping}

Based on the information collected at the January 9, 1998, exploratory meeting, the study team decided to focus on the Winthrop shoreline for the selection of measurement sites. Public-roadaccessible locations between Point Shirley, directly to the east of Runway 27, and Court Park, to the north of Runway 27, were identified as candidate sites (See Figure 1). As mentioned above, this area offered: (1) roadway-accessible sites which represented a variety of source-to-receiver geometries for operations occurring on Runway $9 / 27$; (2) direct aircraft-to-receptor propagation almost entirely over water; (3) a community that has historically been relatively receptive to noise studies; and (4) as compared with others areas surrounding Logan, relatively low ambient sound levels.

To help facilitate planning, and to ensure that study requirements were adequately met, on September 21,1998, the study team conducted an initial site scoping of the candidate area on the Winthrop shoreline. Three measurement sites were identified: a centerline reference site located directly underneath the nominal flight track for departures/approaches on Runway 9/27 (Point 1, 
Figure 2), a second located about 3,000 ft to the north of the nominal track (Point 2, Figure 2), and a third located on Snake Island in Boston Harbor (Point 3, Figure 2). These three locations were the final measurement sites used for the study. The benefits of having two measurements sites on the same perpendicular line from the flight track with the same surface impedance were considered more important than the accessibility issues associated with the Snake Island location. 


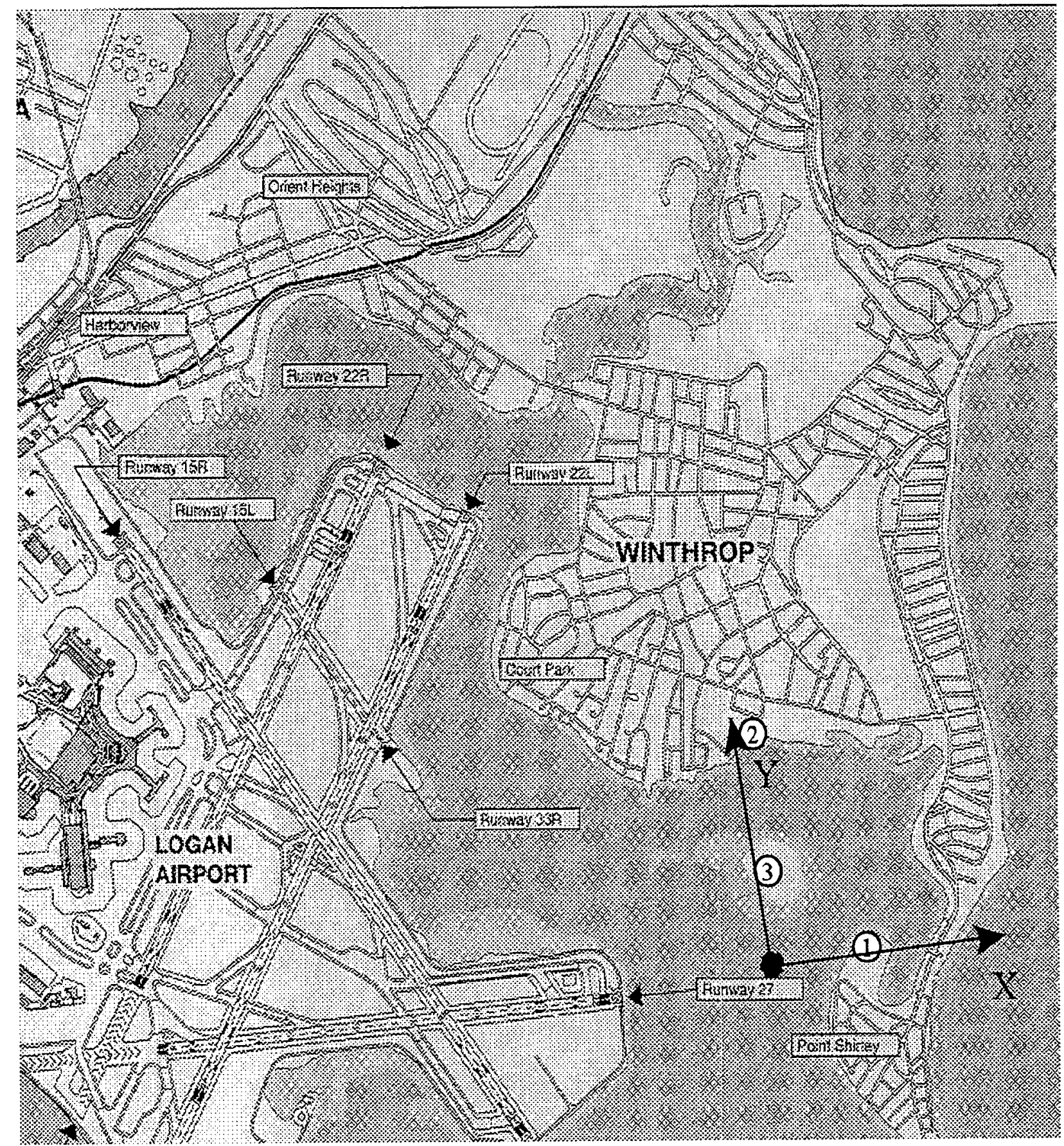

Figure 2. Measurement Site Locations and Site Coordinate System 

an Acoustically Hard Water Surface 


\section{$3 \quad$ Instrumentation}

This section discusses the acoustic instrumentation, the instrumentation used for gathering of timespace-position information (TSPI), the instrumentation used to survey the sites and establish a local coordinate system, and other ancillary instrumentation used in the study. Appendix $\mathrm{C}$ presents detailed technical specifications for the acoustic measurement system. Appendix D presents detailed technical specifications for the TSPI system.

\subsection{Microphone, Preamplifier, and Windscreen}

A microphone transforms sound-pressure variations into electrical signals, that are in turn measured by instruments such as a sound level meter (SLM) or a one-third octave-band analyzer (spectrum analyzer), and/or recorded on tape or some other storage medium. The Brüel and Kjær (B\&K) Model 4155 microphones used in the current study are electret condenser microphones. These microphones utilize a diaphragm of pure nickel, which is coated with a protective quartz film. The microphone backplate is made of a corrosion-resistant high-nickel alloy which carries a negatively charged layer. This design allows the microphone to maintain its own polarization, i.e., often referred to as a prepolarized design. Pre-polarization allows the electret microphone to function as a closed system with regard to humidity*, thus eliminating a concern at the coastal locations and summertime measurement period of the current study. Additionally, B\&K Model 2671 preamplifiers and Model WB 1372 power supplies were employed at each site. A B\&K Model 02373.5 -in $(9 \mathrm{~cm})$ foam windscreen was placed atop each microphone to reduce the effects of wind-generated noise on the microphone diaphragm. By reducing such noise, the signal-to-noise $(S / N)$ ratio of a sound measurement is effectively improved.

\subsection{Spectrum Analyzer}

Each microphone/preamplifier was connected via $100 \mathrm{ft}(30.5 \mathrm{~m})$ of cable to a Larson Davis Laboratories (LDL) Model 2900, two-channel, one-third octave-band analyzer (LDL2900) set-up at the acoustic observer's stations. Each channel of the LDL2900 was setup to continuously measure and store, at 1/4-second time intervals, the unweighted, linearly averaged one-third octave-band spectral time history. In this configuration the LDL2900 (with 4 Megabytes of random access memory) is capable of storing slightly over one half hour of data. During data collection, the LDL2900 at each site was turned on at the audible start of each event, run throughout the event, and

*Traditional condenser microphones are extremely sensitive to humidity. The traditional condenser microphone design can result in electrical arcing in high humidity conditions. Electret microphones do not exhibit this trait. 
shut off either at the conclusion of the event or when ambient noise became audible during the event of interest. The contents of internal memory were periodically transferred to a floppy disk for later off-line reduction and analysis (see Section 5). This data download was only performed during periods when no events of interest were taking place.

\subsection{Digital Audio Tape Recorder}

Each microphone/preamplifier was also connected to a Sony Model PC208Ax digital audio tape (DAT) recorder. The DAT recorder was set up to operate in a four-channel recording mode. The two microphones/preamplifiers were connected to the first two channels. Configured as such, each 295$\mathrm{ft}(90-\mathrm{m})$ tape provided slightly more than 3 hours of recording time. Unlike the LDL2900, the DAT recorder was setup to record continuously throughout a measurement day. Universal Coordinated Time (UTC) was recorded from a True Time Model 705 time code generator on the third DAT channel. The fourth channel of the DAT was unused.

The tape recorded data provided for later repeated playback and analysis of the collected data, including the option for subsequent narrow-band analysis, if necessary.

\subsection{Acoustic Observer Log}

A manual acoustic observer log was maintained to provide a time synchronized history of observed aircraft activity. Ambient noise conditions were also noted on the log sheets. An example of this log is shown in Figure 3.

\subsection{Meteorological Instrumentation}

In addition to the acoustical instrumentation, a Qualimetrics $B$ Transportable Automated Meteorological Station (TAMS) was set up at each of the three measurement locations. The TAMS measured temperature, relative humidity, wind speed and direction, and ambient atmospheric pressure at one-second intervals. Wind speed and direction were 10-second running averages.

\subsection{Time-Space-Position Instrumentation}

The time-space-position information (TSPI) system includes two digital video camera subsystems and their supporting accessories. Each subsystem recorded aircraft events onto video tape that was processed to determine the aircraft's time and position information throughout the event. 


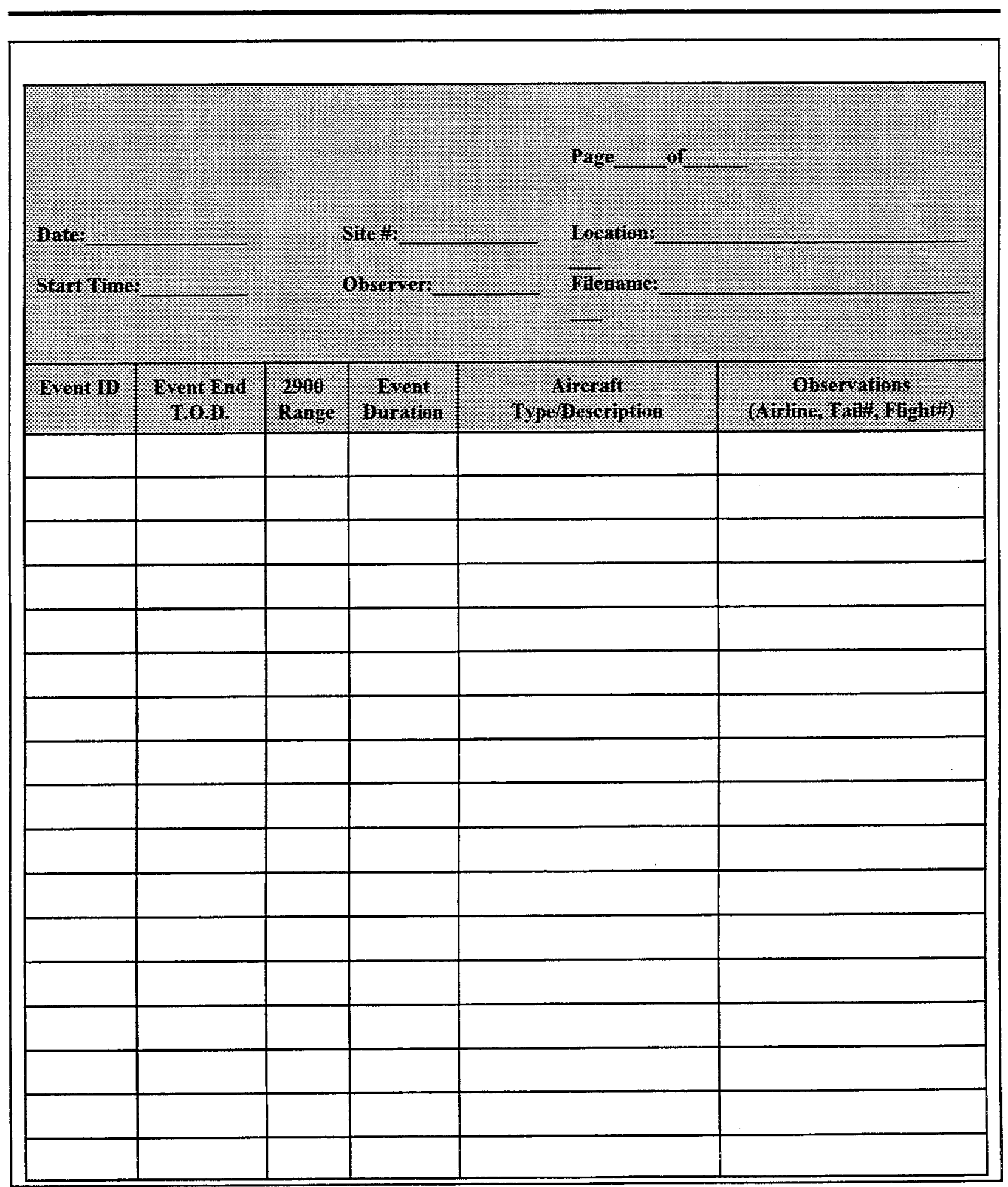

Figure 3. Acoustic Observer Log 
Each subsystem consisted of a Canon Opturaß digital video camera with a wide angle lens and the supporting hardware to enable field calibration of the system. The supporting hardware included portable video targets, a camera support structure that permitted the camera to be rotated about all three axes, a laser and laser mounting structure, and equipment to accurately determine the geometry of the calibration coordinate system.

\subsection{Survey Instrumentation}

A site survey was conducted using a differential Global Positioning System (dGPS) which was designed around two single-frequency (commonly referred to as L1) NovAtel@ Model RT20E GPS receivers and two GLBß Model SNTR 150 transceivers which facilitate remote communication between the two GPS receivers ${ }^{10}$. The two 25-Watt GLB transceivers were tuned to a frequency of $136.325 \mathrm{KHz}$.

The dGPS system also contained a Graphical User Interface (GUI) and supporting software that was tailored for use during aircraft noise certification tests.

The dGPS system was used to determine a coordinate system for the measurement instrumentation and the aircraft (see Figure 2). This coordinate system was also used in the data processing and analysis. The coordinate system used was defined with the positive $\mathrm{X}$ axis running under the departure centerline from Runway 09, the positive $\mathrm{Y}$ axis in the direction of the Snake Island and Corinha Beach measurement locations (positions 3 and 2 in Figure 2, respectively), and the positive $Z$ axis vertically up.

\subsection{Other Instrumentation}

B\&K Model 4231 sound calibrators were used to establish and check the sensitivity of the entire acoustic instrumentation system (i.e., microphone, preamplifier, cables, spectrum analyzer and DAT). The Model 4231 produces a user-selectable $114 \mathrm{~dB}$ sound pressure level at $1 \mathrm{kHz}$.

Time synchronization of all pertinent instrumentation in the measurement chain was performed using a True Time Model 705 time code generator as reference. The Model 705 has a built-in GPS receiver, thus facilitating automatic time synchronization at all remote measurement sites. Universal Coordinated Time (UTC) with a local hour offset was used as the time base for the study. In particular, the LDL2900, the DAT, the meteorological instrumentation, and the video system were all synchronized to facilitate accurate data reduction and analysis. The radar tracking system at Logan is also synchronized to UTC, thus facilitating the coordination of acoustical, meteorological 
and flight track data, if coordination with the radar system data was subsequently deemed necessary.

During measurements, a Radio Shack Model PRO-63 Event Scanner was continuously tuned to the frequency of the Logan control tower. Monitoring of aircraft-to-tower communications greatly assisted in the process of identifying aircraft types.

Motorola Radius GP300 FM radios were utilized for communication between the test director and personnel at each measurement site. 


\section{Field Measurement Procedures}

Measurements were conducted in late June and mid July, 1999, between 9:00 a.m. and 3:00 p.m. on days when Runway $9 / 27$ was in use and winds were below 15 knots ( 17 miles per hour). The measurement days were June 23, June 24, June 29, June 30, July 12, July 14 and July 16.

\subsection{Team Organization}

The measurement team consisted of three groups of two people to operate the acoustic measurement systems, and two additional people to operate the two video cameras. One of the video camera operators doubled as the test director, who would alert the teams to upcoming aircraft events and would also provide data on aircraft types, flight number and ownership.

During a typical measurement event, the personnel at the acoustic measurement sites initiatied the LDL2900 to capture sound level data, and logged pertinent event information such as time of day, event duration, possible contamination, etc. Initiation of the LDL2900 was the responsibility of the personnel on-site at each of the measurement locations, not the test director. This was done so that individuals at each site could make decisions of the start and stop times of events based on the ambient levels and event levels at each site.

\subsection{Measurement System Setup}

Following is a step-by-step description of the daily acoustic system setup at each measurement site:

(1) Each microphone system, including preamplifier and windscreen, was attached to a telescoping tripod mast positioned as close as possible to the shoreline (in the case of the sideline measurement locations, Positions 2 and 3, Figure 2) and directly underneath the nominal flight track (in the case of the centerline measurement location, Position 1, Figure 2). Each mast was adjusted to locate one microphone diaphragm at a height of $5 \mathrm{ft}(1.5 \mathrm{~m})$ and the other directly over the first at a height of $15 \mathrm{ft}(4.5 \mathrm{~m})$ above the local surface. The microphones were oriented for grazing incidence ( $+/-30$ degrees) to the expected nominal flight track. Figure 4 shows the microphone/preamplifier/windscreen arrangement deployed at the Snake Island microphone location during a DC-9 arival.

(2) The LDL2900, DAT, and acoustic observer were positioned in full view of the microphone location, but at a distance of approximately $100 \mathrm{ft}(30.5 \mathrm{~m})$ to eliminate data contamination due to observer activity.

(3) The meteorological instrumentation was positioned approximately 25 feet $(7.5 \mathrm{~m})$ from the observer location, in a position representative of the wind conditions at the microphone 
location. The separation distance between the meteorological instrumentation and the Microphone Location was maintained so that personnel could periodically check the meteorological system and power supply status without influencing the acoustical measurements. The meteorological sensors were placed at approximately 10 feet ( 3 meters) above the ground.

(4) $100 \mathrm{ft}(30.5 \mathrm{~m})$ of cable connected the instrumentation at the microphone location and at the observer location.

(5) The clocks of all pertinent instrumentation (the LDL2900, DAT, meteorological system, and video system) were set using the True Time Model 705 time code generator. UTC, with a local hour offset, was received and translated to a standard analog time code format and recorded on a separate channel of each DAT recorder.

(6) With all electrical components of the acoustic measurement system connected, a preliminary sound level calibration of the system was performed. The purpose of the preliminary calibration was to ensure that all equipment was operating properly.

(7) The electronic noise floor of the entire electrical system was then established using a nontransducive (i.e., mechanically passive) capacitive load in place of the microphone.

(8) After re-installation of the microphone, a pre-measurement sound level calibration of the system was performed.

(9) The windscreen was installed and the preamplifier cable secured to a leg of the measurement mast to prevent wind-induced vibration.

(10) Continuous DAT recordings and meteorological data collection were begun.

(11) Aircraft sound level measurements with the LDL2900 were initiated on a per-event basis.

Following is a step-by-step description of the daily video camera system setup at the two video sites:

(1) The video tripod and three-axis head were assembled at the two sites noted in the dGPS survey (Positions 1 and 3 in Figure 2).

(2) The two video targets were assembled at their known coordinate locations. The heights of targets above the ground were noted for use in later computer processing.

(3) The video camera was started and the UTC time code was recorded as described in Appendix D.

(4) The camera, still running, was mounted on the tripod assembly.

(5) The video camera located at Corinha Beach (Position 2) was rotated on its three-axis head so that the left-of-center video target was in the center of the view finder image. The video camera at Pt. Shirley (Position 1) was rotated clockwise 90 degrees about the roll axis, then pitched up 45 degrees. This was done to maximize the field of view at Pt. Shirley; with the wide angle lens installed, the Optura camera has a field of view of about 90 degrees in the nominally horizontal direction and about 60 degrees in the nominally vertical direction. At 


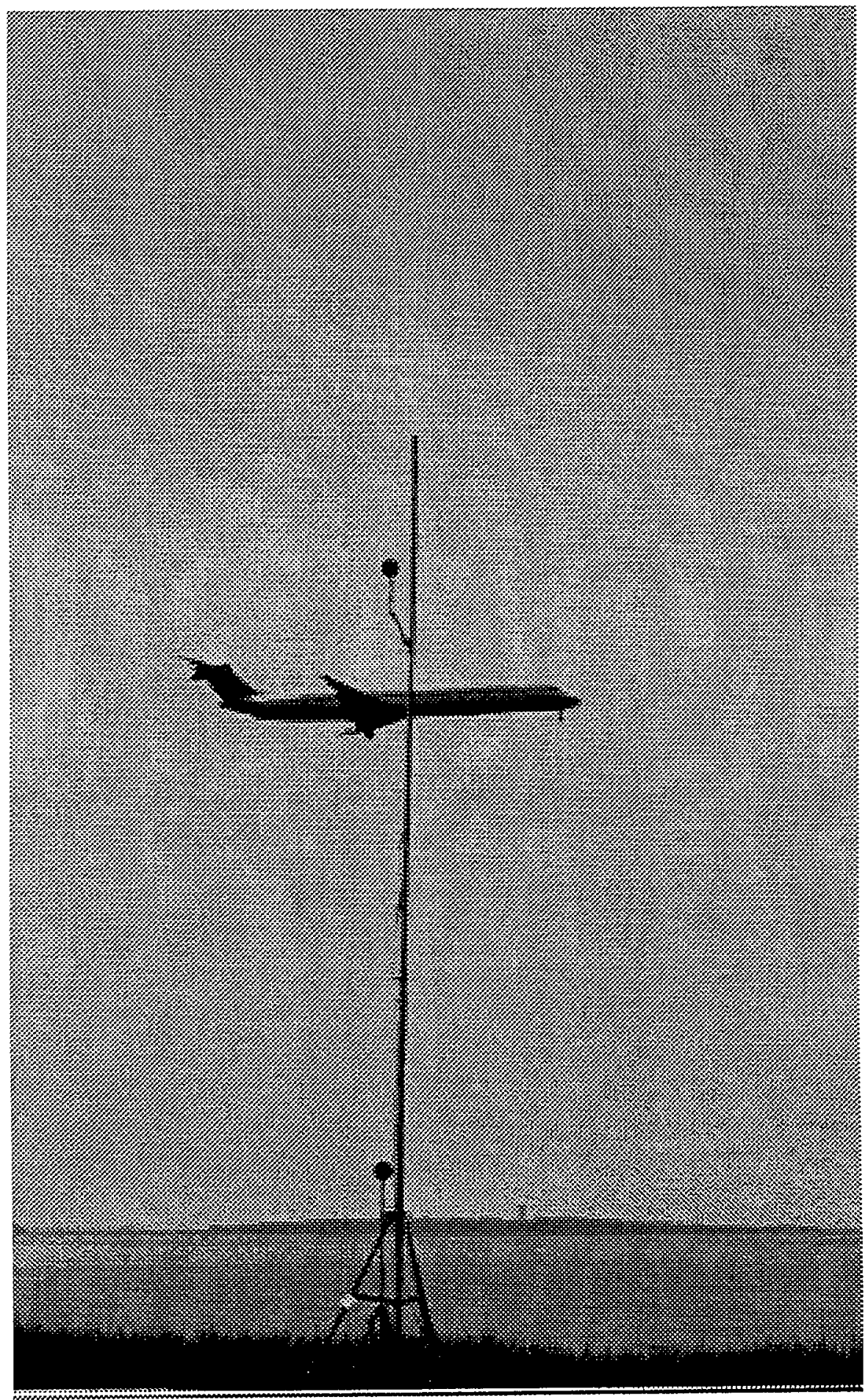

Figure 4. Typical Microphone Arrangement 
Pt. Shirley, the horizontal and vertical directions were switched by rolling the camera 90 degrees. Because the nominal flight path for Runway $9 / 27$ was directly over Pt. Shirley, pitching up the camera 45 degrees allowed the camera to record departing aircraft from the time they left the runway until they passed almost directly overhead.

\subsection{Measurements}

Upon identification of an event by the test director, the acoustic personnel began data capture on the LDL2900 as soon as the event was audible. During data capture, acoustic personnel logged pertinent observations (e.g., noise contamination due to aircraft taxiing, unidentified airport sources, and localized community sources). When the event was no longer audible, or when ambient noise began to influence the event noise levels, the LDL2900 was stopped. The test director also coordinated the numbering and identification of aircraft events.

Throughout measurements, periodic checks were performed on the acoustical, meteorological and video instrumentation for the following: available battery power, remaining internal memory for devices with internal data storage (LDL2900 and meteorological system), and remaining tape in the case of the DAT recorder and the video system.

\subsection{Measurement System Dismantling}

Following is a step-by-step description of the system dismantling that took place upon completion of measurements each day:

(1) A post-measurement sound level calibration of the entire acoustical system was performed and any drift from the initial calibration was documented.

(2) The internal clocks of the LDL2900, DAT, meteorological system, and TSPI instrumentation were compared with the master clock, and any time drift documented.

(3) The video camera UTC time code taping was repeated.

(4) The stored sound level data in the LDL2900 were downloaded to a laptop computer and stored in LDL binary file format.

(5) The meteorological data were saved in a comma-delimited ASCII text file.

(6) All instruments were shut off and the entire system disconnected and stored.

Backup copies of all data files were made daily. The naming scheme for the data files was: "MMDDYYax," where 'MM' is a two-digit representation for the month, 'DD' is a two-digit representation for the day of the month, ' $Y Y$ ' is a two-digit representation of the year, ' $a$ ' is a unique character $\mathrm{ID}$ representing the site, and $\mathrm{x}$ is a sequencing number. Unique file extensions were given 
to the different types of data (e.g., meteorological files have a ".met" extension and binary acoustic data have an ".LDL" extension). 


\section{$5 \quad$ Data Reduction and Analysis}

In order to accomplish the defined objectives (Section 1.2), the sound emitted by each aircraft at the Closest Point of Approach (CPA) to the individual microphone locations was examined in detail. In this study, the symbol used for the A-weighted sound level emitted at the point of closet approach is $\mathrm{L}_{\mathrm{CPA}}$.

Examining $\mathrm{L}_{\mathrm{CPA}}$ provides several benefits. The first benefit is that issues related to directivity are eliminated. At CPA, the aircraft is perpendicular to the microphone; for all three microphone locations, the angle from the centerline of the aircraft to the microphone is always 90 degrees. The second benefit is that timing issues are simplified. With a known three-dimensional flight path vector, calculation of the propagation time from the aircraft to each individual microphone is straightforward. The third benefit is that the noise at CPA is the noise at a single instant of time; the received noise can be analyzed knowing the exact geometry between the aircraft and the receiver. The fourth benefit is that the aircraft undergoes no changes during the single instant of CPA; there are no power setting changes, no flap changes, etc.

\subsection{Data Reduction Process}

A suite of computer programs was written to facilitate data reduction. The organization of this suite of programs and the data flow from one program to the next is presented in Figure 5.

There are three primary input data sets: acoustical data, video data, and meteorological data. For each measurement event: the acoustic data comprise time-stamped one-third octave-band spectral time histories as recorded by the LDL2900 in binary format; the video data comprise video recorded in the field; and the meteorological data comprise time-stamped temperature, relative humidity, atmospheric pressure, wind speed and direction in ASCII format. The following sections describe each program used in the data reduction process.

\subsubsection{Acoustic Data Reduction - LD binary-to-ASCII Program}

This program is a Larson Davis program which converts the proprietary format of the LDL2900 binary data files into ASCII text. The output of the program is the acoustic data in ASCII text format.

\subsubsection{Video Data Reduction}

Data reduction for the video system involves converting the digital image of the aircraft recorded 


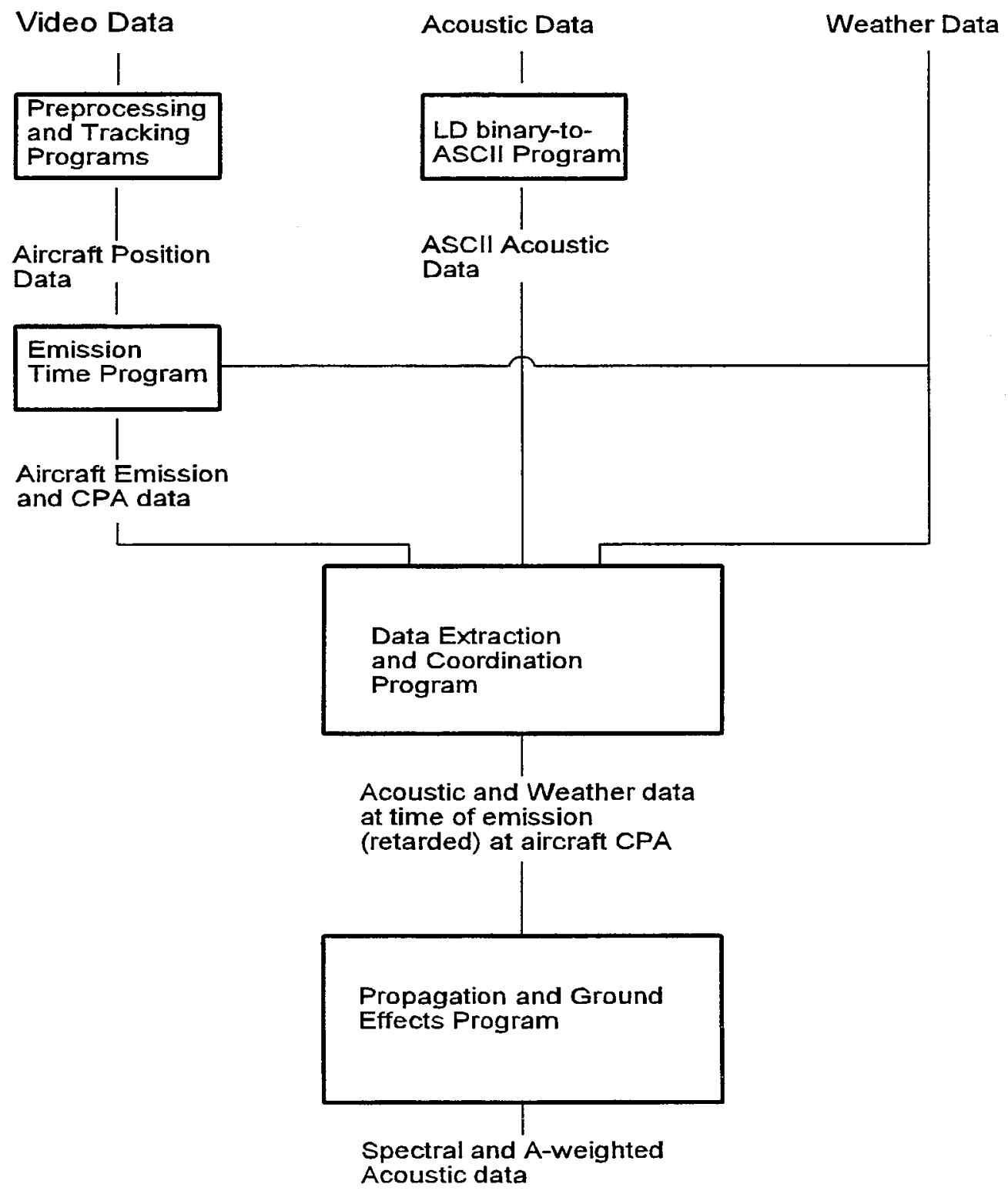

Figure 5. Flow Diagram of Data Reduction Process 
by the two cameras to emission time and three-dimensional CPA position information used by other data reduction programs. This conversion is described in Appendix D.

\subsubsection{Data Extraction and Coordination Program}

This program extracts the acoustic data for the one-third octave band spectra measured at the emission time. The program calculates an energy average of the acoustic data measured at the actual emission time and at the quarter and half second before and after the emission time (a total of five data records, each record is a quarter second long). This procedure corresponded to a total averaging time of 1.25 seconds, or a flight segment of approximately 300 feet for a nominal speed of $160 \mathrm{kts}$.

The output of the program is the averaged one-third-octave spectra from $50 \mathrm{~Hz}$ to $10 \mathrm{KHz}$ for each microphone for each aircraft event centered on CPA. Also included is aircraft type and location information, data on the location of the microphones as a function of time, the ground surface flow resistivity, and the temperature, pressure, relative humidity, and wind speed and direction at the time of CPA.

\subsubsection{Propagation and Ground Effects Program}

This program calculates the known propagation effects from the aircraft to each of the microphone locations, normalizes these data to a reference microphone, and returns the level difference between the normalized data and the actual reference. The known propagation effects are the spherical spreading of sound from a point source $\left[20 \log _{10}\left(\mathrm{~d} / \mathrm{d}_{\mathrm{ref}}\right)\right]$, and atmospheric absorption of sound as a function of frequency. The atmospheric absorption of sound was computed using two different algorithms, those presented in SAE Aerospace Information Report 866a and the International Standard Organization's ISO 9613-1. The data corrected using ISO 9613-1 are presented in subsequent sections. The program also calculates the ground effect using the algorithms of Embleton, Piercy, and Daigle (Reference 13). This ground effects model is described in detail in Appendix E.

The reference microphone used in this study was the 5-foot microphone at Pt. Shirley. The ground effects algorithms were checked by comparing the reference to the 15 -foot microphone at Pt. Shirley. Engine installation effects are quantified by comparing the four microphones at Snake Island and Corinha Beach to the reference microphone.

\subsection{Data Culling Process}

The first step in the reduction of the data was the decision to concentrate the analysis on departure 
data, not arrival data. Departure events significantly outnumber arrival events; this, combined with the lower signal-to-noise ratio of the arrival data and the inability to state with confidence that no power setting changes occur in the final segment of the approach led to the decision to forego analysis of the arrival data.

The entire set of data collected for departure events is shown in Figure 6. This data set represents 339 total departure events measured by the five microphones, which were corrected to the reference microphone. The data points are plotted as a function of elevation angle. The elevation angle was the aircraft's angle above the horizon as seen from the particular microphone. The dependent axis represents the difference between the as-measured corrected data observed at each of the five microphones and the reference microphone.

"Corrected" for the five measurement microphones means the 1.25 second, energy-averaged spectra at CPA were corrected to the same distance as the CPA distance associated with the reference microphone. Correction for these five microphones involves spherical spreading, atmospheric absorption, and ground effect. "Corrected" for the reference microphone involves only the application of the EPD ground effects algorithm (Appendix E) to remove the ground reflection effect present in the measured sound. All data were A-weighted during the analysis. The label on the dependent axis is labeled 'residual.' The residual is believed to be synonymous with the engine installation effect, since all other physical effects on the measured data have been accounted for in the correction process.

The data presented in Figure 6 were culled using two criteria for removing potentially contaminated data. The first criterion was to remove all events that had a recorded wind speed of ten miles per hour (MPH) or greater at any of the three meteorological stations any time in the event. The second criterion was to remove all events that had a possibility of a power setting change before passing over Pt. Shirley. Finally, only the data for a limited number of aircraft types were used in the final analysis, to avoid working with aircraft types that did not have a large sample population.

\subsubsection{Wind Speed Culling}

The wind speed data for all microphone events are shown in Figure 7. Note that the total number of microphone events $(2,034)$ is equal to the total number of departure events (339) multiplied by the total number of microphones (6). The wind speed culling criterion was to remove from the analysis all the data from the six microphones for any event for which any of the three meteorological stations measured a wind speed of $10 \mathrm{MPH}$ or higher during the event. This criterion forced the removal of all events measured after noontime on each of the measurement days. 


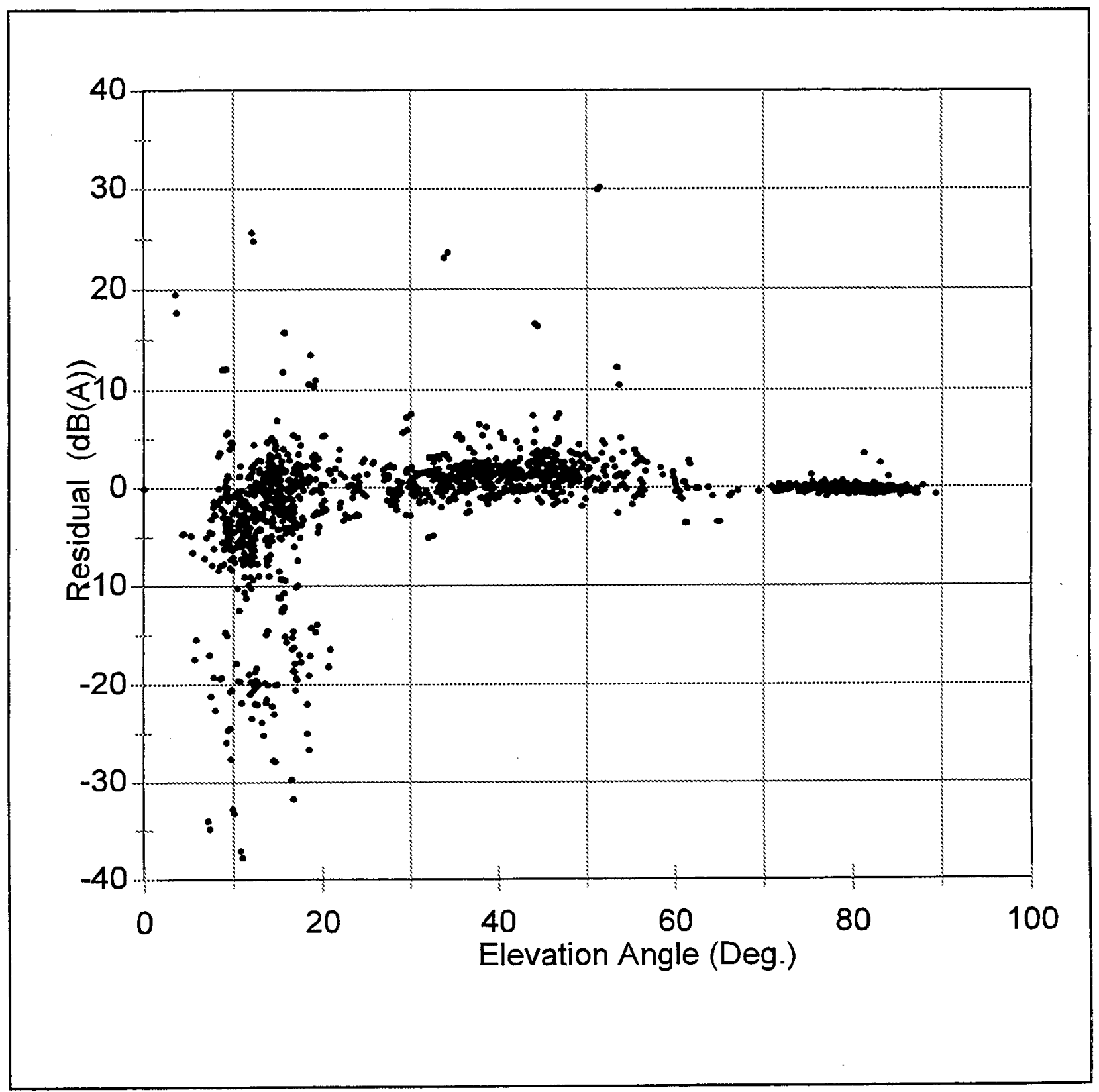

Figure 6. All Departure Data 


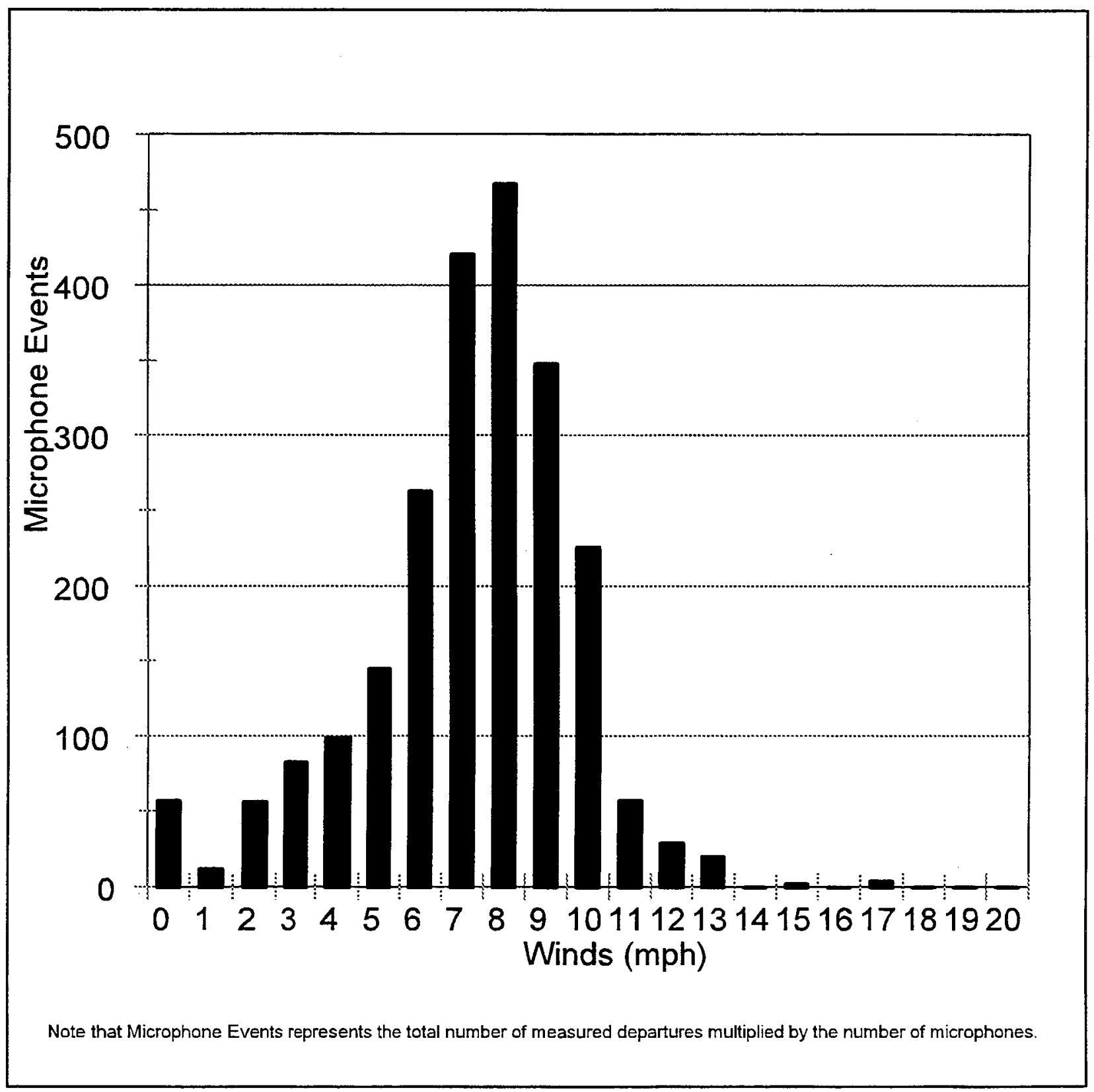

Figure 7. Wind Data, All Departure Events 


\subsubsection{Climb Gradient Culling}

The second criterion used to cull the departure data eliminated any events that possibly included power setting reductions before the aircraft passed over the reference microphone at Pt. Shirley. These power setting reductions are sometimes referred to as cutbacks. Possible cutbacks were identified by a reduction in the climb gradient during the last observed segments of the recorded flight. Any event that had a climb gradient of less than $80 \%$ of the climb gradient for the entire observed event was removed from the analysis. An example of an aircraft that has a climb gradient of $80 \%$ or greater for the last observed segment of the flight is shown in Figure 8. This event was retained in the final data set. An example of an aircraft that has a climb gradient of less than $80 \%$ for the last observed segments of the flight is shown in Figure 9. This event was removed from the final data set.

This climb gradient culling was important because Pt. Shirley lies just before the region where cutbacks occur for typical departures off Runway 9. The FAA permits cutbacks to occur at altitudes at or above 800 feet Above Ground Level (AGL) ${ }^{11}$, although cutbacks at 1000 feet are more typical of normal airline procedures ${ }^{12}$. By the time they pass over Pt. Shirley, most aircraft were between 800 and 1000 feet. Those aircraft that did not exhibit cutbacks were probably either relatively heavy aircraft, aircraft departing with reduced takeoff thrust, or aircraft which are cutting back at a higher altitude than the minimum permitted by the FAA.

\subsubsection{Aircraft Types}

After the culling steps listed above, six aircraft types were considered to have an adequately large population for inclusion in the analysis. These six types were the B-727, DC-9, MD-80, B-737 (CFM series engines), B-757, and A320. All other aircraft types were excluded from further analysis. Note that within each of these types there are large possible variations in weights, engine thrust settings, and, for the B-757 and A320, different engines. These differences do not affect this analysis, since the data set collected for each aircraft event was only referenced to itself, not to an aircraft group.

Table 1 shows the effect of the two culling processes. Of 339 total departures collected during the seven days of measurements, 237 events were recorded for the six primary aircraft types listed above. Of these 237 events, 45 met the wind and climb gradient criteria and were retained for final analysis. The table shows the further division of aircraft into two subgroups: those with engines mounted on the wings ("wing-mounted") and those with engines mounted on the aft fuselage ("tailmounted").

The retained data are shown in Figure 10. This shows the 45 retained aircraft events with 5 data 


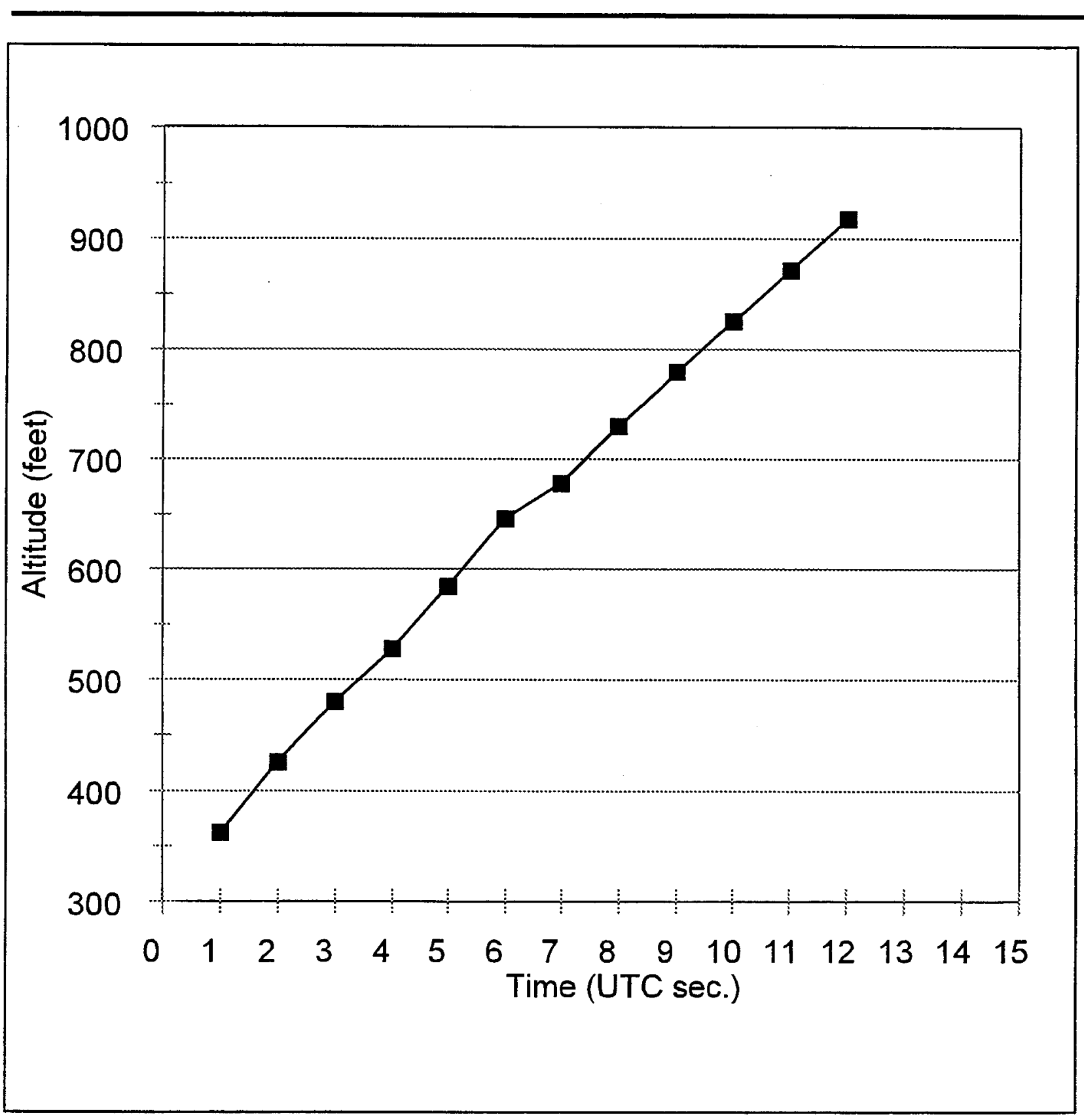

Figure 8. Profile of Retained Event 


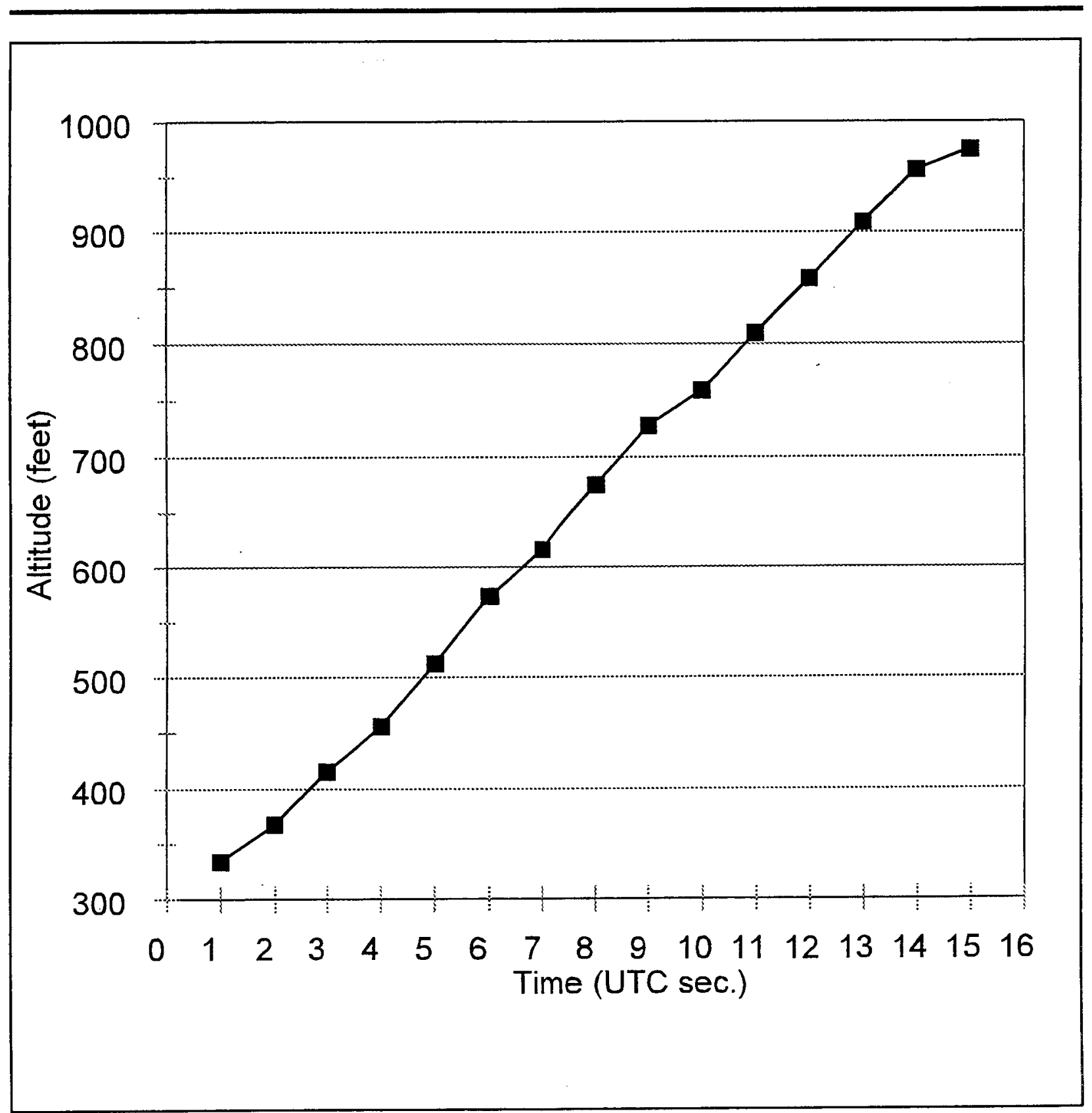

Figure 9. Profile of Culled Event 
Table 1. Summary of Retained Departure Data

\begin{tabular}{|c|c|c|}
\hline \multicolumn{3}{|c|}{ Collected Data for all Aircraft types: } \\
\hline & $\begin{array}{l}\text { Departures: } \\
\text { Arrivals: }\end{array}$ & \\
\hline Major Aircraft Types & Collected Data & Retained Data \\
\hline & (Departure Only) & (Departure Only) \\
\hline A320 Family & 22 & 6 \\
\hline B737 Family (CFM only) & 47 & 8 \\
\hline B757 & 43 & 9 \\
\hline Wing-mounted Subtotal & 112 & 23 \\
\hline B727 & 56 & 8 \\
\hline DC9 & 28 & 6 \\
\hline MD80 Family & 41 & 8 \\
\hline Tail-mounted Subtotal & 125 & 22 \\
\hline Total & 237 & 45 \\
\hline
\end{tabular}

The retained data contain no winds greater than $10 \mathrm{mph}$ at any of the three measurement sites during the entire event and have no events with a final climb gradient less than $80 \%$ of the observed average climb gradient. 


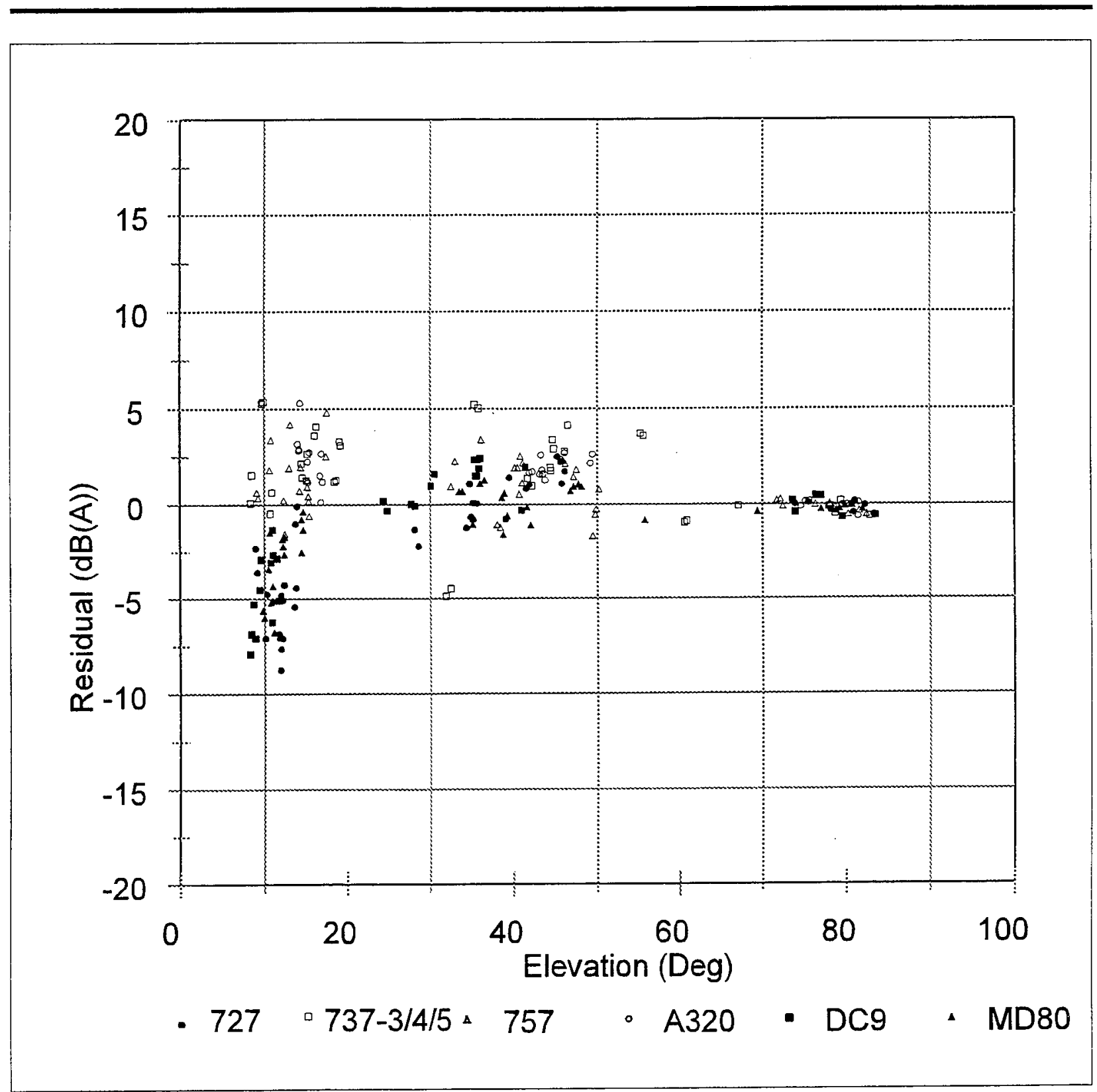

Figure 10. Retained Departure Data 
points for each event. The data points are plotted as a function of elevation angle. The residual may possibly contain meteorological effects, but retaining only data for which wind speeds were less than 10 miles per hour should eliminate the majority of these effects. A statistical analysis of noise levels versus various meteorological conditions for data collected by the Logan noise monitoring system in the summer of 1998 is presented in Appendix B. These data showed no correlation between temperature, wind speed, and time of day. The data tend to cluster in three groups. The data cluster between 8 and 20 degrees was from Corinha Beach, the data cluster from 20 to 60 degrees was from Snake Island, and the data cluster above 60 degrees was from Pt. Shirley.

\subsection{Analysis of Retained Data}

This section presents an analysis of the retained data. The first step in the analysis was to confirm that no problems existed with the signal-to-noise ratio of the measurements collected at Corinha Beach, the most distant measurement site from the nominal tracks. The second step was to examine the value of the ground flow resistivity used for correcting data measured at the Pt. Shirley site. For the two over-water propagation measurement sites, a flow resistivity of 20,000 c.g.s rayls was used. An analysis was then performed to examine the differences between aircraft types based on engine location. A statistical analysis by aircraft type was performed. Finally, an examination of the installation effects for all types of aircraft was conducted.

\subsubsection{Signal-to-Noise ratio at Corinha Beach}

Signal-to-noise ratio is the ratio of the desired signal to the ambient or background levels which interfere with the measurement of the desired signal. At a minimum, a desired signal should be 10 $\mathrm{dB}$ greater than the background levels. With a $10 \mathrm{~dB}$ rise above the noise floor, the error in the signal due to the background levels can be neglected.

Figures 11 and 12 show the A-weighted time histories for two typical events at Corinha Beach, one a B-727, the other a B-757. The B-727 has a peak level over $22 \mathrm{~dB}$ above the background level, and, more applicable to this study, has a sound level at $\mathrm{CPA}\left(\mathrm{L}_{\mathrm{CPA}}\right)$ of about $15 \mathrm{~dB}$ above the background level. The B-757 has a peak level about $15 \mathrm{~dB}$, and an $\mathrm{L}_{\mathrm{CPA}}$ of about $12 \mathrm{~dB}$, above the background level. Signal-to-Noise ratios, even for the aircraft with quieter, modern high-by-pass ratio engines, were not an issue for the departure events studied.

\subsubsection{Ground Impedance at Pt. Shirley}

The ground cover at $\mathrm{Pt}$. Shirley was closely mowed grass. For this type of ground cover, a range of flow resistivities between 150 and $300 \mathrm{c.g}$.s. rayls is recommended by Embleton, et. $\mathrm{al}^{13}$. The results 
of using these flow resistivities to correct the data measured at the five-foot reference microphone are shown in Figure 13. The only noticeable difference occurred at the half-wavelength interference frequency of $63 \mathrm{~Hz}$. For an A-weighted analysis, this difference was effectively negligible. For all further analysis, the flow resistivity of 150 c.g.s. rayls was used.

\subsubsection{Effect of Engine Location}

Examination of Figure 10 shows that data measured for different aircraft types tend to cluster based on engine location. This is particularly noticeable at the lower elevation angles observed from Corinha Beach. Figure 10 displays the data for those aircraft with tail-mounted engines (B-727, MD80 , and DC-9) as closed symbols and the data for those aircraft with wing-mounted engines (B-737 CFM series engines, B-757, and A320) as open symbols. The rest of this section presents an analysis of the data based on these separate groups of aircraft. 


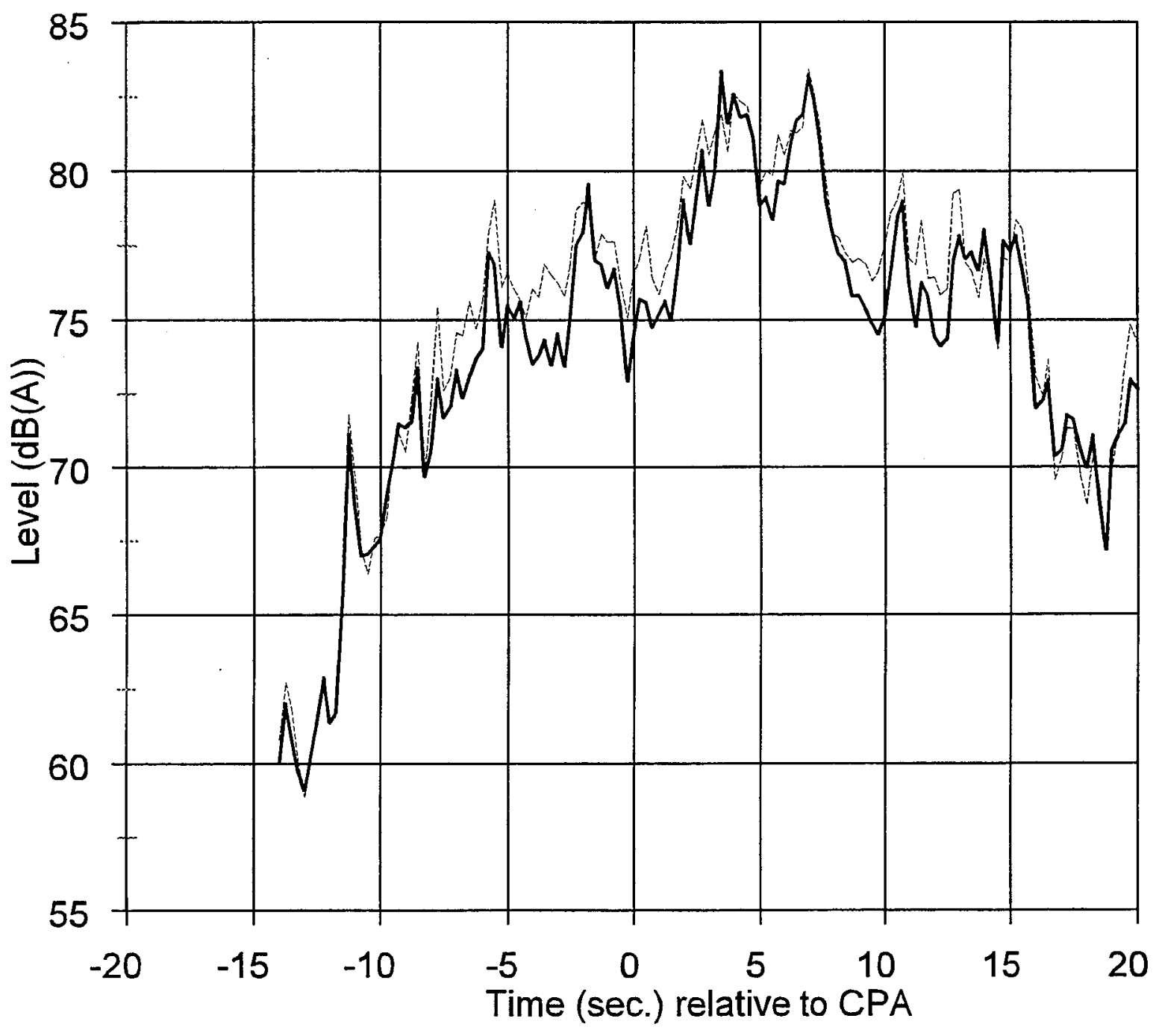

- $5 \mathrm{ft}$. mic.

15 ft. mic.

Figure 11. A-Weighted Time History, B-727 


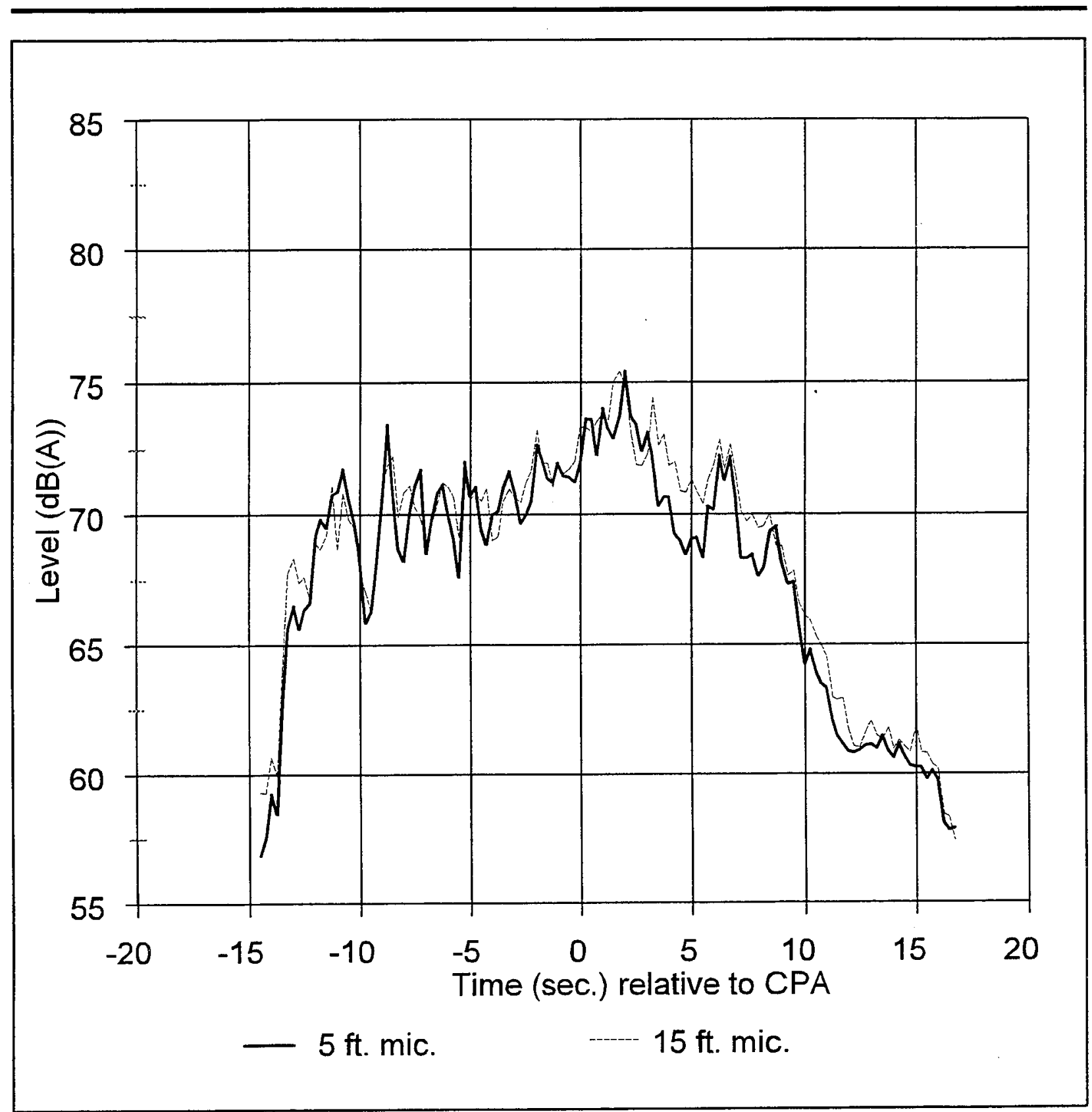

Figure 12. A-weighted Time History, B-757 


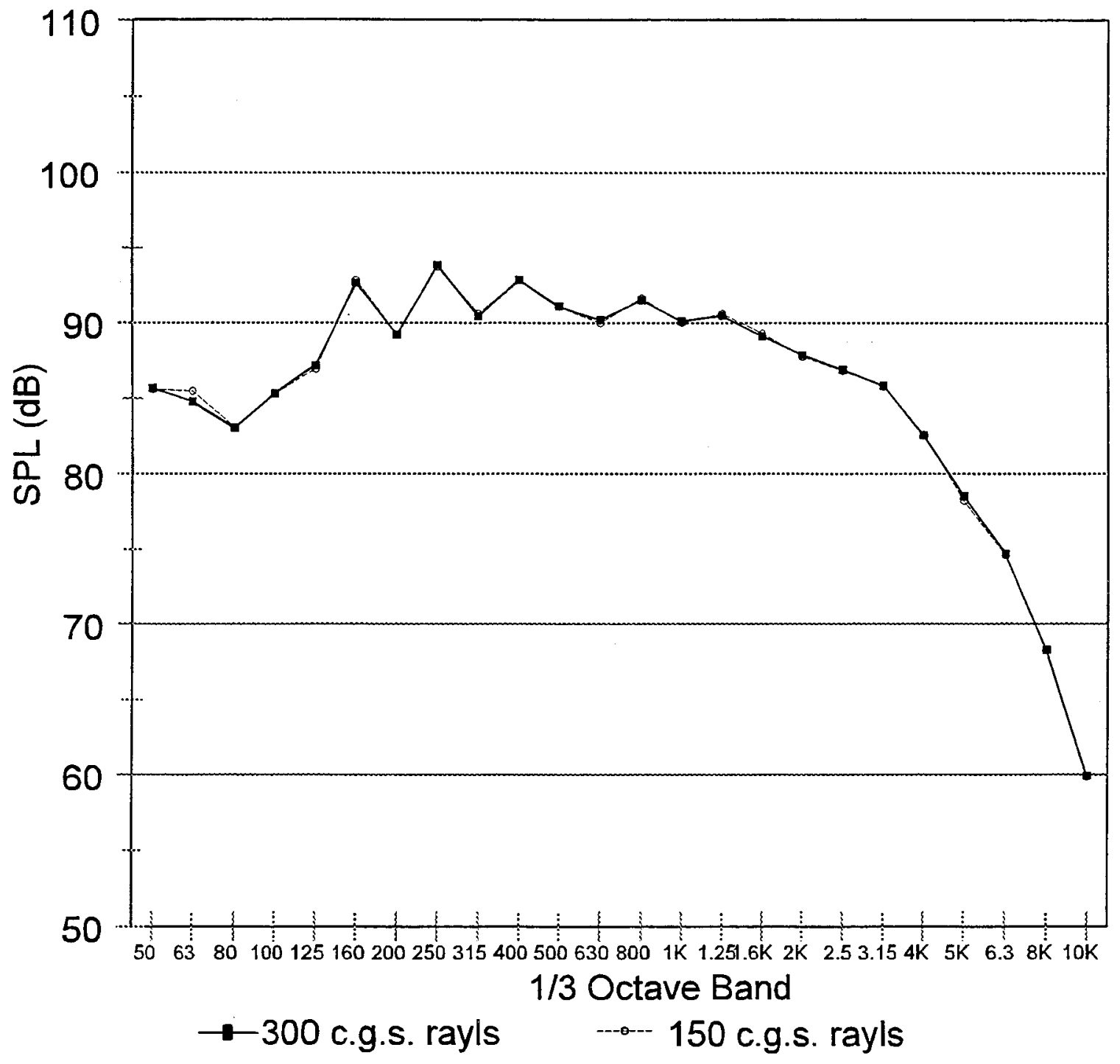

Figure 13. Comparison of Corrected Spectra at Pt. Shirley Using 150 and 300 c.g.s. Rayls Flow Resistivity 


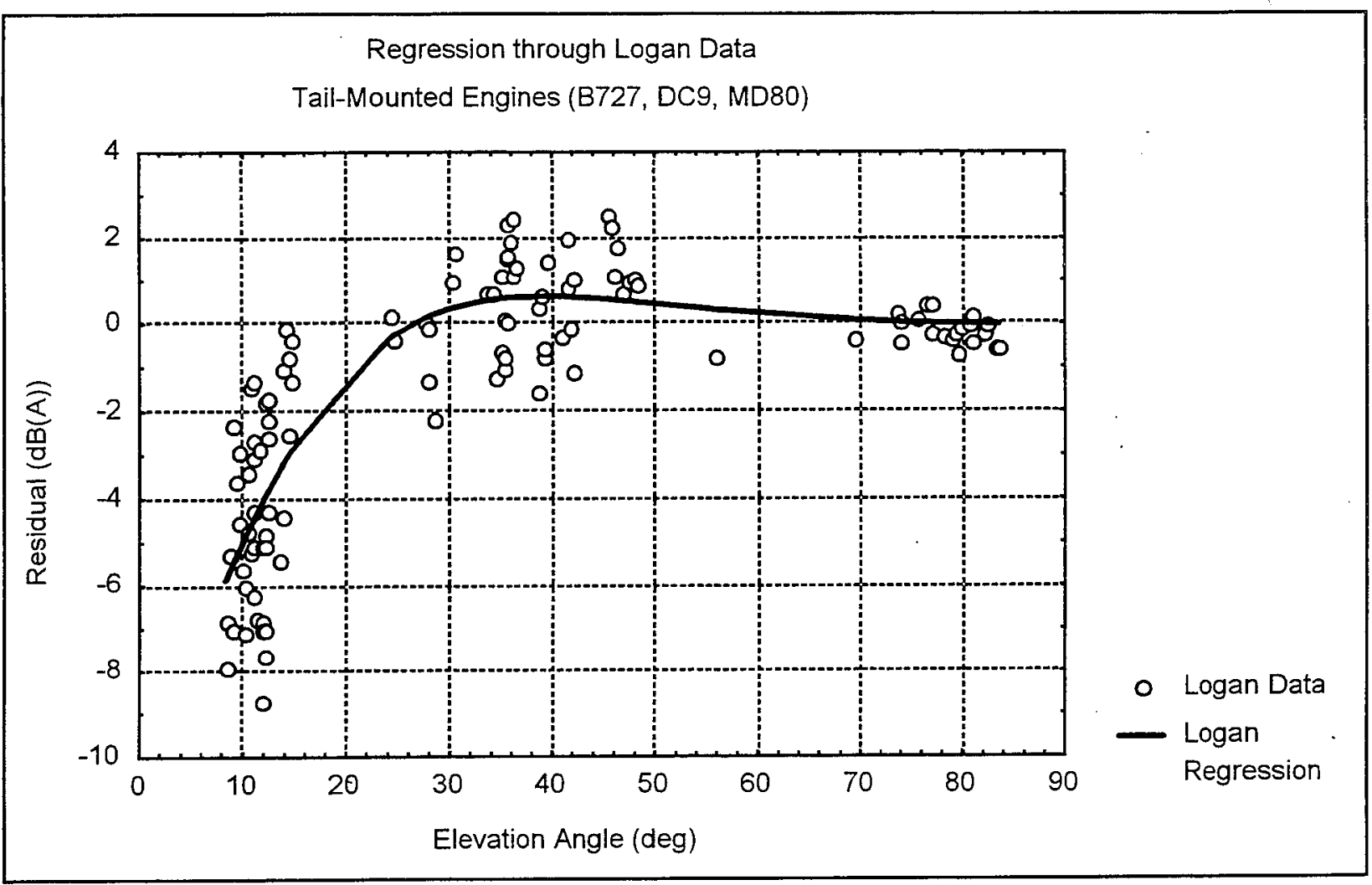

Figure 14. Regression Through Logan Data, Tail-Mounted Engines

\subsubsection{Statistical Analysis}

Figure 14 shows the three aircraft types with tail-mounted engines as a separate group from the entire set of data shown in Figure 10. An exponential regression line has been drawn through the data to enable the reader to better view the trend in the data. The residual effect of these aircraft is pronounced between 8 and 20 degrees of elevation. 


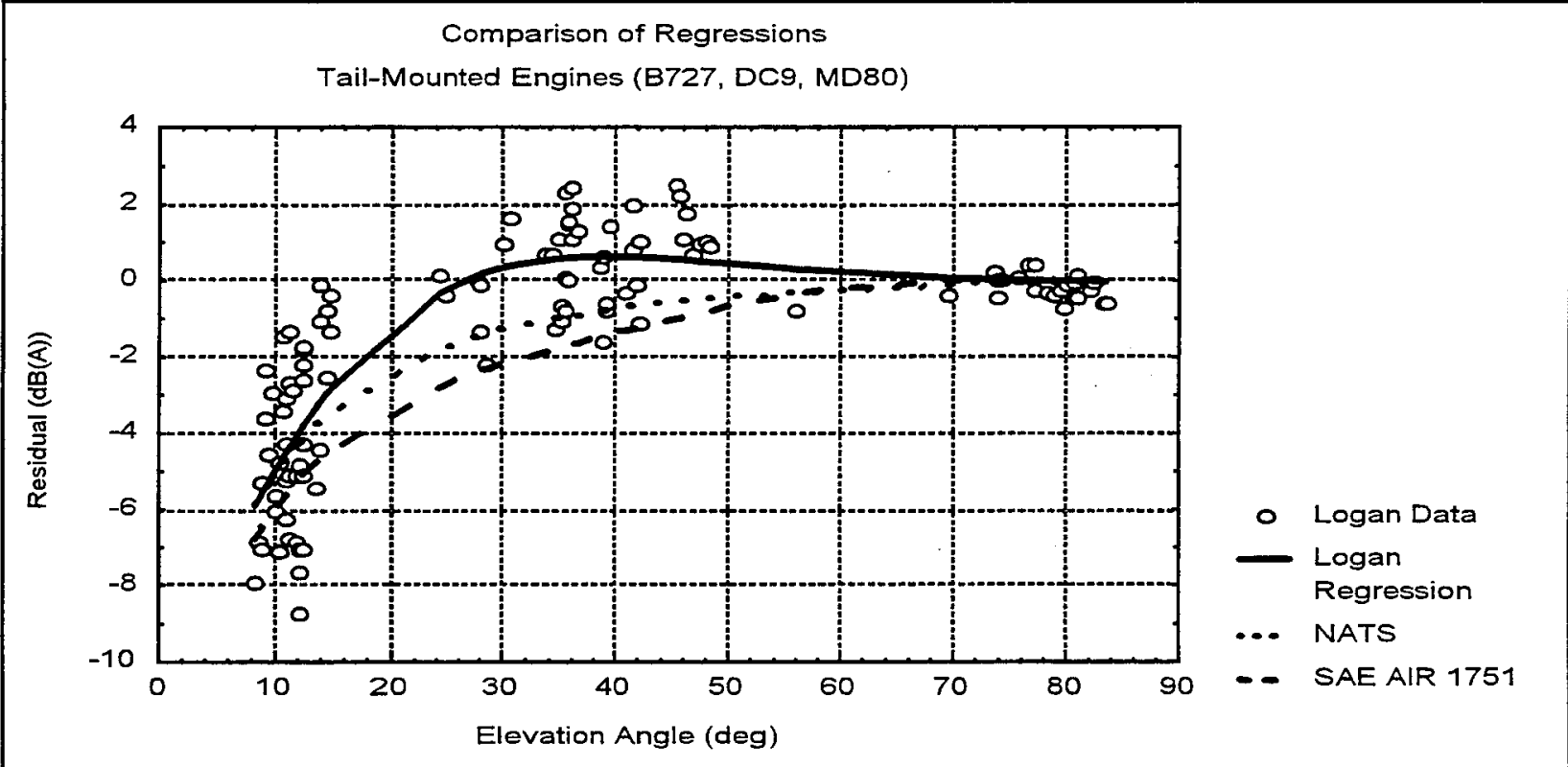

Figure 15. Comparison of Regressions, Tail-Mounted Engines

Figure 15 shows the same data as Figure 14 with the addition of the lateral attenuation curves of SAE AIR 1751 and the lateral attenuation for the same tail-mounted aircraft suggested by National Air Traffic Services, Ltd (NATS). Note that the SAE AIR 1751 curve and the NATS curve represent true lateral attenuation, whereas the residual curve for the Logan study represents engine installation effect as discussed previously. At angles above about 10 degrees, theory shows that ground effects can be neglected; consequently, above 10 degrees, engine installation effects, residual, and lateral attenuation are essentially synonymous. 


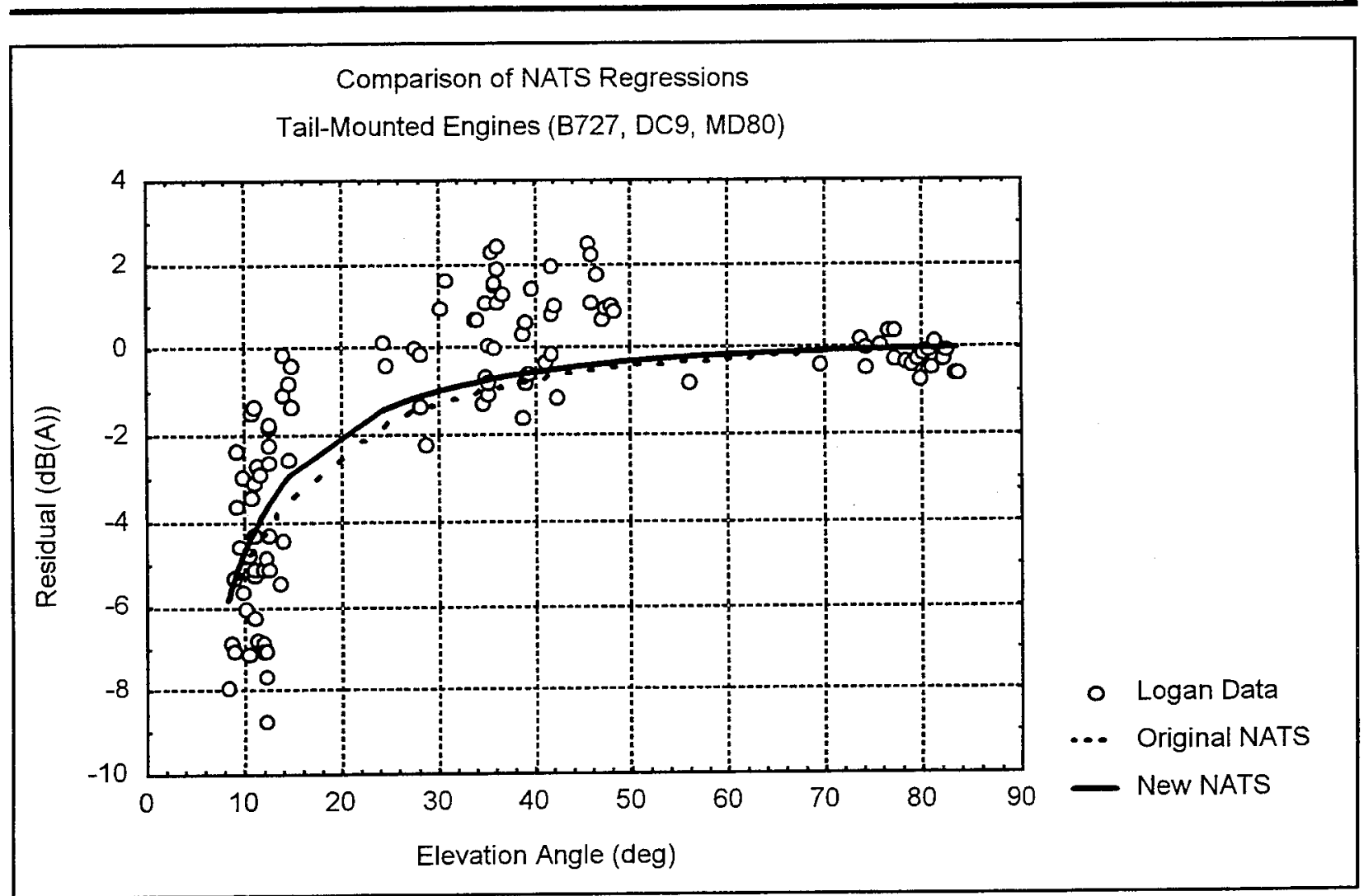

Figure 16. Comparison of NATS Regressions with Original and New Coefficients, TailMounted Engines

Because the NATS lateral attenuation curve is based on empirical data, it was possible to derive coefficients for the NATS curve using the data collected for this study. The result of this process is presented in Figure 16; the figure also includes the original NATS curve found using the Gatwick data. The difference between the curves is small, suggesting that the data collected at the two airports for tail-mounted aircraft were similar, and that the actual curve is dependent on the statistical method selected. 


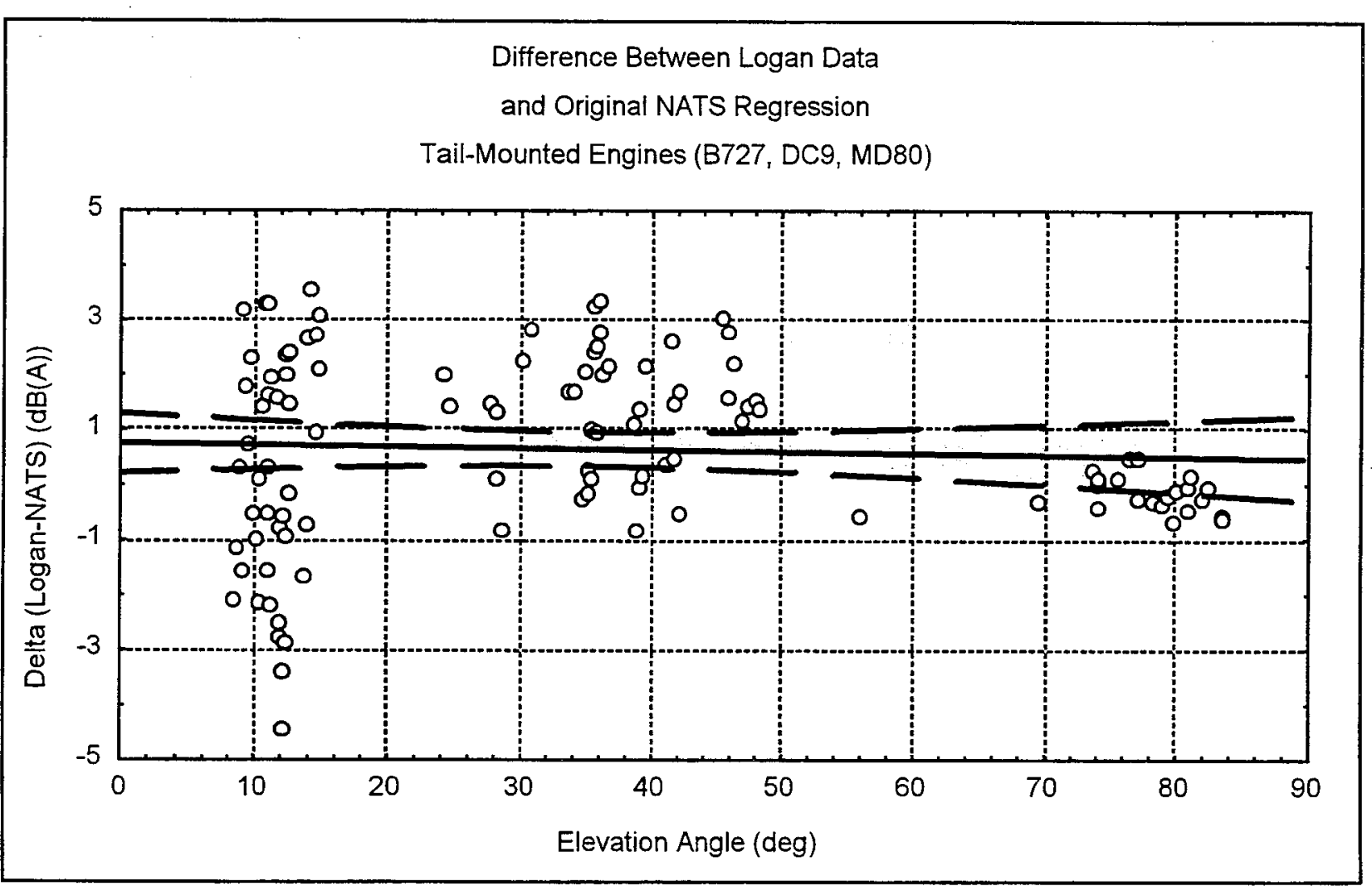

Figure 17. Difference Between Logan Data and Original NATS regression, Tail-Mounted Engines

To determine if a statistically significant difference between the NATS curve and the data collected at Logan exists, the differences between the NATS curve and the Logan data were plotted as a function of elevation angle. The $95 \%$ confidence intervals (CI) for these differences were then calculated. Figure 17 shows the results of these calculations. The best linear fit of the difference is slightly less than one $\mathrm{dBA}$ for all elevation angles. At all angles, the lower $\mathrm{CI}$ line is very close to encompassing the zero line. Although the two data sets are not statistically equivalent at all elevation angles, the differences are small. 


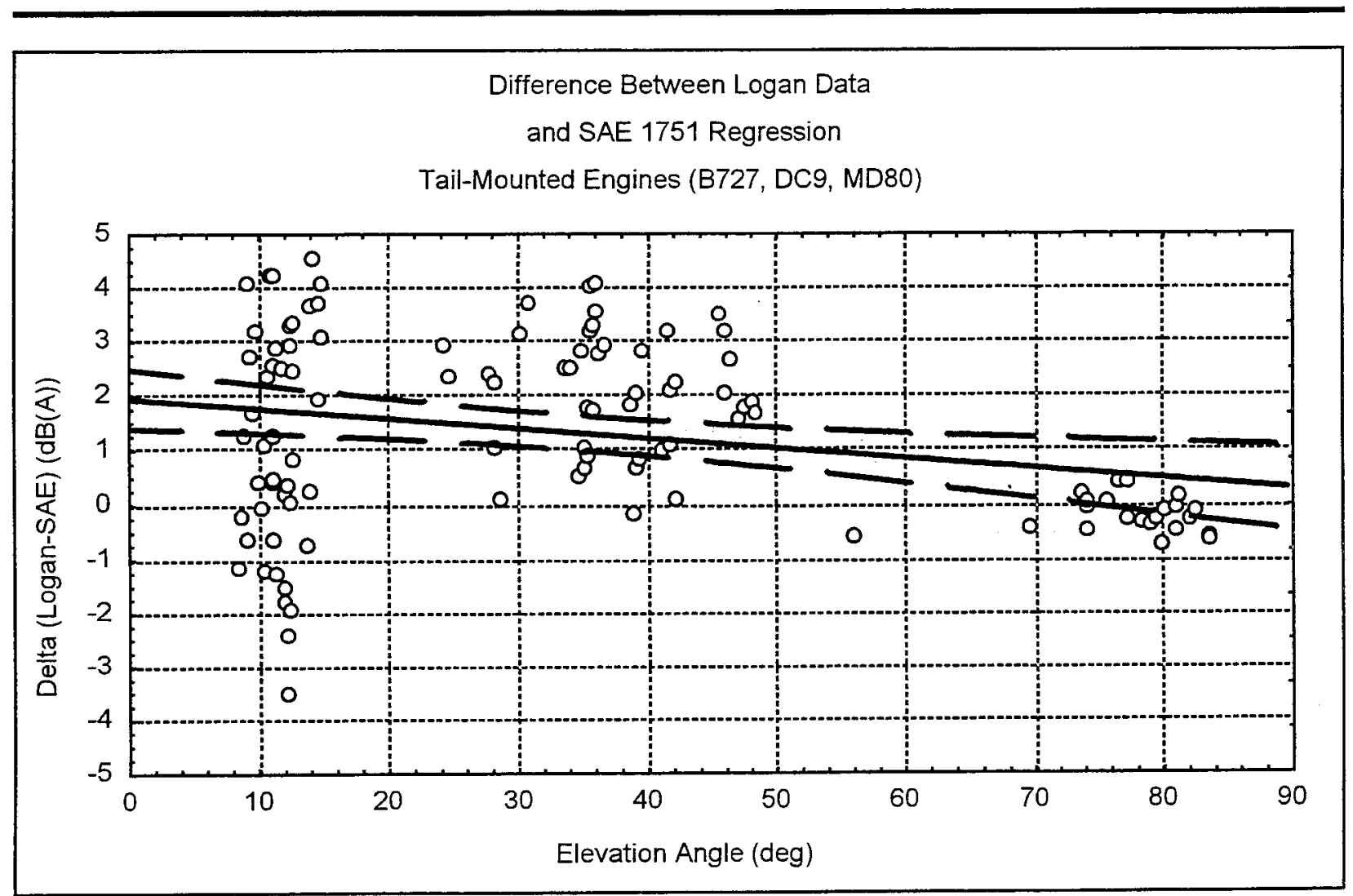

Figure 18. Difference Between Logan Data and SAE AIR 1751 Regression, Tail-Mounted Engines

The difference between the SAE AIR 1751 equation for lateral attenuation and the Logan data is presented in Figure 18. The figure also displays the $95 \%$ confidence intervals of the best linear fit through the data. The difference data varies from zero directly overhead (where, by definition, no lateral attenuation exists), to around $2 \mathrm{dBA}$ difference at the lower angles where the engine installation effects are expected to become pronounced. 


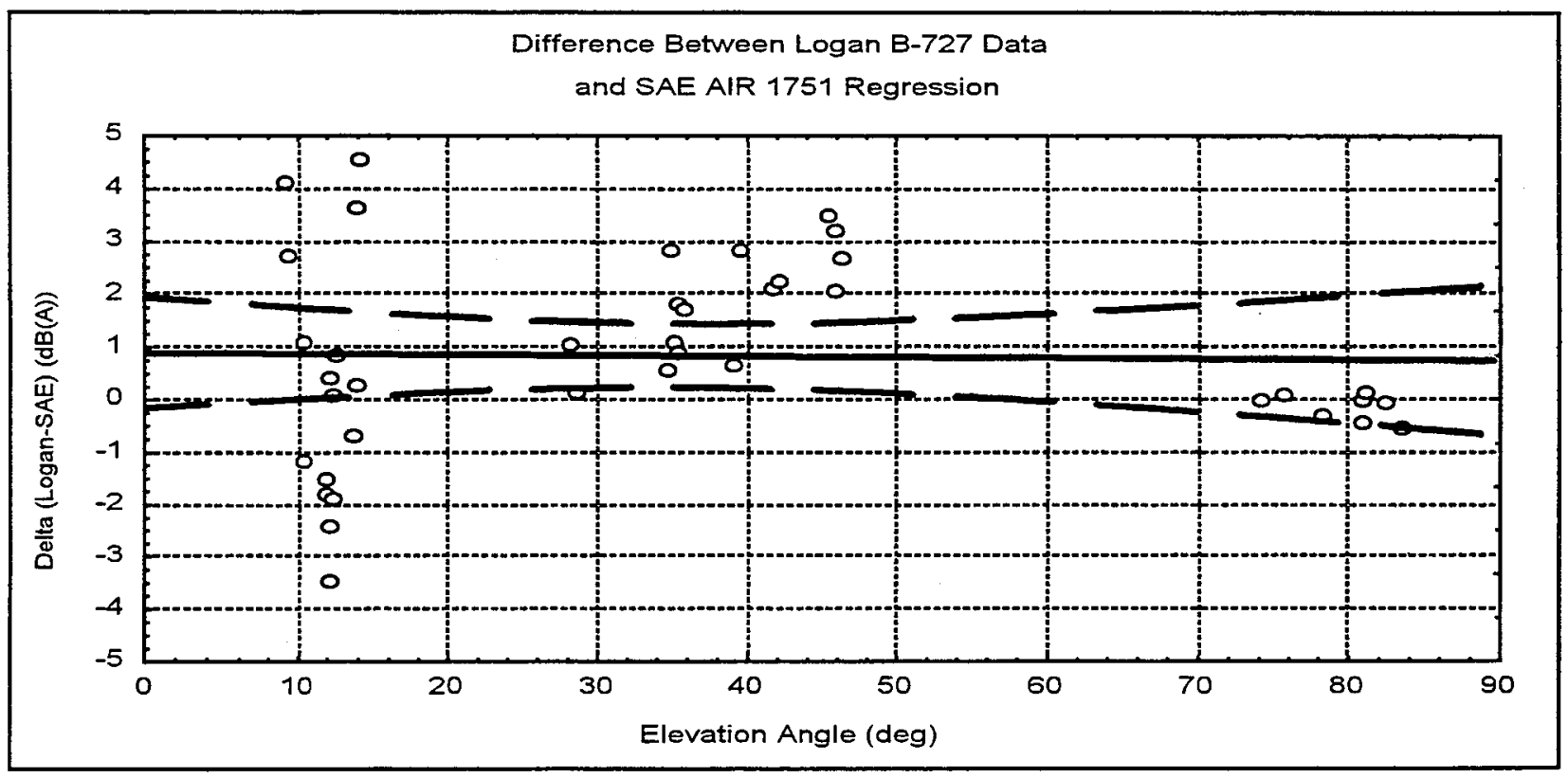

Figure 19. Difference Between Logan B-727 Data and SAE AIR 1751 Regression

Figure 19 shows the difference between the SAE AIR 1751 equation for lateral attenuation and the data measured at Logan for the B-727 aircraft. The figure also shows the $95 \%$ confidence intervals of the best linear fit through the data. At high and low angles, the confidence intervals encompass zero, indicating there is no statistically significant difference between the Logan data and the SAE AIR 1751 equations for the B-727 at these angles. Between about 20 and 50 degrees, a statistically significant difference does appear between the Logan data and the SAE AIR 1751 equations. However, the difference is on the order of a few tenths of a decibel. The agreement between the Logan B-727 data and the SAE AIR 1751 equation was expected since, as mentioned previously, the SAE AIR 1751 data set is dominated by the B-727 aircraft. 


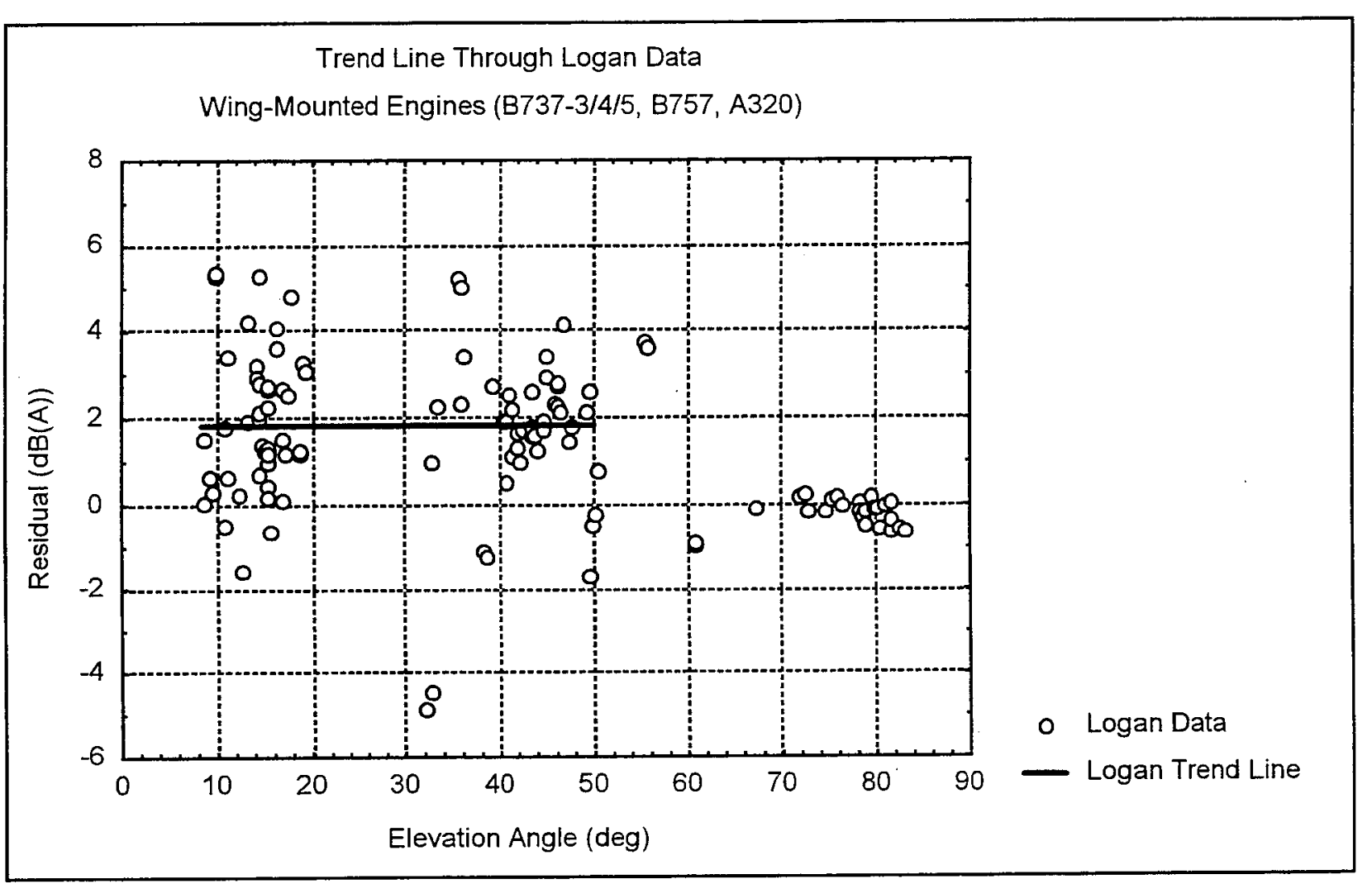

Figure 20. Trend Line Through Logan Data, Wing-Mounted Engines

Figure 20 shows the three aircraft types with wing-mounted engines as a separate group. A "trend line" has been drawn through the data at the lower elevation angles to enable the reader to better view the general behavior of the data. This trend line is the arithmetic average of the data at angles below 60 degrees. The residual effect for these aircraft is the opposite of the tail-mounted engine group. For these aircraft an augmentation at the lower elevation angles is observed; the noise measured for these aircraft is higher than what would be measured directly under the aircraft at the same slant distance. For elevation angles below 60 degrees, this augmentation appears independent of elevation angle. 


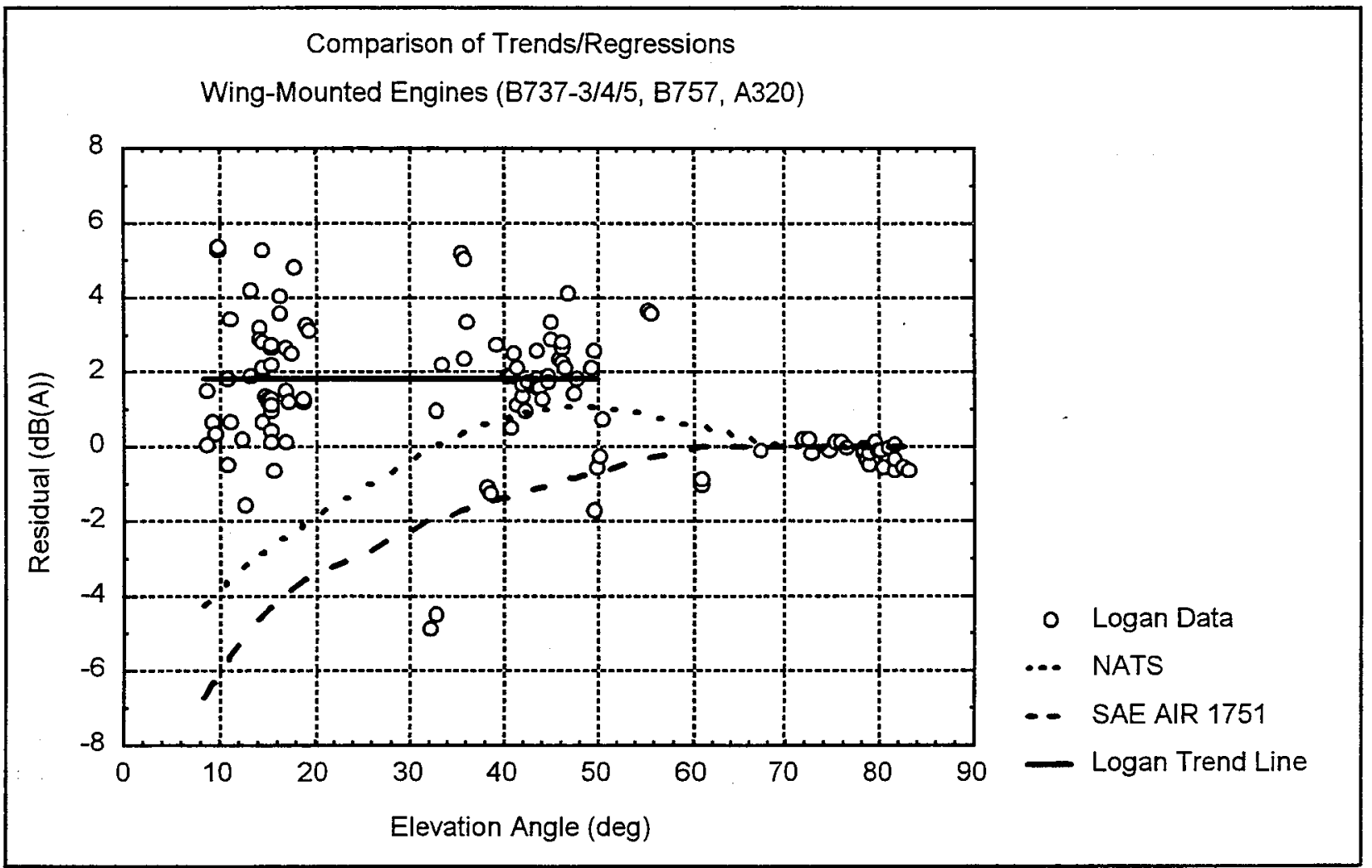

Figure 21. Comparison of Trends/Regressions, Wing-Mounted Engines

Figure 21 shows the Logan data and trend line for the aircraft with wing-mounted engines, along with the SAE AIR 1751 and the NATS lateral attenuation curves. The NATS curve shows similar augmentation between 20 and 60 degrees as seen in the Logan data, but the data differ substantially at the lower elevation angles. This difference was large enough that further statistical comparison of the wing-mounted data was not meaningful. In addition, the difference between the Logan data and the SAE AIR 1751 curve of approximately $4 \mathrm{~dB}$ at the mid-angles and $8 \mathrm{~dB}$ at the low angles should be noted. These large differences at low angles for aircraft with wing-mounted engines imply that noise prediction models that use the existing lateral attenuation algorithms may be underpredicting the noise generated by these aircraft by a similar magnitude. 


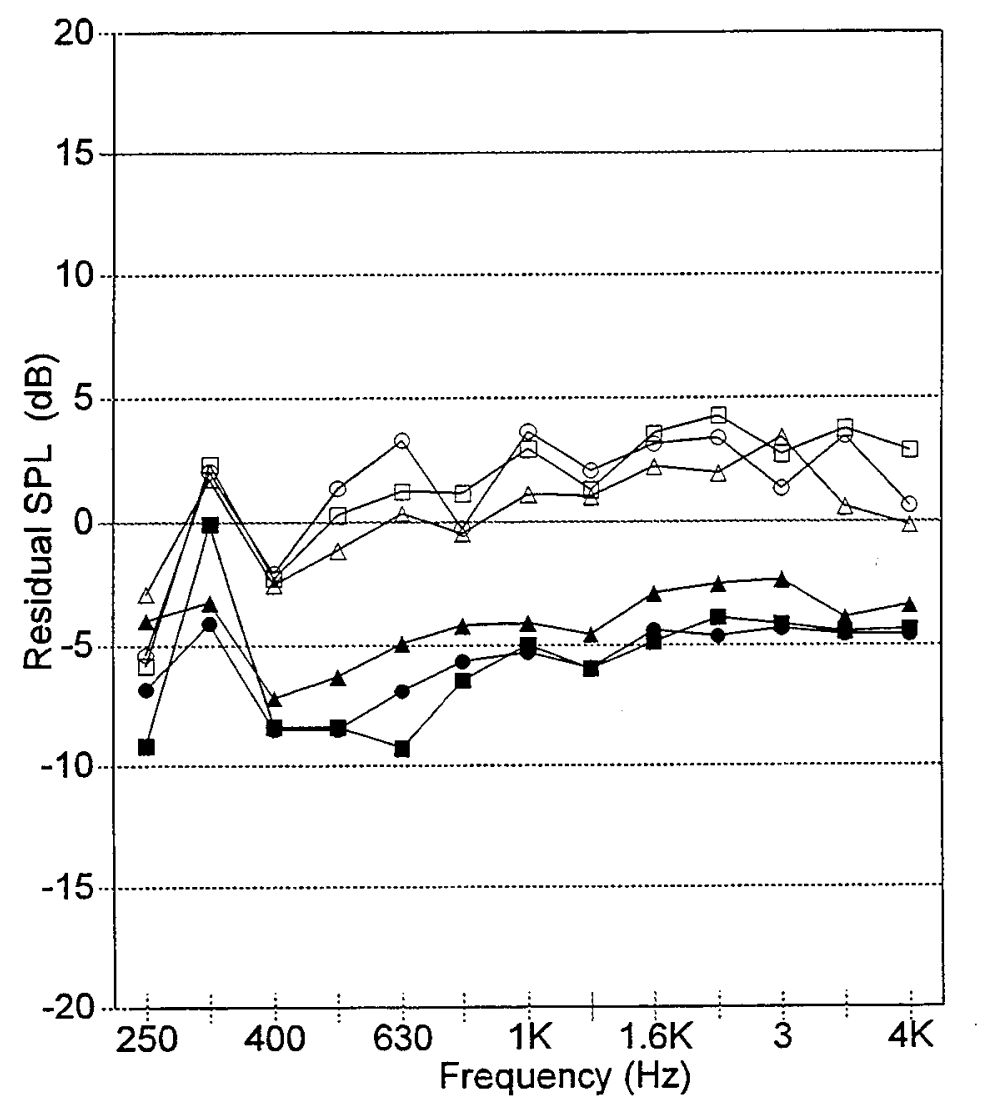

$\square$

B $737-3 / 4 / 5$

$\triangle$

B757

$-0$

A320

$\rightarrow$

B727

$\rightarrow$

DC9

$\rightarrow$

MD80

\section{Figure 22. Residual as a Function of Frequency, Elevation Angles from 8 to 20 Degrees}

\subsubsection{Installation Effects}

Figure 22 shows, for elevation angles between 8 and 20 degrees, the average residual effect for the six retained aircraft types as a function of frequency for frequencies between $250 \mathrm{~Hz}$ and $4000 \mathrm{~Hz}$. These frequencies are essential to the A-weighted analysis presented herein. As can be seen, there is a clear separation between the wing-mounted and tail-mounted aircraft. Figure 22 also shows that the installation effect is not a strong function of frequency for these six aircraft types. This relative lack of frequency dependance for each of the six types is a further indicator that signal-to-noise was not a factor, and, more importantly, that a significant difference in residual exists between aircraft with tail-mounted and wing-mounted engines. 


\subsection{Additional Observations}

The first topic in this section is an overview of the differences in aircraft geometries, and how these differences may help explain the figures presented in Section 5.3. The second topic in this section examines the correlation between the $\mathrm{L}_{\mathrm{CPA}}$ data measured in this study and the SEL data presented in Reference 8.

\subsubsection{Geometry of Aircraft}

The data presented in Section 5.3 showed significant differences in the engine installation component of lateral attenuation between aircraft with wing-mounted engines and aircraft with tailmounted engines. Possible reasons for these differences are related to the differences in physical geometry of these two groups of aircraft.

\subsubsection{Aircraft with Tail-Mounted Engines}

Noise generated by jet engines has a number of discrete sources. These discrete sources include the fan, the compressor and turbine machinery, the combustor, and primary (jet) and secondary (fan) exhausts. These noise sources tend to be directional. The fan noise generally propagates forward, the machinery and combustor noise propagates perpendicularly, and the exhaust noise tends to propagate to the rear ${ }^{14}$. Because this study examines noise emitted at CPA, fan noise and exhaust noise are probably not major factors in the residuals presented in Section 5.3.

When aircraft with tail-mounted engines are perpendicular to the receiver at low angles ( 8 to 20 degrees), the farthest engine is completely shielded by the fuselage or the vertical stabilizer. With complete shielding of the farthest engine(s), the noise would be reduced up to $3 \mathrm{~dB}(10 \log (1 / 2)=-3)$ for a two-engine aircraft and up to $4.8 \mathrm{~dB}(10 \log (1 / 3)=-4.8)$ for a three-engine aircraft in the limiting case of closely-spaced, co-linear engines. Hodge ${ }^{15}$ has noted that additional attenuation may be due to aerodynamic flow-field effects. These effects are the scattering of the engine noise as it passes through the wing down-wash and the wingtip vortices. These effects, combined with some shielding of the farthest engine(s), may account for the residual at low angles seen in Figures 14 through 16.

For aircraft with tail-mounted engines at mid-range elevation angles (20 to 60 degrees), the farthest engine may be visible under the fuselage. As such, the aircraft with tail-mounted engines tend to show an augmentation similar to the aircraft with wing-mounted engines (Figures 14 and 20, respectively). This augmentation for aircraft with tail-mounted engines may be due to the combination of the incomplete shielding of the farthest engine and the reflection of the noise from 
the closest engine off the relatively flat horizontal and vertical stabilizers.

A comparison of the uncorrected A-weighted time histories levels measured at Corinha Beach and Pt. Shirley for an aircraft with tail-mounted engines is given in Figure 24. An important feature of Figure 24 is the reduction in level around the time of CPA for the measurements made at Corinha Beach. Note that the reduction is present for both the $5-\mathrm{ft}$. and $15-\mathrm{ft}$. microphones, indicating that this reduction is not an artifact of the measurement technique. This reduction in level at CPA for the Corinha Beach measurements appears in the majority of the time histories for the retained aircraft with tail-mounted engines. There is no corresponding dip in the time history for the reference measurement made at $\mathrm{Pt}$. Shirley. The presence of this local reduction in the A-weighted data at Corinha Beach is a time history representation of the residual described in Section 5.3.

\subsubsection{Aircraft with Wing-Mounted Engines}

Modern jet aircraft with wing-mounted engines do not have constant chord wings, but rather have a significant taper ratio. The taper ratio is highest between the engine and the fuselage, where the leading edge of the wing is swept while the trailing edge projects almost perpendicular to the fuselage. This means the engine farthest from the receiver has a fairly broad and flat surface from which to reflect noise.

For the three types of aircraft with wing-mounted engines included in this report, the engines are either forward or under the wing. These locations provide limited opportunity for noise from the closest engine to reflect off aircraft surfaces. In addition, these locations provide limited opportunity for noise from either engine to be shielded by the fuselage. However, as mentioned above, noise from the farthest engine could possibly reflect off the underside of the fuselage and the wing center section. These reflections may account for the augmentation at elevation angles below 60 degrees shown in Figures 20 and 21. Conversely, the lack of any apparent residual as a function of angle in these figures indicates that aerodynamic flow-field effects may be negligible for aircraft with wing-mounted engines.

In addition, the residual augmentation seen in Figures 20 and 21 for aircraft with wing mounted engines may be due to assumed perfectly straight source-to-receiver paths that, in fact, were not. Figure 23 presents an example of modeled ground effect as a function of reflection angle. The figure is based on the EPD ground effects model used in this study. The figure represents a ground distance of 1000 meters between the source and the receiver, which is approximately the CPA distance from Corinha Beach. The figure shows a ground effect of about three decibels when reflections angles are less than about one degree and less than one decibel when reflection angles are above about 10 degrees. The combined average ground effect based on the EPD model 
for the aircraft observed from Snake Island and Corinha Beach is 0.57 decibels. If the source-toreceiver sound path was curved, the actual reflection angle would be slightly lower than was assumed with straight-path propagation. The effect of applying this lower reflection angle (and increased ground effect) would be to reduce the residual augmentation. This residual augmentation may also be inherent in the data for aircraft with tail-mounted engines (Figures 14 and 15). Lower actual reflection angles could be possibly caused by the effects of water surface conditions on the propagation path and/or micro-meteorological effects at the water/air boundary ${ }^{16}$. Investigation of these factors is beyond the scope of this study.

A comparison of the uncorrected A-weighted time histories levels measured at Corinha Beach and Pt. Shirley for an aircraft with wing-mounted engines is given in Figure 25. Unlike Figure 24 , there is no reduction in level for the Corinha Beach measurements at the time of CPA. None of the aircraft with wing-mounted engines shows a reduction in level similar to that shown in Figure 24 .

\subsubsection{Relationship of $\mathrm{L}_{\mathrm{CPA}}$ and Integrated Metrics}

The ability to accurately track aircraft, and to coordinate that tracking information with acoustic data was an important component of this study. Most uncontrolled aircraft noise studies conducted to date have not had the luxury of this precise coordination, and so have relied on integrated noise metrics such as SEL and/or DNL. Integrated metrics correlate with community response to aircraft noise, and provide a useful comparison of noise levels, but they do not allow close dissection of individual components of aircraft noise. One of the problems with integrated metrics is that they can contain noise data generated during different aircraft configurations. For example, an SEL metric for a departure will generally contain all the aircraft noise generated during a period in which the noise of the aircraft is within $10 \mathrm{~dB}$ of the maximum noise generated by the aircraft. This period will, by definition, contain the noise produced over a range of directivity angles and slant distances. The period may also contain noise during different aircraft configurations such as power setting changes or flap changes. Even when the SEL is based on a CPA distance for an aircraft altitude less than the standard cutback altitude, the SEL will contain significant energy when the aircraft is above the cutback altitude. These unknowns in the SEL tend to make the metric in some ways less trustworthy than a metric that looks at the noise generated at a known instant of time and at a known constant angle.

Although the SEL metric may not be as precise a tool as the $\mathrm{L}_{\mathrm{CPA}}$ metric for examining the details of aircraft noise, examination of the data collected at Logan showed a high correlation between $\mathrm{L}_{\mathrm{CPA}}$ and SEL. For measurements made at Corinha Beach, the correlation is shown in Figure 26. For the equation $S E L=14.2+0.99 L C P_{A}$, the correlation coefficient is 0.92 . 


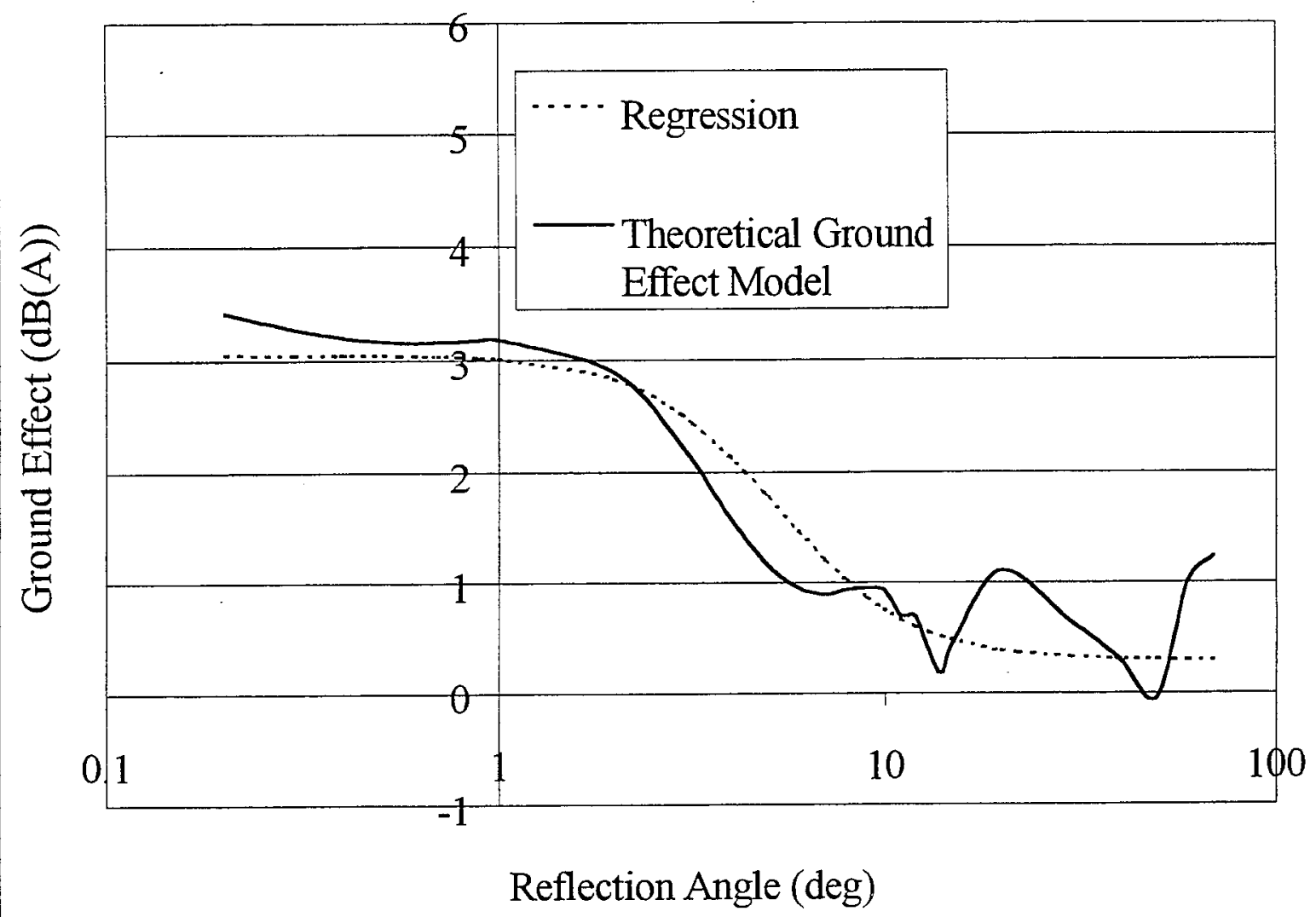

Figure 23. Ground Effect, 1000 meters; Based on EPD model 


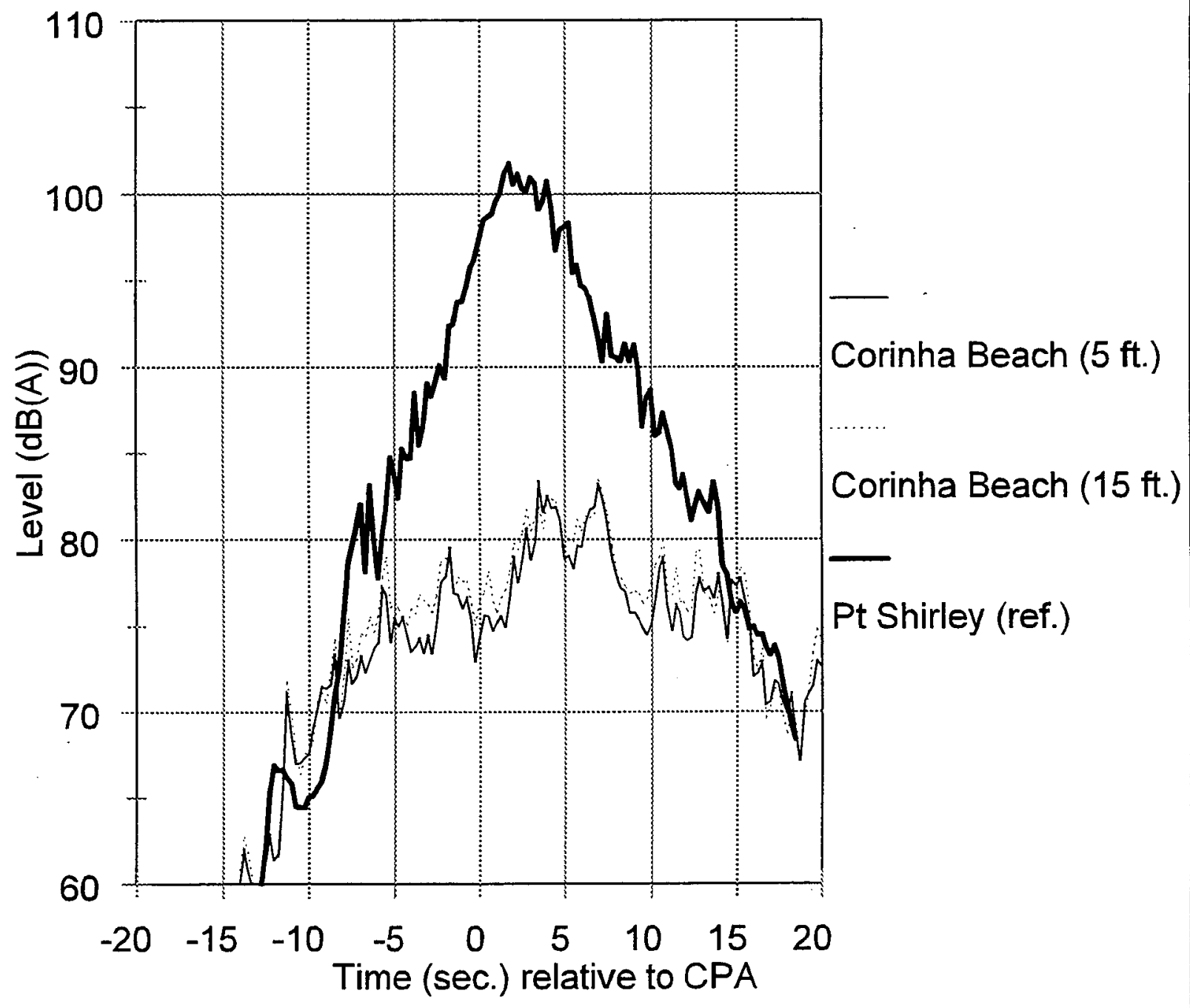

Figure 24. A-weighted Time History of B-727 Departure, Corinha Beach and Pt. Shirley 


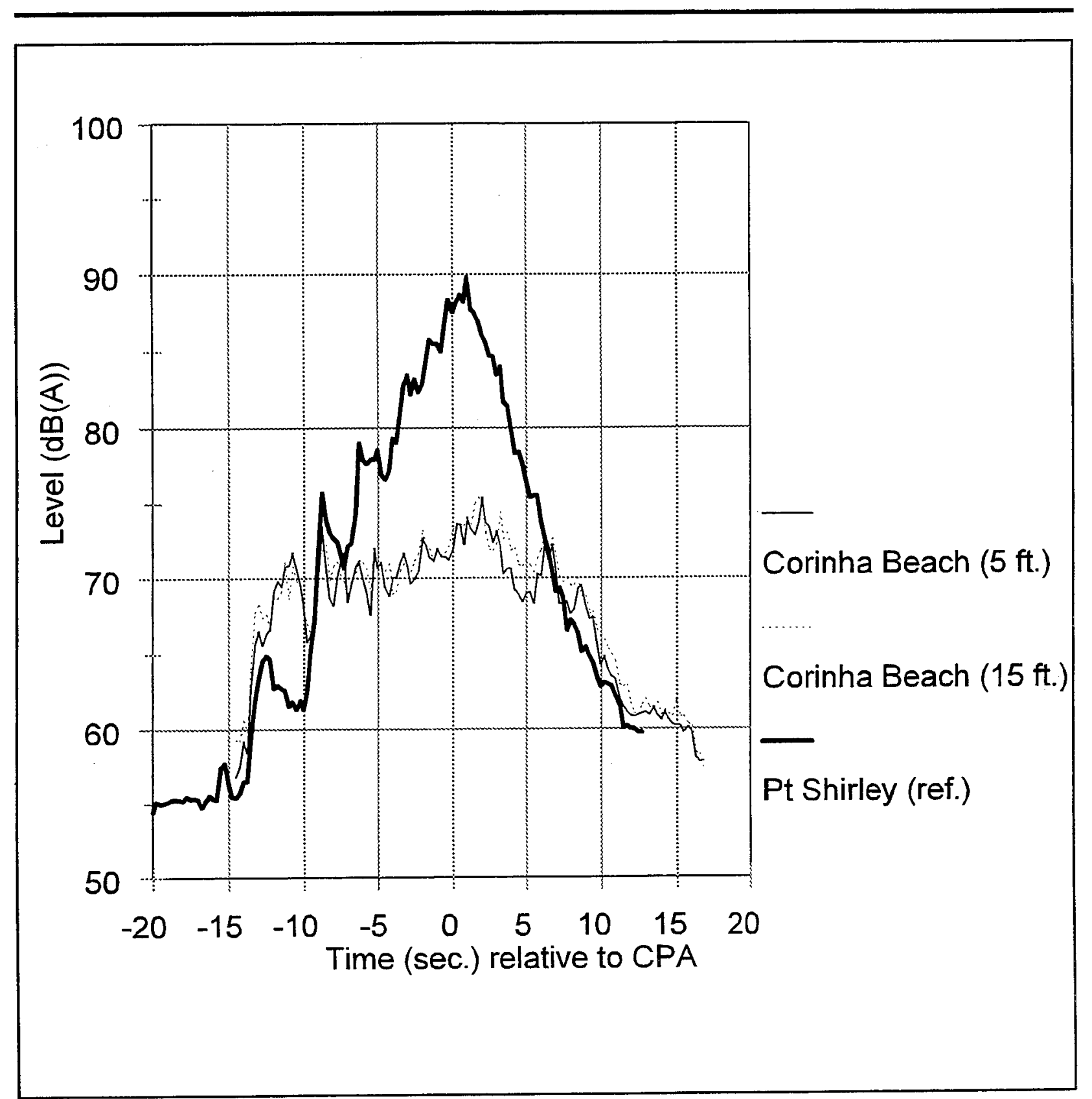

Figure 25. A-weight time History of B-757 Departure, Corinha Beach and Pt. Shirley 
For measurements made at Pt. Shirley, the correlation is shown in Figure 27. For the equation $S E L=8.0+L_{C P A}$, the correlation coefficient is 0.92 .

The data shown in Figures 26 and 27 used to generate the corresponding equations were based on the 727 and 757 aircraft only. These are the two most common types of aircraft in each of the sub-groups examined. Also, although a correlation exists at each site, no conclusions can be drawn that the SEL data at Corinha Beach correlates with the SEL data at Pt. Shirley. The methods of correcting the data from Corinha Beach to the reference microphone at Pt. Shirley relied on knowing the exact aircraft location and spectra at each moment in time. This information is lost in the SEL metric. Despite this caveat, the high correlation between the SEL and $\mathrm{L}_{\mathrm{CPA}}$ descriptors may indicate that the conclusions of this study would not change if SEL were selected as the metric of analysis. 


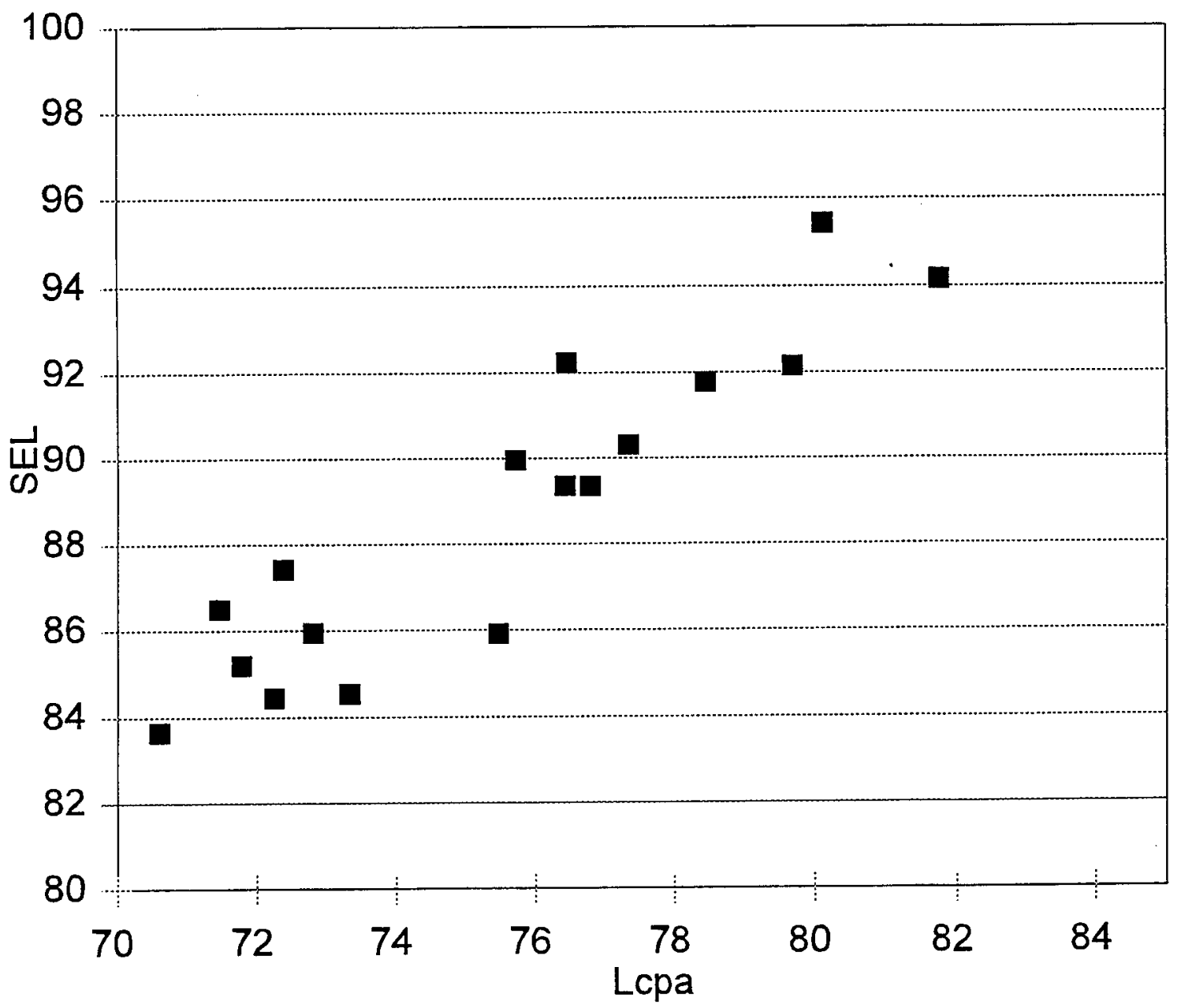

Figure 26. $\mathbf{L}_{\mathrm{CPA}}$ versus $S E L$, Corinha Beach 


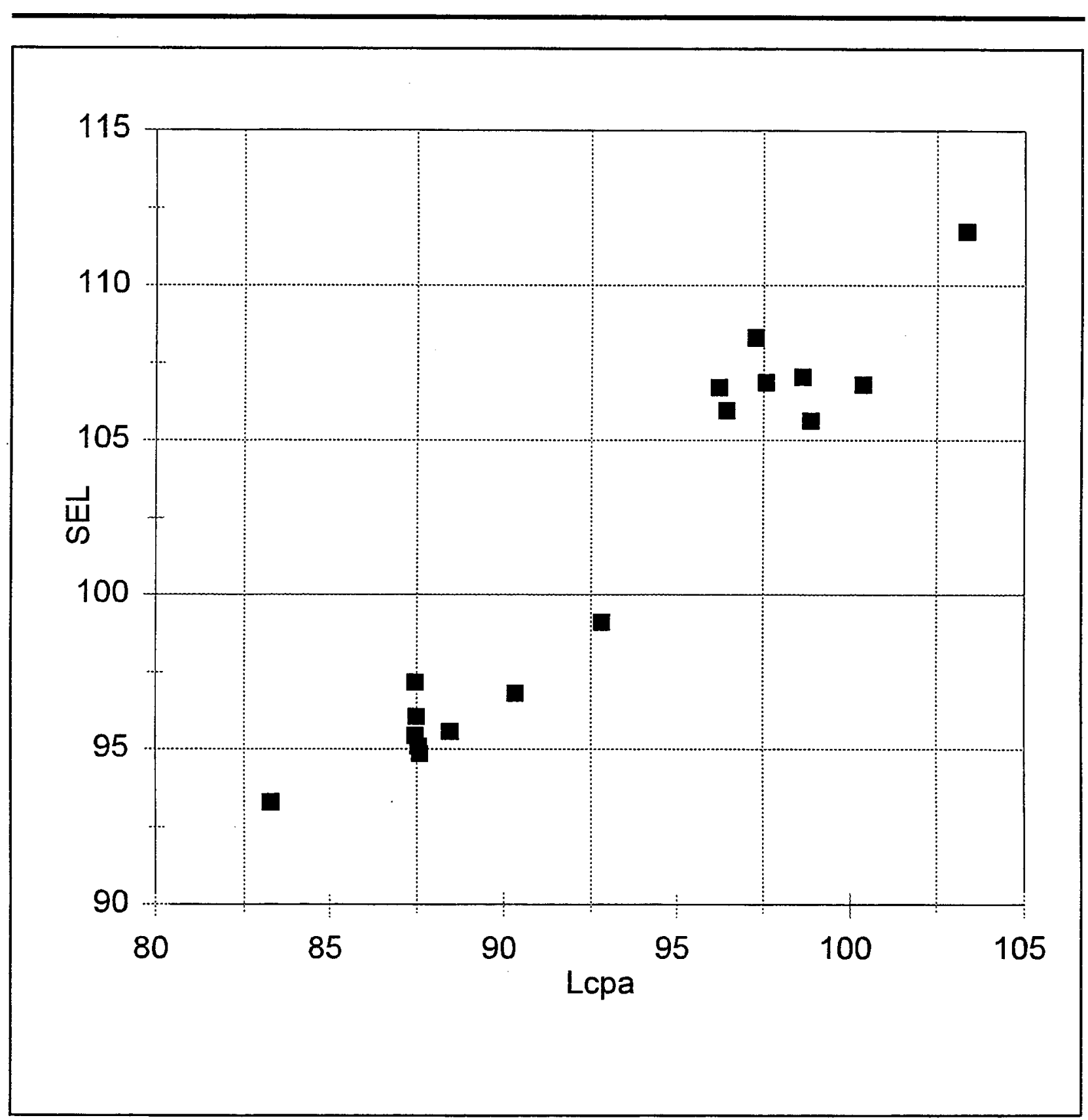

Figure 27. $\mathrm{L}_{\mathrm{CPA}}$ versus $\mathrm{SEL}$, Pt. Shirley 


\section{Conclusion and Recommendations}

Based on the analysis of the data collected at Logan, the following conclusions are made:

- The ground effects algorithms based on the work of Embleton, Piercy and Daigle (Reference 13) appear reasonable for A-weighted metrics. These algorithms produce the expected results at overhead angles, where the reference microphone and the associated 15-foot microphone correct to essentially the same A-weighted values.

- Aircraft engine location directly impacts lateral attenuation/installation effects. For the six types of aircraft used in the final analysis, these aircraft have distinctly different engine installation effects at the closest point of approach.

- Lateral attenuation/installation effects for the aircraft with tail-mounted engines substantially agree with SAE AIR 1751 and data recently collected by NATS in the U.K. As expected, the primary aircraft included in the development of SAE AIR 1751 have measured lateral attenuation/installation effects consistent with the SAE AIR 1751 algorithms.

- $\quad$ Significant differences exist between aircraft with wing-mounted engines and SAE AIR 1751. For the flight track measurement geometries in this study, aircraft with wingmounted engines had a lateral augmentation, not an attenuation. The data collected in the current study for aircraft with wing-mounted engines also differ from data recently collected by NATS in the U.K., especially at elevation angles below about 20 degrees.

- Because aircraft with wing-mounted engines have become much more predominant in the fleet since SAE AIR 1751 was developed, inclusion of updated lateral attenuation algorithms for these aircraft in the next generation of noise models will result in substantial improvement in model accuracy as well as an increase in the areas of the predicted noise contours.

Before SAE AIR 1751 can be modified, more data are required to help understand the differences observed in the current study compared with the recent studies conducted by NATS. These data should be collected in an environment where all aircraft parameters can be controlled. The metrics used in such a data collection effort should be the same as those used in the standard noise models that would make use of such data. Further, since relatively good agreement has been obtained for aircraft with tail-mounted engines, this additional work should focus on aircraft with wing-mounted engines. 

an Acoustically Hard Water Surface 


\section{Appendix A: Study Team Members}

\section{Volpe National Transportation Systems Center, Acoustics Facility:}

\section{Gregg G. Fleming}

B.S., Electrical Engineering, University of Lowell, Massachusetts. Manager of the Volpe Center Acoustics Facility. Mr. Fleming was responsible for all aspects of the study.

\section{David Senzig, P.E.}

M.S., Mechanical Engineering, University of Washington, Seattle, Washington. Mr. Senzig was the principal investigator on the study. He was involved with all aspects related to study design, data collection, data reduction and analysis.

\section{Paul J. Gerbi}

B.S., Electrical Engineering, University of Lowell, Massachusetts. Mr. Gerbi provided data reduction programming support.

\section{Amanda Rapoza}

B.S., Acoustic Engineering, University of Hartford, Connecticut. Ms. Rapoza provided data analysis support.

\section{David R. Read}

Mr. Read was responsible for all aspects related to the acoustical instrumentation, both preparatory and in the field.

\section{Christopher J. Roof}

B.S., Electrical Engineering and Music, Boston University, Massachusetts. Mr. Roof provided data collection support.

\section{Edward J. Rickley}

M.S., Electrical Engineering, Lowell Technical Institute, Massachusetts. Mr. Rickley provided 
data reduction programming support.

\section{Massachusetts Institute of Technology:}

\section{John-Paul B. Clarke}

Sc..D., Aeronautics and Astronautics, Massachusetts Institute of Technology (MTT), Cambridge, Massachusetts, Charles Stark Draper Assistant Professor of Aeronautics \& Astronautics, MT. Professor Clarke was responsible for all MIT efforts and consulted on all aspects of the study.

\section{Alex Y. Lee}

M.S., Aeronautics and Astronautics, MIT, Cambridge, Massachusetts. Mr. Lee was involved with all aspects related to study design, data collection, data reduction and analysis. He was responsible for coordination between the Volpe Center and MT, and supervising undergraduate students during field measurement and video data processing.

\section{Christopher Gouldstone}

Junior, Department of Aeronautics and Astronautics, MIT, Cambridge, Massachusetts. Mr. Gouldstone provided field measurement and video data processing support.

\section{Nicholas J. Kim}

Freshman, MIT, Cambridge, Massachusetts. Mr. Kim provided field measurement and video data processing support.

\section{Ayanna T. Samuels}

Freshman, MIT, Cambridge, Massachusetts. Ms. Samuels provided field measurement and video data processing support.

\section{Shane Suehisa}

Freshman, MIT, Cambridge, Massachusetts. Mr. Suehisa provided field measurement and video data processing support. 


\section{Appendix B: Statistical Analysis of Airport Noise Monitoring and Radar Tracking Data}

An analysis of the sound level data collected by three of Logan's remote monitoring stations (rms 4, 6 and 7) in July 1998 was performed to determine if any significant trends could be identified (e.g., was there a dependency on temperature, wind speed, or time-of-day which might correlate well with ambient sound level?). These three rms were located in the same general area of Winthrop used for measurements in support of the current study.

The sound level data files were combined with meteorological data from the airport's weather station (hourly temperature, dewpoint, wind speed and wind direction) and arrival/departure data (arrival/departure time, runway, and aircraft type).

The hourly meteorological data were assigned to each sound level event (regardless of aircraft type) based on closest time of day. The maximum sound level for each event at each rms was charted against temperature (Figure 28), wind speed (Figure 29), and time of day (Figure 30). As can be seen, no relationship between these parameters and the sound level data was discernable.

To try to more closely examine any possible relationships, arrival/departure data from Runway 9/27 were hand-matched with the sound level event data measured at rms 4 for July 1 and 2, 1998. If the arrival time was within \pm 15 seconds of the event end time, it was considered a correct match. If the departure time was within \pm 15 seconds of the event start time, it was considered a correct match. Of the 1,118 sound level events examined, only 257 or $23 \%$ could be confidently matched with a specific aircraft arrival or departure. Due to the low correlation, and the laborious nature of this by-hand task, no further like analyses were performed. It was determined that resources were better spent elsewhere. 


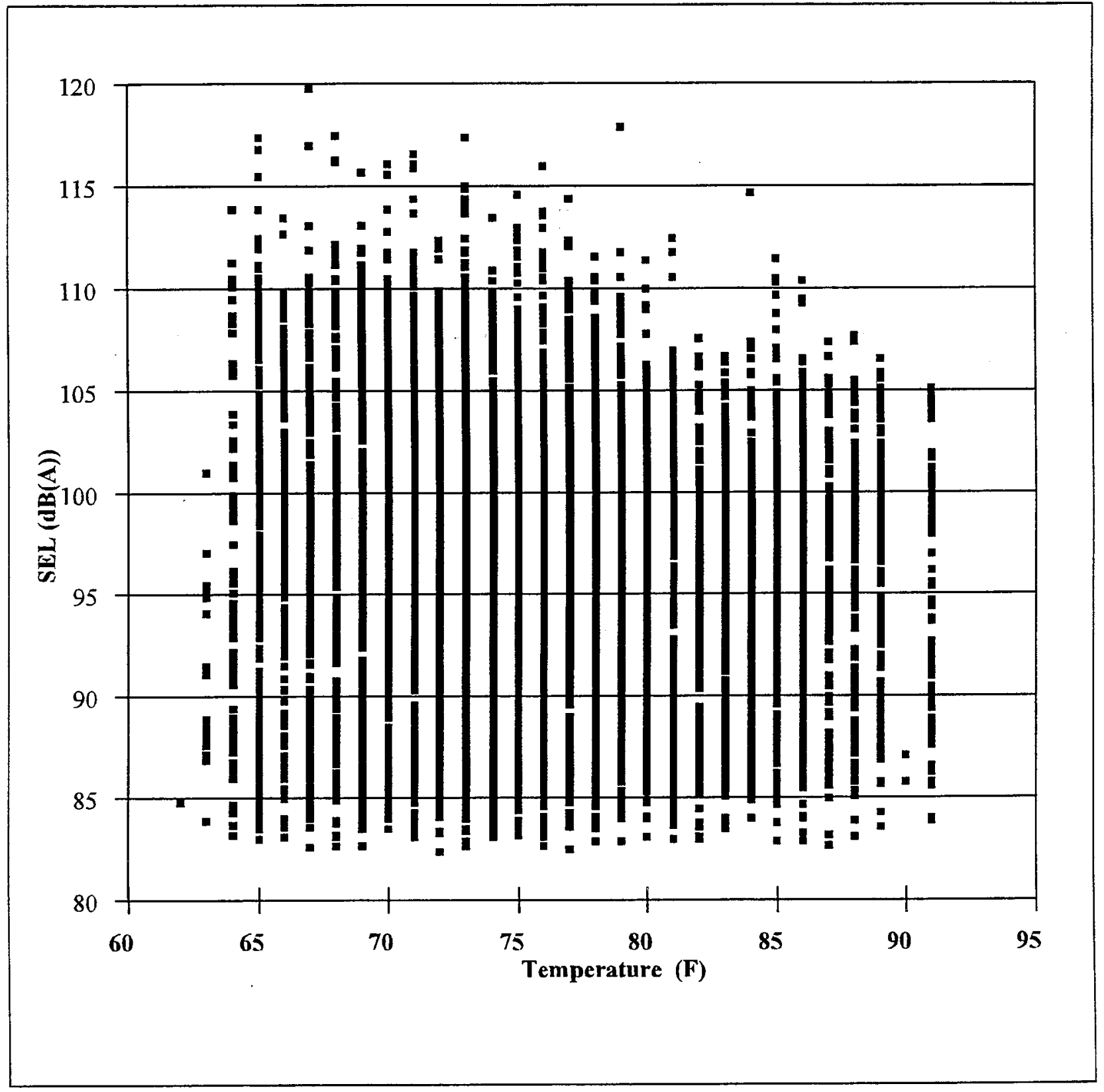

Figure B-1. SEL Versus Temperature, July 1998 


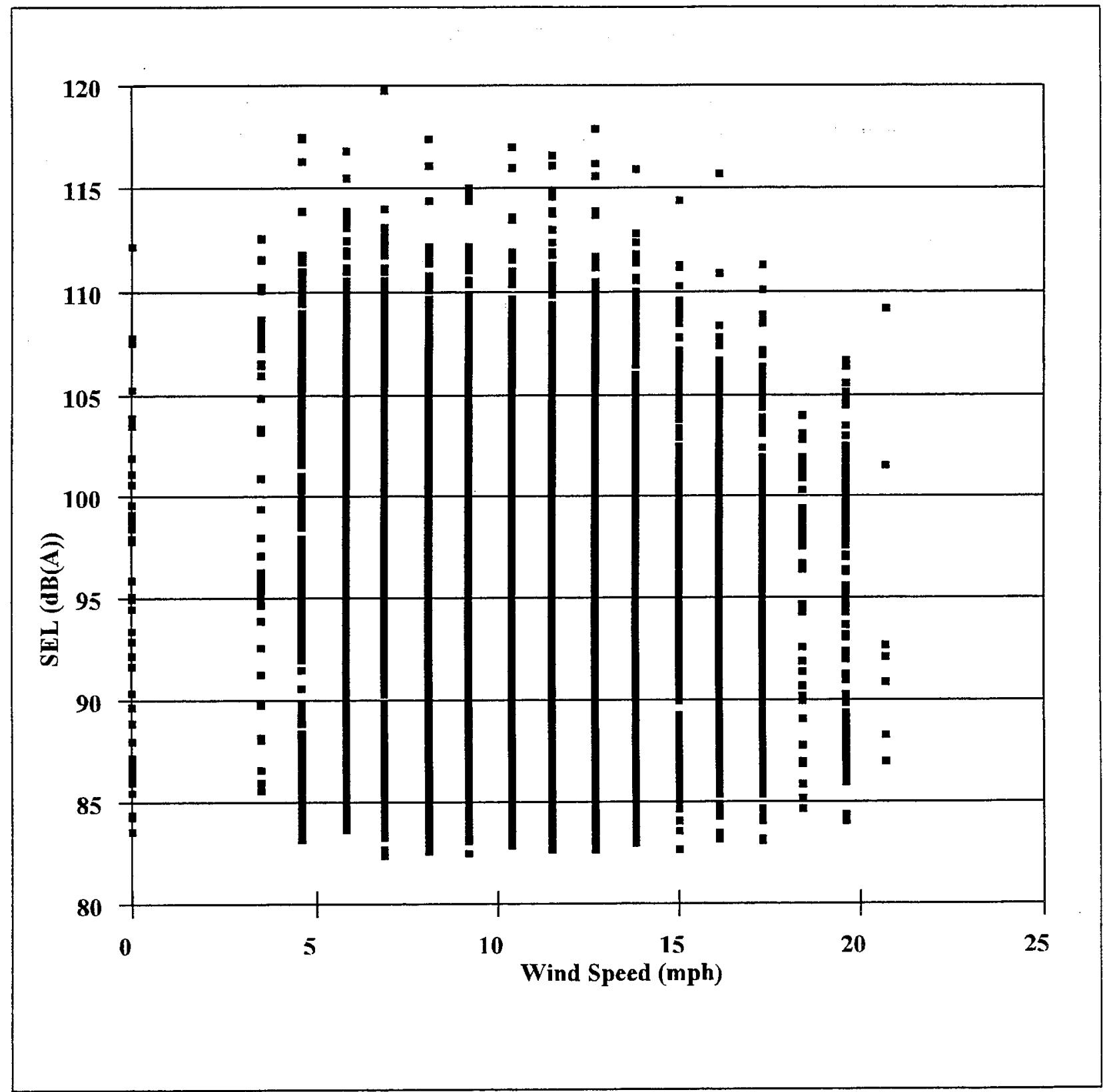

Figure B-2. SEL Versus Wind Speed, July 1998 


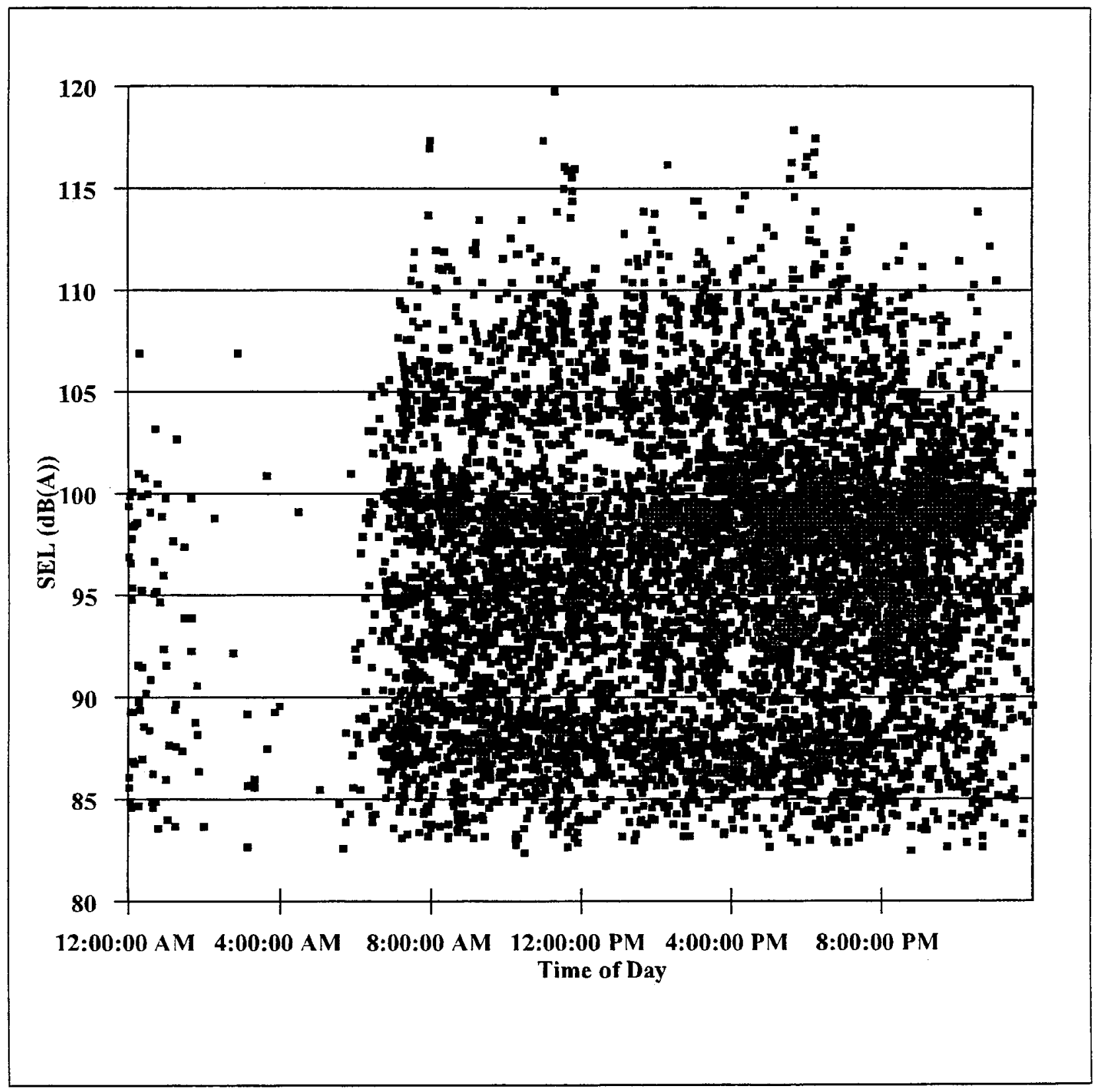

Figure B-3. SEL Versus Time of Day, July 1998 


\section{Appendix C: Acoustic Instrumentation Systems Reference}

\section{C.1 Instrumentation List}

\section{C.1.1 B\&K Deltatron Microphone System:}

Model 4155 Electret Condenser Microphone.

Model 2671 Deltatron Preamplifier.

Model WB1372 Deltatron Power Supply.

Custom-fabricated BNC to XLR adapters.

Custom-fabricated 4-conductor $150 \mathrm{ft}(45.7 \mathrm{~m})$ or $100 \mathrm{ft}$ (30.5 m) shielded XIR

microphone cables.

\section{C.1.2 Spectrum Analyzer (LDL2900):}

LDL Model 2900 Spectrum Analyzer.

\section{C.1.3 Digital Audio Tape (DAT) Recorder:}

Sony Model PC208Ax DAT.

\section{C.1.4 Ancillary:}

B\&K Model 4231 Sound Calibrator.

1/2-in Microphone Simulator (Dummy Microphone).

17 Ah Gel-Cell Battery, or

40 Ah Gel-Cell Battery.

Tripod.

Mast.

TAMS Meteorological Station.

\section{C.2 Configuration}

C.2.1 LDL Model 2900 Spectrum Analyzer:

1. Range settings - Normal calibration at $114 \mathrm{~dB}$ SPL will automatically set the input range to $120 \mathrm{~dB}$. Change the input range as required for data collection. All such changes must be logged.

C.2.2 SONY Model PC208Ax DAT Recorder:

1. Mode - Operate at $20 \mathrm{kHz}$ bandwidth ( $10 \mathrm{kHz}$ is sufficient if necessary). Configure as

C-1 
2-channel@1X speed, or 4-channel@2X speed. Note: $295 \mathrm{ft}(90 \mathrm{~m})$ tape provides 3 hours recording time at $1 \mathrm{X}$ speed.

2. Range - Input voltage range: Calibrate at $1 \mathrm{~V}$ using $114 \mathrm{~dB}$ SPL calibration signal. Range changes after calibration provide the following gain values:

\begin{tabular}{lrrl} 
Range & \multicolumn{1}{c}{ Gain } & Overload & Linear Floor \\
\hline $0.5 \mathrm{~V}$ & $+6.0 \mathrm{~dB}$ & $114.0 \mathrm{~dB}$ & $29.0 \mathrm{~dB}$ \\
$1.0 \mathrm{~V}$ & $0.0 \mathrm{~dB}$ & $120.0 \mathrm{~dB}$ & $35.0 \mathrm{~dB}$ \\
$2.0 \mathrm{~V}$ & $-6.0 \mathrm{~dB}$ & $126.0 \mathrm{~dB}$ & $41.0 \mathrm{~dB}$ \\
$5.0 \mathrm{~V}$ & $-14.0 \mathrm{~dB}$ & $134.0 \mathrm{~dB}$ & $49.0 \mathrm{~dB}$ \\
$10.0 \mathrm{~V}$ & $-20.0 \mathrm{~dB}$ & $140.0 \mathrm{~dB}$ & $55.0 \mathrm{~dB}$
\end{tabular}

Note: If IRIG B Time Code is being recorded, set corresponding DAT input channel to 5 $\mathrm{V}$ range.

\section{C.3 Operation}

\section{C.3.1 Setup:}

1. Run microphone cable and connect between B\&K Model 2671 Deltatron preamplifier and B\&K Model WB1372 Deltatron power supply. Note: Custom-fabricated BNC-to$\mathrm{XIR}$ adapter cables are required at both ends of the microphone cable.

2. Interconnect equipment per Figure 9.

3. Connect power lead for Sony Model PC208Ax to $40 \mathrm{Ah}$ gel-cell battery. Connect power cable to recorder. Turn on all equipment.

4. Set time and date on Sony Model PC208Ax, and LDL2900 Analyzer per Master Clock.

5. Check instrument settings, especially recorder speed, channel configuration and input range.

\section{C.3.2 Calibration:}

1. Remove foam windscreen from microphone.

2. Carefully apply calibrator to microphone. 
3. Carefully apply power to calibrator (114 dB setting).

4. Wait ten seconds for system to stabilize.

5. Perform calibration of LDL Model 2900.

6. Once the frontend has been calibrated and a steady calibration signal is observed, record the calibration signal on the Sony Model PC208Ax for one minute. The oneminute duration is required to ensure that the DAT recorder's event ID system does not get "scrambled." A 30-second duration is sufficient when using the PC208Ax's $2 \mathrm{X}$ speed mode. Ensure that no gain or weighting is being applied at the front end by checking the setup parameters of the LDL Model 2900. A normal calibration will illuminate 4 segments on the Sony Model PC208Ax LCD display.

7. After recording the calibration signal, turn off the calibrator and remove it from the microphone.

8. Remove the microphone from the B\&K Model 2671 Deltatron preamplifier.

9. Attach the $1 / 2$-in microphone simulator to the B\&K Model 2671.

10. Capture and record one minute of microphone simulator floor (Recording of a 30second duration should be sufficient when operating the PC208Ax at $2 \mathrm{X}$ speed mode). The LDL Model 2900 Spectrum Analyzer should indicate approximately 16 to $20 \mathrm{~dB}(\mathrm{~A})$ in the SLM mode.

11. Remove the microphone simulator, and re-install the microphone.

12. Attach the calibrator to the microphone.

13. Apply power to calibrator ( $114 \mathrm{~dB}$ setting).

14. Wait 10 seconds for calibrator signal to stabilize.

15. Perform normal calibration of the LDL Model 2900.

16. After calibrating the sound level meter and observing a steady-state calibration signal, record the calibration signal on the DAT recorder for one minute (minimum 30 seconds 
when using the PC208Ax at $2 \mathrm{X}$ speed).

17. After recording the calibration signal, turn off the calibrator and remove it from the microphone. Attach the foam windscreen.

18. The acoustic system is ready for initiation of measurements.

\section{C.4 System Performance Limits}

Table 2. System Performance Limits

\begin{tabular}{|c|c|c|c|}
\hline Womonom & 1100 & 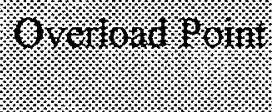 & (x) \\
\hline $\begin{array}{l}\text { B\&K Deltatron Mic } \\
\text { System }\end{array}$ & & $140 \mathrm{~dB}$ SPL & $\sim 20 \mathrm{dBA}$ \\
\hline LD 2900 Analyzer & $120 \mathrm{~dB}$ Range & $134 \mathrm{~dB}$ SPL & $\sim 41 \mathrm{~dB}$ \\
\hline $\begin{array}{l}\text { SONY PC208Ax } \\
\text { DAT Recorder }\end{array}$ & $1 \mathrm{~V}$ Input Range & $120 \mathrm{~dB}$ SPL & $\begin{array}{l}35 \mathrm{~dB} \text { (linearity } \\
\text { floor, } \mathrm{FS}-85 \mathrm{~dB} \text { ) }\end{array}$ \\
\hline
\end{tabular}

\section{C.5 Power Requirements and Considerations}

\section{C.5.1 Power requirements:}

B\&K Model WB1372 Deltatron Power Supply: 3 x 9V cells Typical "life": $\quad>\mathbf{4 0}$ hours
LDL Model 2900:
$12 \mathrm{~V}(\sim \mathrm{A})$

Typical "life":

40 hours if powered by separate gel-cell

11-16 hours if same gel-cell powers Sony Model PC208Ax

SONY Model PC208Ax:

$$
11 \text { to } 30 \mathrm{~V}(\sim 1.5 \text { to } 2.4 \mathrm{~A} \text { (a) } 12 \mathrm{~V})
$$

Typical "life":

16 to 25 hours when powered by separate gel-cell battery 11-16 hours if same gel cell powers LDL Model 2900

B\&K Model 4231 Calibrator: 4 x AA cells 
TAMS Met System:

Typical "life":

Laptop:

Typical "life":

Time Code:
$12 \times$ AA cells or $12 \mathrm{~V}$

$>24$ hours on a set of AA cells

1-2 A@12V

$\sim 9$ hours if powered by same gel cell as time code

-3.5A@12V

C-5 
Lateral Attenuation of Aircraft Sound Levels Over an Acoustically Hard Water Surface
Appendix C: Acoustic Instrumentation

ป

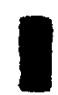

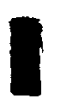

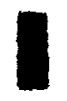

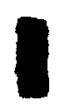

]

8

】

I

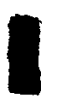

1

1

】

1

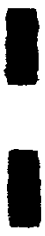

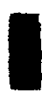

C-6

I

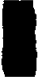




\section{Appendix D: Video Tracking System}

\section{D.1 Introduction}

The video tracking system was comprised of two digital video camera subsystems. Each subsystem recorded aircraft events onto video tape which were processed to determine the aircraft's time and position information throughout the event.

Each subsystem consisted of a Canon Optura ${ }^{\circledR}$ digital video camera with a wide angle lens and the supporting hardware to enable field calibration of the system. The supporting hardware included portable video targets, a camera support structure that permitted the camera to be rotated about all three axes, a laser and laser mounting structure, and equipment to accurately determine the geometry of the calibration coordinate system.

\section{D.2 System Calibration}

Prior to beginning field measurements, the system was calibrated. System calibration meant determining the relationship between the pixel representation of a given image and the actual azimuth and elevation angles of that image from the center of the camera. The method of determining this relationship is described in this section.

The system calibration was based on knowing both the pixel representation of a known object and the actual azimuth and elevation angles of that object in three-dimensional space. For this video system, the known object was an orthogonal grid projected onto an approximately 9 feet by 16 feet ( 2.7 meters by 4.9 meters) screen.

The heights above the ground of the upper and lower corners of the grid on the screen were measured. The origin point on the grid was arbitrarily chosen. A laser was attached to the camera so that the entire camera and laser assembly could be rotated and translated on the threeaxis tripod head. The origin of the grid was illuminated with the laser so that the height of the camera above the ground could be adjusted to match the height of the grid origin above the ground. This height was noted and used in later calculations of azimuth and elevation.

With the camera and grid point positions known in three-dimensional space, a transformation of the pixels of the filmed grid to a spherical system centered on the camera was performed. Pixels not on the actual grid were found from linear interpolation. No extrapolation beyond the known grid was performed. 


\section{D.3 Field Set-up and Data Collection}

The two video cameras were located at Pt. Shirley and Corinha Beach. Two calibration targets were set up in the field of view of each camera. The locations of the cameras and the calibration targets in the measurement coordinate system were noted on each day of measurements. Daily notation was required since the cameras and targets could be accurately placed in the XY plane, but the heights $(Z)$ of the equipment would vary daily depending on the actual placement of the equipment above the ground.

Prior to recording aircraft events, video footage of a UTC-based clock was recorded. This recording of a precise clock signal directly on the video tape allowed accurate synchronization of the two cameras. A second recording of the UTC-based clock was added to the end of the tape so that any drift of the camera's internal clock during the 45 minutes or so of actual footage was noted and corrected in the final data processing. The camera ran continuously from the first UTC time code collection, through all the events of interest, to the second and last UTC time code collection recorded on each tape.

\section{D.4 Video Data Reduction}

After the tracking data were collected in the field, these data were converted into a form usable by the Volpe Center's video data reduction computer programs. These computer programs are described in the following sections.

\section{D.4.1 Video Data Reduction - Preprocessing and Tracking Programs}

The translation of an aircraft event from the X-Y pixel system and local time recorded by the cameras to the measurement time and coordinate systems used by the other processing programs involved several steps. One set of steps dealt with the time transformation, the other dealt with the coordinate transformation.

The time transformation involved four steps. The first step was the calculation of the difference between the camera time and UTC time at the beginning of the recording. The second step was the calculation of the expected camera time at the end of the recording using the NTSC drop code time frame system ${ }^{*}$. If the expected camera end time did not match the reported camera end

*The NTSC system operates at 29.97 frames per second. For frame counting, each second is assumed to have 30 frames, except that the first second of every minute which is not evenly divisible by 10 contains only 28 frames. 
time, then a camera time drift occurred. The third step applied a linear approximation of any drift to all times on the tape. The fourth step was to use the NTSC drop code time frame system to exactly match the drift-corrected camera time with UTC time.

The coordinate transformation involved five steps. The first step was to convert the $\mathrm{X}-\mathrm{Y}$ pixels into the elevation and azimuth angles of a spherical coordinate system centered on the camera. This step made use of the grid interpolation process discussed above. The next step was to transform this spherical system to a normalized Cartesian system. This Cartesian system was then rotated twice, first about the roll axis and then about the pitch axis. These rotations had little effect on the Corinha Beach camera, but were important for the Pt. Shirley camera with its large roll and pitch. Next, the Cartesian system was re-translated back to a final spherical system. Finally, the azimuth angles of the final spherical system were used to find the aircraft position in the X-Y plane of the measurement coordinate system. The position in the X-Y plane was combined with the elevation angles of the two cameras to produce two estimates of the aircraft altitude. These altitude estimates were averaged to produce a final estimate of the aircraft altitude.

The output of the program was the three-dimensional aircraft position in the measurement coordinate system at one-second intervals. Also included were aircraft type information, data on the location of the microphones as a function of time, and the ground surface impedance; these data were passed through the program without modification.

\section{D.4.2 Video Data Reduction - Emission Time Program}

This program calculated the time the noise emitted by each aircraft event was received at a particular microphone. The aircraft's CPA to each microphone pair was calculated, then the distance from the aircraft to each microphone was found. The sound propagation time from the aircraft to the microphone was found using the distance and the speed of sound as a function of the temperature at the time of CPA. The temperature at Snake Island was used as the primary source of data for processing since it was most representative of the temperature over the propagation path to each of the different microphones. If the Snake Island weather data were not available, the Pt. Shirley weather data were used. Temperature is the only component of the weather data used in this program.

The output of the program was the time the noise emitted at CPA was received by each microphone for each aircraft event. Also included was aircraft type and location information, data on the location of the microphones as a function of time, and the surface flow resistivity; these data were passed through the program without modification. 


\section{D.5 System Accuracy}

The video TSPI system was tested for accuracy on several occasions using the Volpe Center's dGPS TSPI system ${ }^{10}$ as a reference. In general, when compared with the dGPS, the video system was within 10 feet in each of the three axes. 


\section{Appendix E: Ground Effects Model}

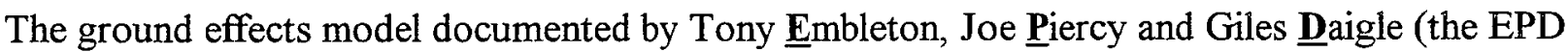
model) of the National Research Council (NRC) of Canada is the foundation for the updated overground propagation effect slated for inclusion in $\mathbb{I N M}^{13,17,18}$. Consequently, only a brief overview is presented herein. It is important to point out, however, that the EPD model is an assemblage of acoustic research that dates back to the works of Ingard in the $1950 \mathrm{~s}^{19}$. The derivative work most germane to the discussion presented herein is that of Delany and Bazley, and Chessel120,21. It is also important to note that there are other ground effects models that are based on an assemblage of similar and/or identical research conducted over the years ${ }^{22,23,24}$. Many of these models will generate identical results to those computed by the EPD model, primarily because they are based on the above-referenced works of Delany, et. al. The EPD model was the primary focus of INM because of the extensive field measurement validation performed in support of its development.

The basic EPD model is defined by the following equation:

$$
\begin{array}{cc}
\begin{array}{c}
\text { Direct } \\
\text { Path }
\end{array} & \begin{array}{c}
\text { Ground-Reflected } \\
\text { Path }
\end{array} \\
\frac{p}{p_{0}}=\left\langle\left(\frac{e^{i k_{1} r_{1}}}{k_{1} r_{1}}\right)\right\rangle+\left\langle R_{p}\left(\frac{e^{i k_{1} r_{2}}}{k_{1} r_{2}}\right)+\frac{\left(1-R_{P}\right) F(\omega) e^{i k_{1} r_{2}}}{k_{1} r_{2}}\right\rangle
\end{array}
$$

In Equation 1, the first term on the right-hand side represents the pressure associated with the direct source-to-receiver sound path, and the second and third terms represent the pressure associated with the ground-reflected source-to-receiver sound path.

The plane-wave reflection coefficient, $R_{p}$ in Equation 1 is computed as follows:

$$
R_{p}=\frac{\left[Z_{2} \sin \phi-Z_{1} \sqrt{\left(1-\left(\frac{k_{1}^{2}}{k_{2}^{2}}\right) \cos ^{2} \phi\right)}\right.}{\left[Z_{2} \sin \phi+Z_{1} \sqrt{\left(1-\left(\frac{k_{1}^{2}}{k_{2}^{2}}\right) \cos ^{2} \phi\right)}\right]}
$$


In addition, the complex ground wave function, $F(\omega)$ is computed as follows*:

$$
F(\omega)=1+i \pi^{1 / 2} \omega^{1 / 2} e^{-\omega}+\operatorname{erfc}(-i \sqrt{\omega})
$$

In [1] through [3], $p_{0}$ is the pressure near the source at a reference distance of one wavelength; $k_{1}$ and $k_{2}$ are the wavenumbers of the sound field in air and in the ground surface; $Z_{1}$ and $Z_{2}$ are the corresponding specific acoustic impedances of the two media; $r_{1}, r_{2}$, and $\phi$ are the distance from the source to the receiver, the distance from the geometrical image of the source to the receiver, and the angle between the specularly reflected ray and the ground surface (see Figure 31); and $\omega$ is the numerical distance given by the following equation:

$$
\omega=\frac{2 i k_{1} r_{2}}{\left(1-R_{p}\right) \cos ^{2} \phi}\left(\frac{Z_{2}}{Z_{1}}\right)^{2}\left(1-\frac{k_{1}^{2}}{k_{2}^{2}} \cos ^{2} \phi\right)
$$

Delany and Bazley (Ref. 20) have developed expressions for the specific acoustic impedance, $Z_{2}=R_{2}+\mathrm{i} X_{2}$, and wavenumber $k_{2}=\alpha_{2}+\mathrm{i} \beta_{2}$, of the ground surface. These equations are as follows:

$$
\begin{aligned}
& \frac{R_{2}}{\rho_{1} c_{1}}=1+9.08\left(\frac{f}{\sigma}\right)^{-0.75} \\
& \frac{X_{2}}{\rho_{1} c_{1}}=11.9\left(\frac{f}{\sigma}\right)^{-0.73} \\
& \frac{\alpha_{2}}{k_{1}}=1+10.8\left(\frac{f}{\sigma}\right)^{-0.70} \\
& \frac{\beta_{2}}{k_{1}}=10.3\left(\frac{f}{\sigma}\right)^{-0.59}
\end{aligned}
$$

In the Delaney and Bazley equations, $f$ is frequency and $\sigma$ is the effective flow resistivity of the ground surface expressed in c.g.s. rayls. The effective flow resistivity used for this study was either 150 c.g.s. rayls for acoustically soft ground or 20,000 c.g.s. rayls for acoustically hard ground. Note: for consistency with the EPD model, the sign in [5] for the term $X_{2} / \rho_{1} c_{1}$ was changed as compared with that included in the original Delany and Bazley Reference.

*A Computer implementation of the complementary error function (erfc) is presented in Computer Approximations (1968) by Hart, et. al., as well as Numerical Recipes (1986) by Press, et.al. 
Figure 32 presents an example of the acoustically soft ground effect as a function of frequency for a rather simple source-to-receiver geometry (source height $=0.31 \mathrm{~m}$; receiver height $=1.2 \mathrm{~m}$; and source-to-receiver distance $=15.2 \mathrm{~m}$ ). Similar figures are presented in References 13, 17, and 18 for various source-to-receiver geometries. To ensure proper implementation of the model the data presented in these published graphics were all verified separately with the version of the EPD model implemented in support of INM development.

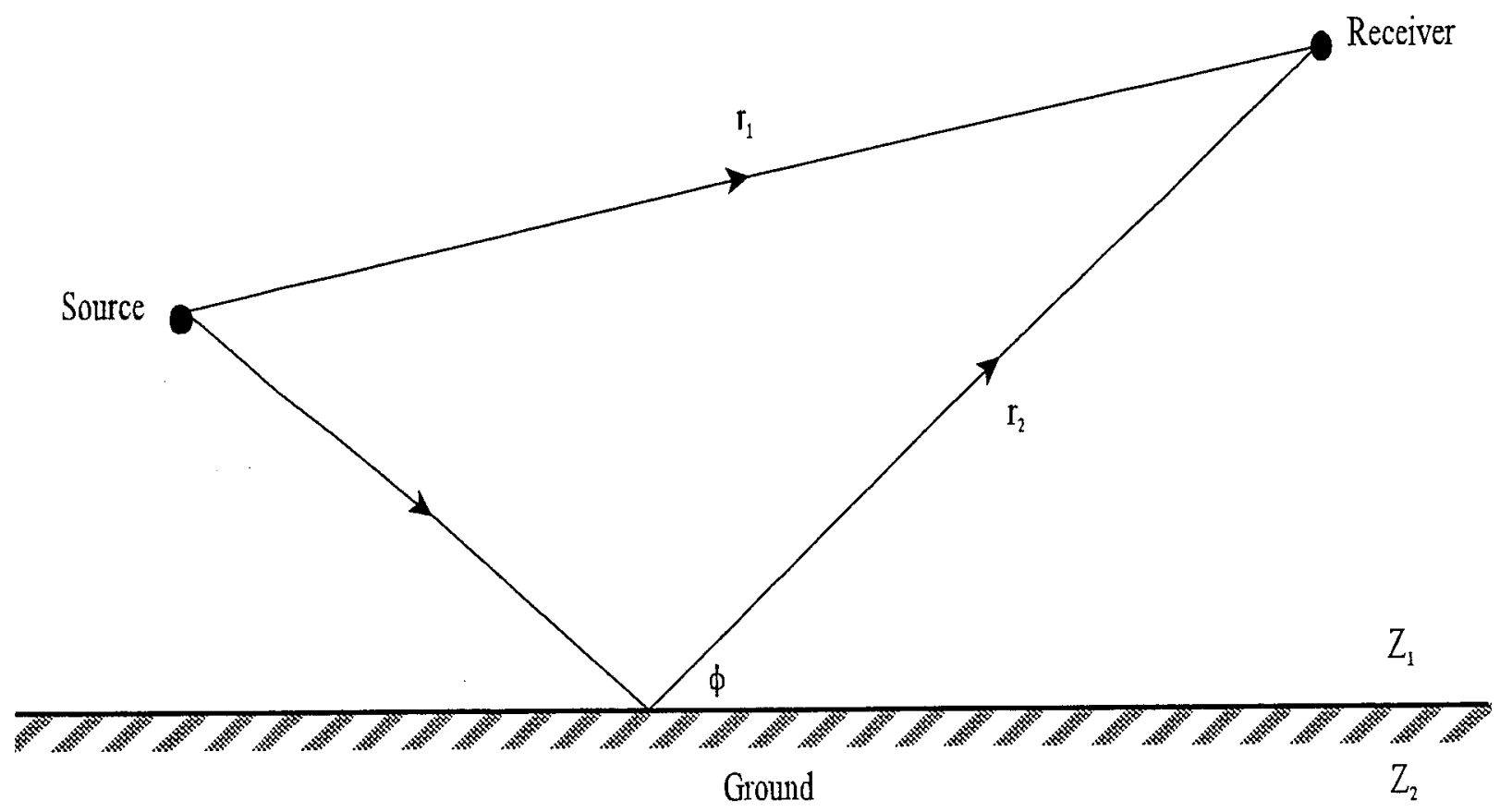

Figure E-1. Generic Geometry for EPD Model 


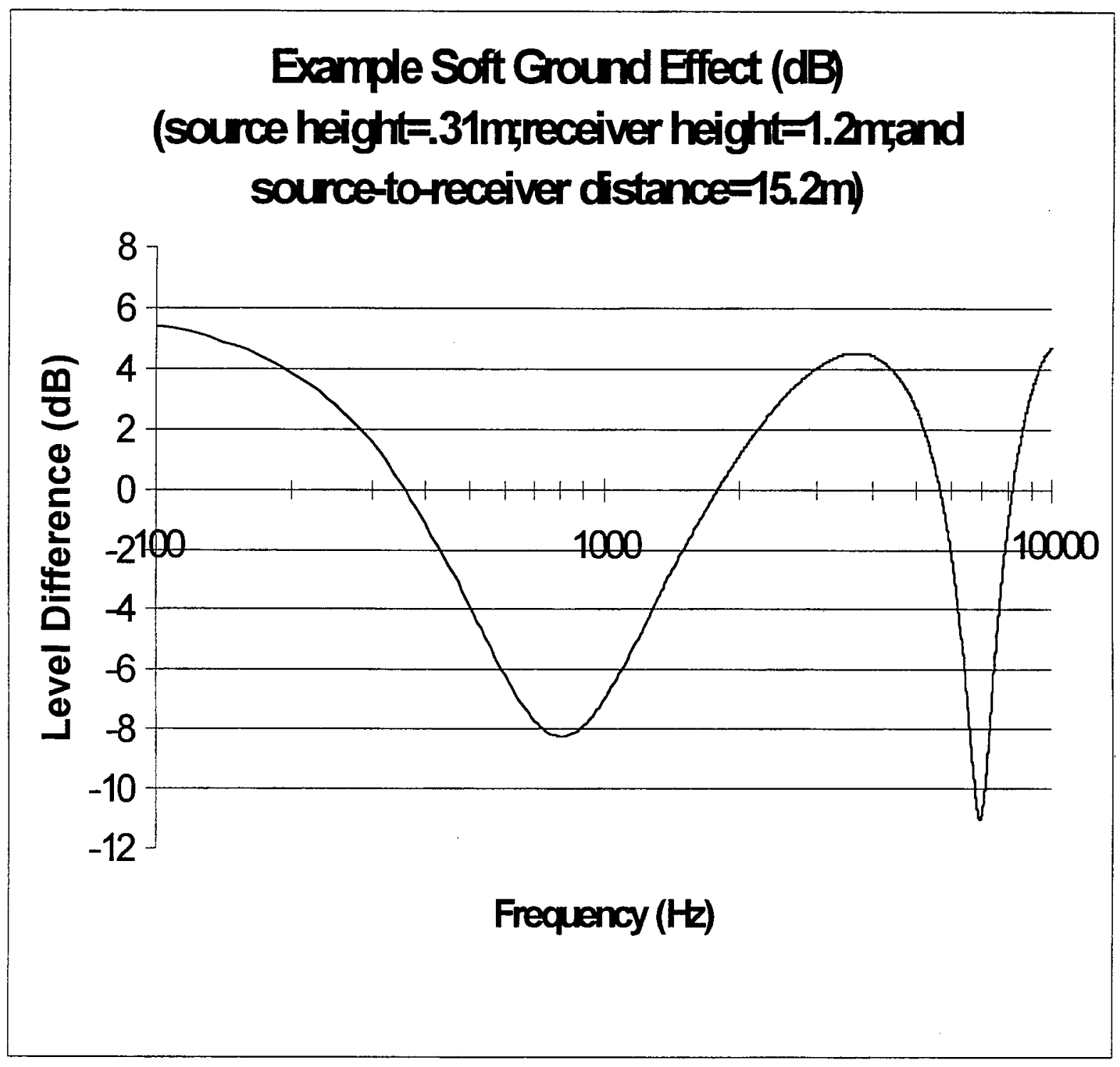

Figure E-2. Example Computation for EPD Model

E-4 


\section{References}

1. Society of Automotive Engineers, Committee A-21, Aircraft Noise. "Prediction Method for Lateral Attenuation of Airplane Noise During Takeoff and Landing", Aerospace Information Report No. 1751, Society of Automotive Engineers, Inc., Warrendale, Pennsylvania, March 1981.

2. Willshire, W.L. "Lateral Attenuation of High-By-Pass Ratio Engined Aircraft Noise", NASA Technical Memorandum 81968, National Aeronautics and Space Administration, Hampton, Virginia, April 1981.

3. Speakman, J.D., and B.F. Berry. "Modeling Lateral Attenuation of Aircraft Flight Noise", Internoise 92 Conference Proceeding, Internoise 92, Toronto, Ontario, July 1992.

4. Engineering Science Data Unit (ESDU). "Lateral Attenuation Calculations", ESDU AN66, London, April 1990.

5. Bishop, D.E., and J.M. Beckmann. "Study of Excess Sound Attenuation as Determined From FAR Part 36 Aircraft Noise Certification Measurements", BBN Report No. 4219, Bolt Beranek and Newman, Cambridge, Massachusetts, May 1980

6. Gulding, John, et. al. "Integrated Noise Model (INM) Version 6.0 User's Guide", Report No. FAA-AEE-99-03, Federal Aviation Administration, Washington, D.C., December 1996

7. Fleming, Gregg G., et. al. "Integrated Noise Model (INM) Version 5.1 Technical Manual", Report No. FAA-AEE-97-04, Federal Aviation Administration, Washington, D.C. 1997.

8. Smith, M.J.T, et. al. "Development of an Improved Lateral Attenuation Adjustment for the UK Aircraft Noise Contour Model", ANCON, DRAFT, R\&D report 9953, Department of Operational Research and Analysis, National Air Traffic Services Ltd., London, November 1999.

9. Massachusetts Port Authority. "Boston-Logan International Airport 1996 Annual Update", Report No. EOEA \#3247/5146, Boston, Massachusetts, September 1997.

10. "Volpe Center Acoustics Facility Time-Space-Position-Information System", John A. Volpe National Transportation Systems Center, Acoustics Facility, Cambridge, Massachusetts, August 1999. 
11. Federal Aviation Administration, "Noise Abatement Departure Profiles", Advisory Circular 91-53A, Washington, D.C., July 1993.

12. Senzig, David A.., Mary E. Eagan, and Edward M. Baldwin. "Evaluation of Noise Abatement Departure Procedures", HMMH report 292631.03, Burlington, Massachusetts, May 1996.

13. Embleton, Tony F.W., Joe E. Piercy, and Giles A. Daigle. "Effective flow resistivity of ground surfaces determined by acoustical measurements," J. Acoust. Soc. Am., Vol 74, No. 4, pp 1239-1243, Melville, N.Y., October 1983.

14. Peart, Noel A., et. al. "Flyover-Noise Measurement and Prediction, Aeroacoustics of Flight Vehicles, vol. 2: Noise Control", ed. Hubbard, Harvey H., pp. 357-382, Acoustical Society of America, Melville, N.Y., 1995.

15. Hodge, Charles G. 'Quiet Aircraft Design and Operational Characteristics', ibid, pp. 383414

16. Roll, H., U., "Physics of the Marine Atmosphere," Academic Press, New York, 1965.

17. Embleton, Tony F.W. "Sound Propagation Outdoors - - Improved Prediction Schemes for the 80's," Noise Control Engineering Journal, Vol. 18, No. 1, pp 30-39, Washington, D.C., 1982.

18. Embleton, Tony F.W., Joe E. Piercy, and Giles A. Daigle. "Outdoor Sound Propagation Over Ground of Finite Impedance," J. Acoust. Soc. Am. Vol. 59, No. 2, pp 267-277, Melville, N.Y., 1976.

19. Ingard, K.U. "A review of the influence of meteorological conditions on sound propagation," J. Acoust. Soc. Am. Vol. 25, No. 3, pp 405-411, Melville, N.Y., 1953.

20. Delaney, M.E. and E.N. Bazley. "Acoustical properties of fibrous absorbent materials," Appl. Acoust. Vol 3, pp. 105-116, Oxford, England, 1970.

21. Chessell, C.I. "Propagation of noise along a finite impedance boundary," J. Acoust. Soc. Am. Vol. 62, pp 825-834, Melville, N.Y., 1977.

22. De Jong, B.A., A. Moerkerken, and J.D. van der Toorn. "Propagation of Sound over Grassland and over an Earth Barrier," J. Acoust. Soc. Am. Vol. 86, No. 1, pp 23-46, Melville, N.Y., 1983. 
23. Engineering Science Data Unit (ESDU). "The prediction of sound attenuation as a result of propagation close to the ground", ESDU pac A9436, London, England, November 1994.

24. Slutsky, S., and H.L. Bertoni. "Parallel Noise Barrier Prediction Procedure", Volpe National Transportation Systems Center, Cambridge, Massachusetts, June 1987. 


\section{INDEX}

$-\mathbf{A}-$

Acoustic Data .................................. 21, 23, 25, 50

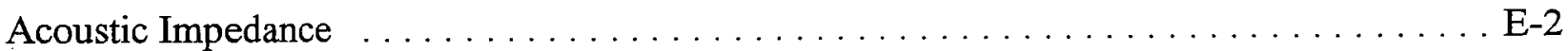

Acoustic Instrumentation . . . . . . . . . . . . . . . . . . . . 11, C-1

Aerodynamic ............................. 2, 48, 49

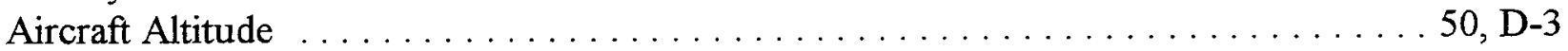

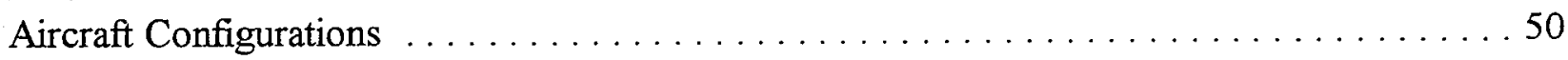

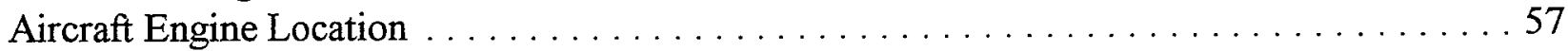

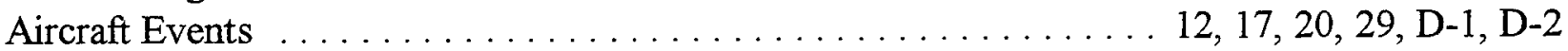

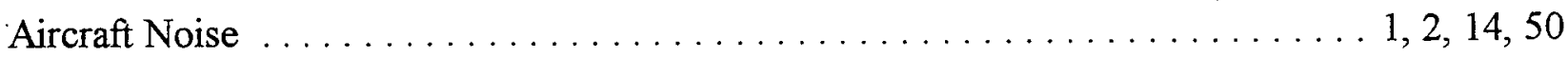

Aircraft Noise Certification Tests . . . . . . . . . . . . . . . . . . . . . . . . . 14

Aircraft Noise Studies . . . . . . . . . . . . . . . . . . . . . . . . . 50

Aircraft Types .................... 5, 15, 17, 26, 29, 32, 34, 39, 45, 47

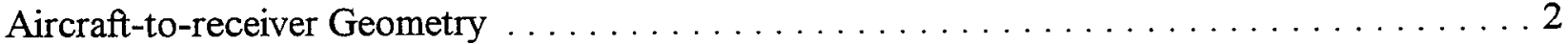

Ambient Sound Levels . . . . . . . . . . . . . . . . . . . . . . . . . 5, 7

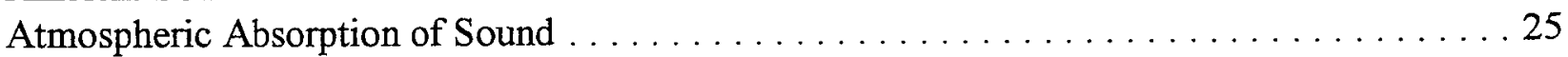

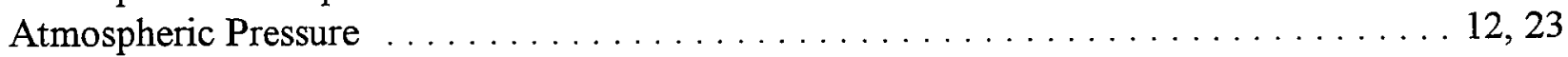

A-weighted Metrics . . . . . . . . . . . . . . . . . . . . . . . . . 57

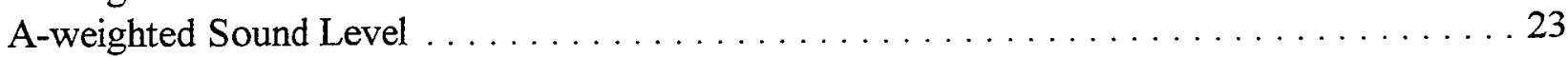

A-weighted Time Histories $\ldots \ldots \ldots \ldots \ldots \ldots \ldots \ldots \ldots \ldots \ldots \ldots \ldots \ldots \ldots \ldots \ldots \ldots \ldots \ldots \ldots \ldots, 49,50$

-B-

B-727

$29,34-36,44,52$

B-757

$29,34,35,37,53$

$-\mathrm{C}-$

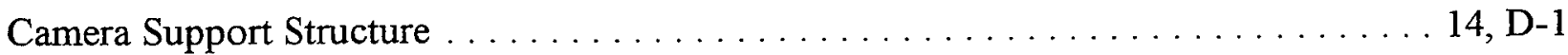

Climb Gradient .............................. 26, 29, 32

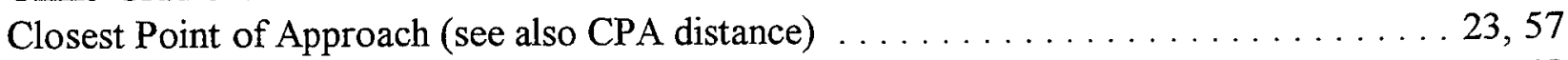

Combustor Noise . . . . . . . . . . . . . . . . . . . . . . . . . . . . 48

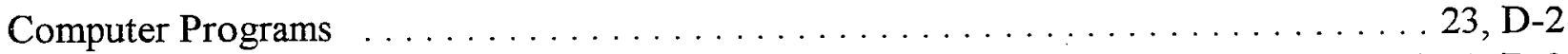

Corinha Beach $\ldots \ldots \ldots \ldots \ldots \ldots \ldots \ldots \ldots \ldots \ldots \ldots \ldots$ 14, 18, 25, 34, 35, 49, 50, 52-55, D-2, D-3

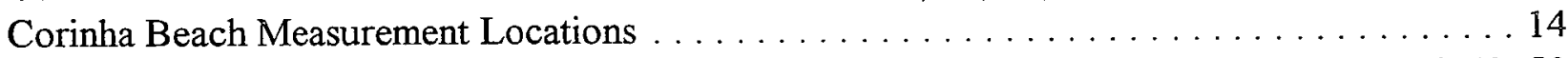

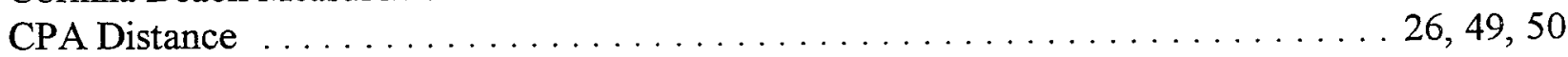

-D-

DAT Recorder

$12,18,20, \mathrm{C}-1, \mathrm{C}-3, \mathrm{C}-4$ 


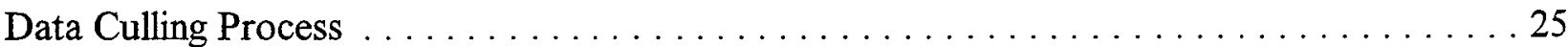

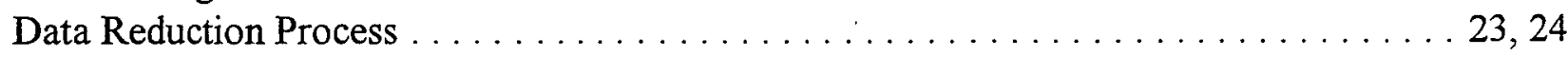

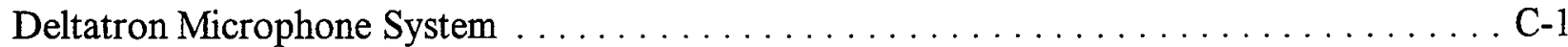

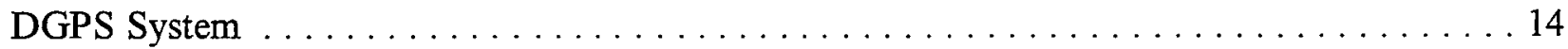

Digital Audio Tape Recorder . . . . . . . . . . . . . . . . . . . . . . . . . 12

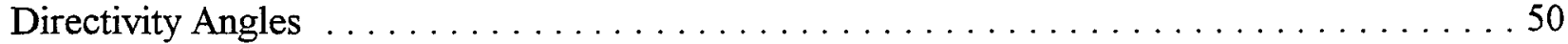

-E-

Electrical System . . . . . . . . . . . . . . . . . . . . . . . . . . 18

Electronic Noise Floor of . . . . . . . . . . . . . . . . . . . . . . . . . . 18

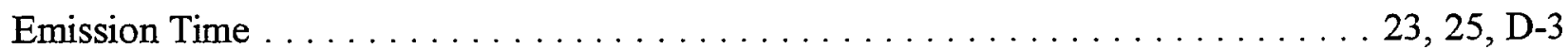

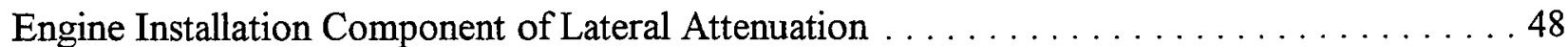

Engine Installation Effects $\ldots \ldots \ldots \ldots \ldots \ldots \ldots \ldots \ldots \ldots \ldots \ldots \ldots \ldots \ldots \ldots \ldots \ldots \ldots \ldots, 5,25,40,43,57$

EPD Model . . . . . . . . . . . . . . . . . . . . . 49, 51, E-1, E-3, E-4

Exhaust Noise . . . . . . . . . . . . . . . . . . . . . . . . . . . . . . 48

$-\mathbf{F}$ -

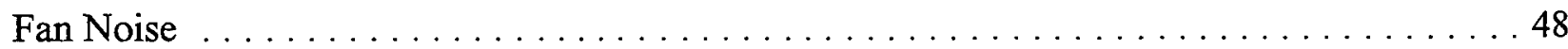

$-\mathbf{G}-$

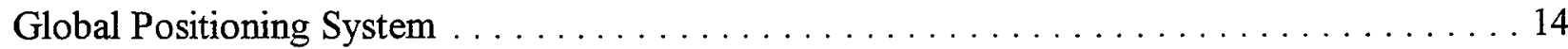

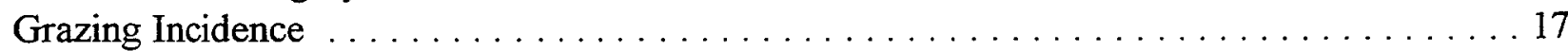

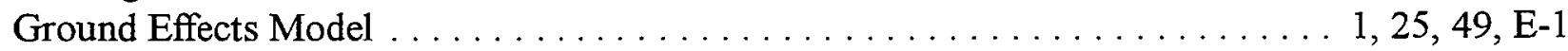

$-\mathbf{I}-$

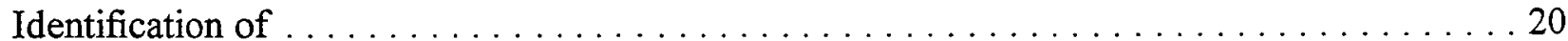

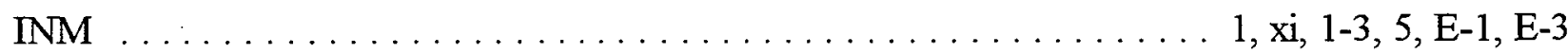

Installation Effects $\ldots \ldots \ldots \ldots \ldots \ldots \ldots \ldots \ldots \ldots \ldots \ldots \ldots \ldots \ldots \ldots \ldots \ldots \ldots \ldots, 3,5,25,34,40,43,47,57$

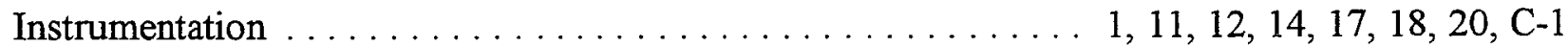

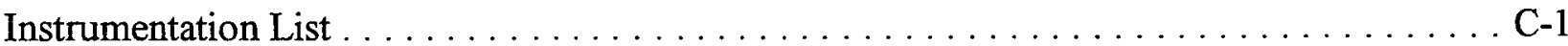

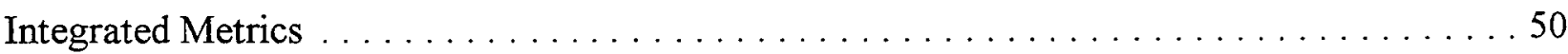

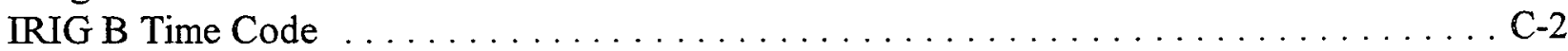

$-\mathbf{L}-$

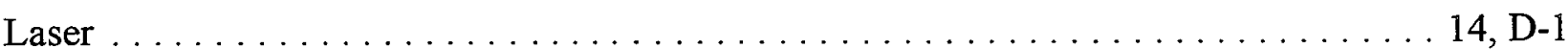

Lateral Attenuation of Aircraft Sound Levels . . . . . . . . . . . . . . . . 1, 1

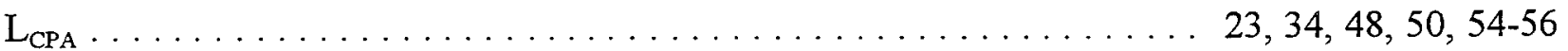




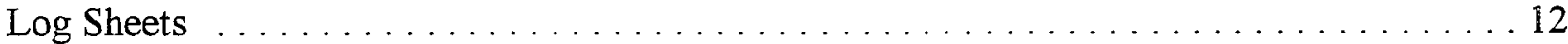

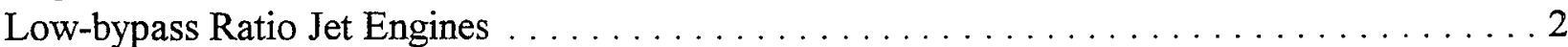

$-\mathbf{M}-$

Measurement Procedures . . . . . . . . . . . . . . . . . . . . . . . 1, 17

Measurement System Setup . . . . . . . . . . . . . . . . . . . . . . . . . . . . . . . . 17

Meteorological Conditions . . . . . . . . . . . . . . . . . . . . . . . 29, E-1

Meteorological Data ......................... 18, 20, 23, B-1

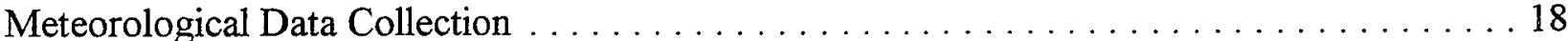

Meteorological Effects . . . . . . . . . . . . . . . . . . . . . . 29, 50

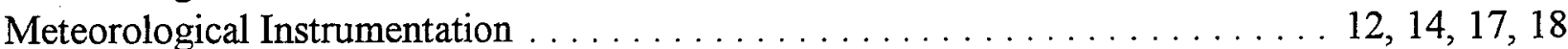

Microphone ............. 5, 11, 12, 14, 17-19, 23, 25, 26, 34, 54, 57, C-1-4, D-3

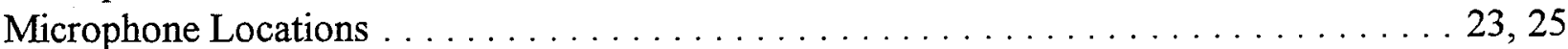

$-\mathrm{N}-$

National Air Traffic Services (see also NATS) . . . . . . . . . . . . . . . . 2, 40

NATS ................................. 2, 3, 40-42, 46, 57

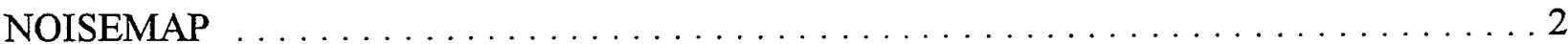

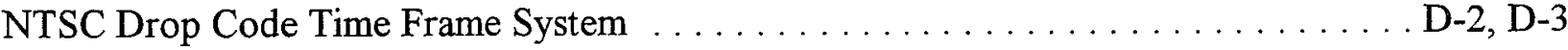

$-\mathbf{O}-$

Observer $\log \ldots \ldots \ldots \ldots \ldots \ldots \ldots \ldots \ldots \ldots \ldots \ldots \ldots \ldots \ldots \ldots \ldots \ldots \ldots \ldots \ldots, 13$

-P-

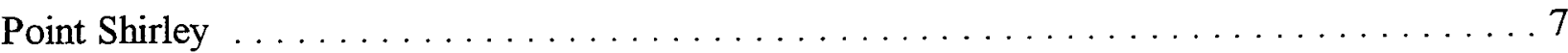

-R-

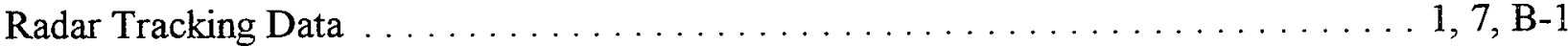

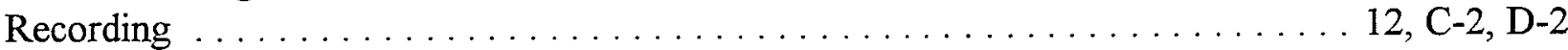

Refraction of Sound $\ldots \ldots \ldots \ldots \ldots \ldots \ldots \ldots \ldots \ldots \ldots \ldots \ldots \ldots \ldots \ldots \ldots \ldots \ldots \ldots \ldots, 2$

$-\mathbf{S}-$

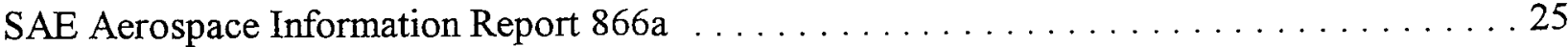

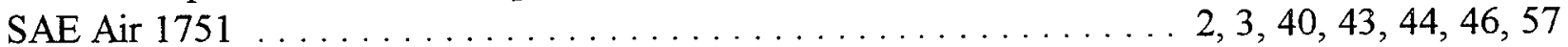

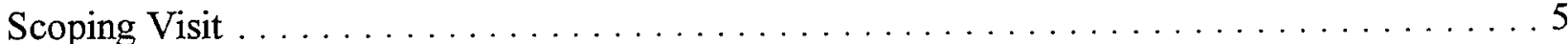

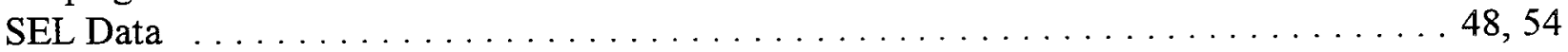

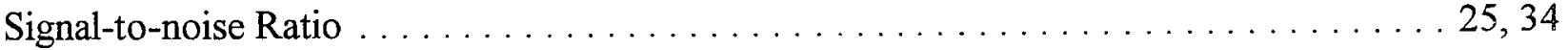


Site Selection

Snake Island $8,14,17,25,34,49, \mathrm{D}-3$

Source-to-receiver Geometry

Source-to-receiver Sound Path $49, \mathrm{E}-1$

Spectrum Analyzer

Statistical Analysis $1,7,29,34,39, \mathrm{~B}-1$

Subsystem Recorded $12, \mathrm{D}-1$

Survey Instrumentation 14

System Accuracy $\mathrm{D}-4$

System Performance Limits

$-\mathbf{T}-$

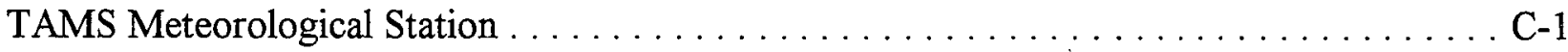

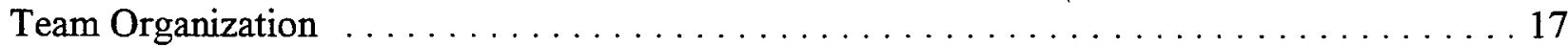

Technical Specifications . . . . . . . . . . . . . . . . . . . . . . . 11

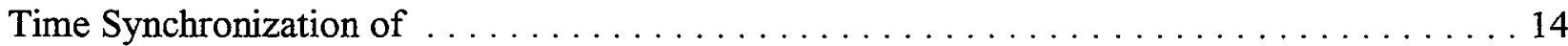

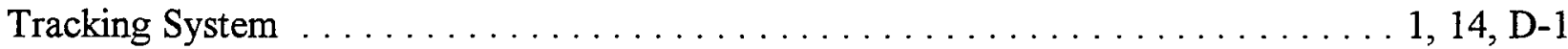

Transportable Automated Meteorological Station . . . . . . . . . . . . . . . . . . . 12

TSPI Instrumentation . . . . . . . . . . . . . . . . . . . . . . . . . . 20

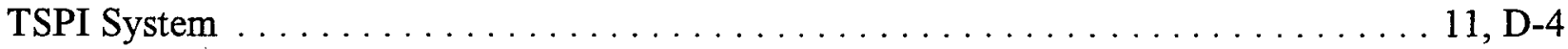

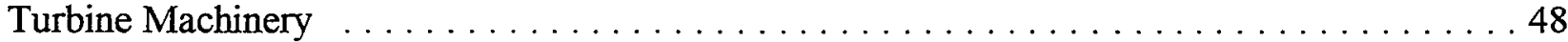

$-\mathbf{U}-$

UTC Time

$-\mathrm{V}-$

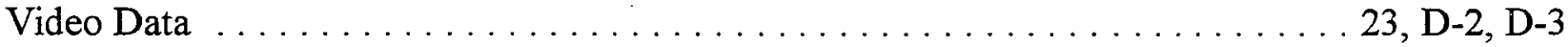

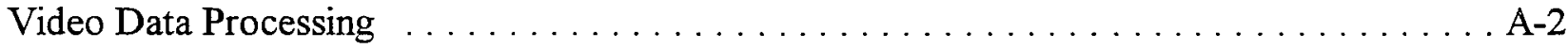

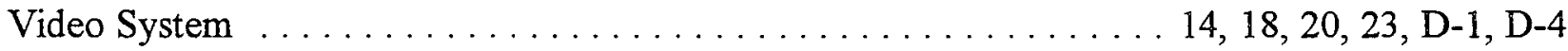

$-\mathbf{W}-$

Water $\ldots \ldots \ldots \ldots \ldots \ldots \ldots \ldots \ldots \ldots \ldots \ldots \ldots \ldots \ldots \ldots \ldots \ldots \ldots \ldots \ldots \ldots \ldots \ldots \ldots \ldots, 5,7,34,50$

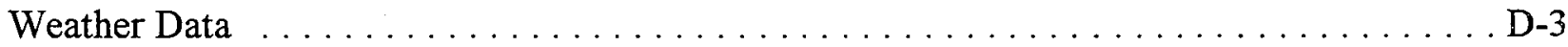

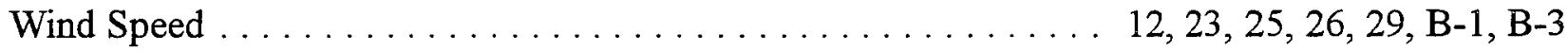

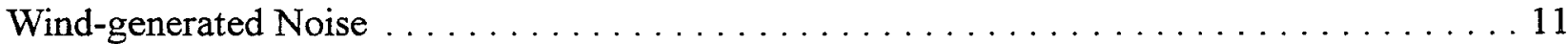

Wind-induced Vibration . . . . . . . . . . . . . . . . . . . . . . . . . 18

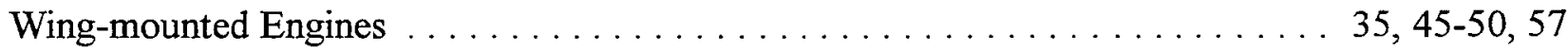

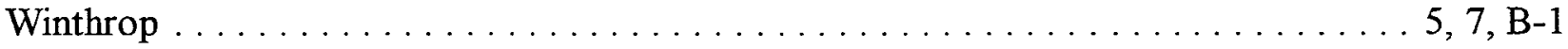

